\title{
WestVirginiaUniversity
}

THE RESEARCH REPOSITORY @ WVU

Graduate Theses, Dissertations, and Problem Reports

2000

\section{Net section rupture in tension members with connection eccentricity}

Peter Atwood Bartels

West Virginia University

Follow this and additional works at: https://researchrepository.wvu.edu/etd

\section{Recommended Citation}

Bartels, Peter Atwood, "Net section rupture in tension members with connection eccentricity" (2000). Graduate Theses, Dissertations, and Problem Reports. 999.

https://researchrepository.wvu.edu/etd/999

This Thesis is protected by copyright and/or related rights. It has been brought to you by the The Research Repository @ WVU with permission from the rights-holder(s). You are free to use this Thesis in any way that is permitted by the copyright and related rights legislation that applies to your use. For other uses you must obtain permission from the rights-holder(s) directly, unless additional rights are indicated by a Creative Commons license in the record and/ or on the work itself. This Thesis has been accepted for inclusion in WVU Graduate Theses, Dissertations, and Problem Reports collection by an authorized administrator of The Research Repository @ WVU. For more information, please contact researchrepository@mail.wvu.edu. 
Net Section Rupture in Tension Members

with Connection Eccentricity

\title{
Peter Atwood Bartels
}

\author{
Thesis submitted to the \\ College of Engineering and Mineral Resources \\ at West Virginia University \\ in partial fulfillment of the requirements \\ for the degree of
}

\author{
Master of Science \\ in \\ Civil Engineering
}

\author{
Karl E. Barth, Ph.D., Chair \\ Hung-Liang (Roger) Chen, Ph.D. \\ Julio F. Davalos, Ph.D. \\ Department of Civil and Environmental Engineering
}

\author{
Morgantown, West Virginia \\ 2000
}

Keywords: Connection Eccentricity, Tension Members, Bolted Connections 


\section{ABSTRACT \\ Net Section Rupture in Tension Members with Connection Eccentricity}

\section{Peter Atwood Bartels}

Tension members consisting of single and double angles, single channels and similar sections are frequently used for lateral bracing and as truss elements. Such members will normally have eccentric connections, and it is often permitted, by current design specifications, to neglect this eccentricity in the design of the member. In this study, load tests were performed on three series of short tension member specimens to investigate the influence of varying connection eccentricity and length on the load capacity of the members. Additionally, studies were conducted to investigate the influence of hole fabrication methods. Two methods were used: punched holes and drilled holes. Rupture load capacity of the net section was observed to be significantly reduced with moderate connection eccentricity, and a net section efficiency factor is developed and proposed as a replacement for the current shear lag factor in determining the effective net area of a WT tension member. 


\section{ACKNOWLEDGEMENTS}

Funding for this work was provided by the West Virginia University Senate Research Grant program. Additionally, specimen fabrication was in part donated by Ohio Valley Steel Company.

I would like to thank Dr. Davalos for encouraging me to purse my Master's Degree and challenging me in my studies. Additionally, I would like to thank Dr. Chen for the instruction I received from him while at West Virginia University and his willingness to serve on my committee.

Dr. Orbison, of Bucknell University, was supportive and helpful in the experimental programs for this research. His amiable nature is also appreciated.

Thanks to Dr. Barth who offered me the opportunity to work under his direction in the pursuit of my graduate degree. He provided the guidance and support to make this present study and accompanying thesis possible. The instruction and training I received under him have challenged me to grow as an individual and as an engineer.

I would like to thank my friends for their friendship, those at C\&MA who have caused me to grow in my walk with Jesus Christ, and my family who are, in every regard, highly valued.

But, all praise must be given to the Lord of Creation, by whose grace I have been blessed and have accomplished what I have accomplished. 


\section{TABLE OF CONTENTS}

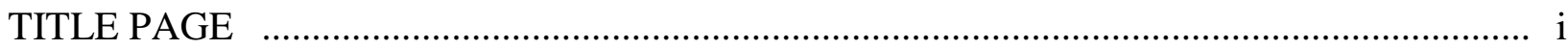

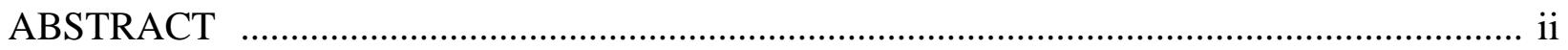

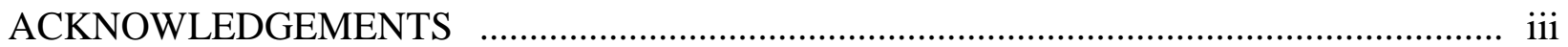

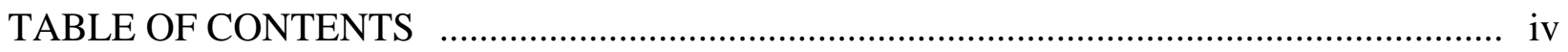

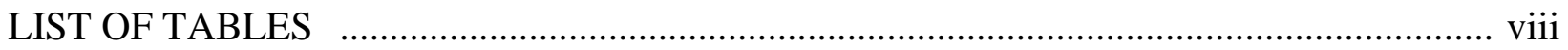

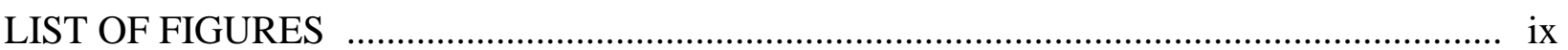

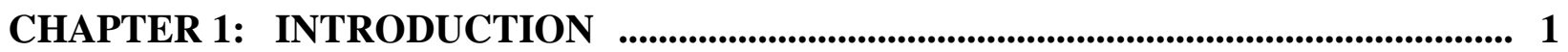

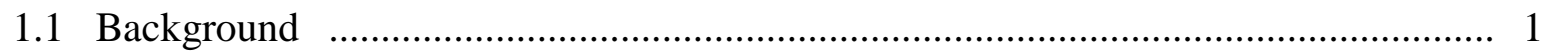

1.1.1 Present Design Considerations ........................................................... 1

Gross Section Yielding .................................................................. 2

Net Section Rupture ........................................................................ 2

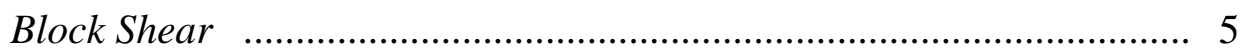

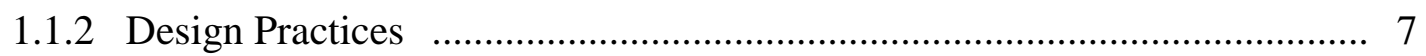

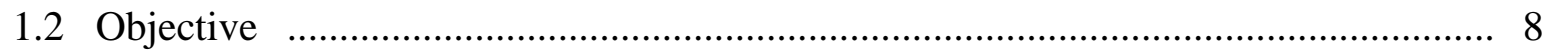

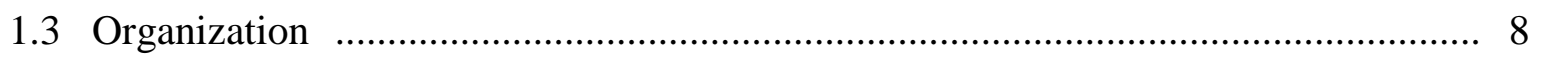

CHAPTER 2: LITERATURE REVIEW ................................................................... 13

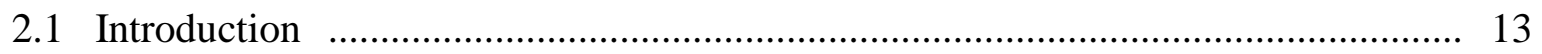


2.2 Prior Studies of Block Shear and Net Section Rupture

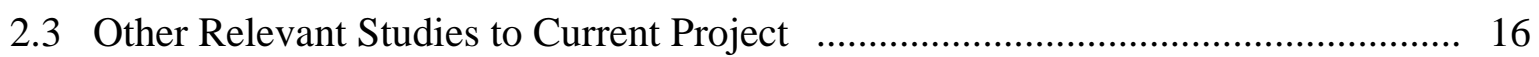

2.3.1 Development of Effective Net Area, the Shear Lag Factor U ................ 16

2.3.2 Shear Lag Effects on Net Section Rupture ........................................ 19

Connection Length ........................................................ 19

Other Influencing Variable ..................................................... 21

Predictions of $U$ factor ......................................................... 22

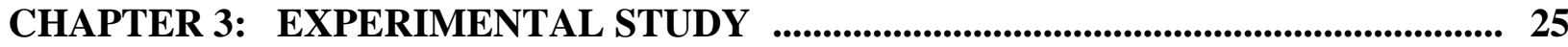

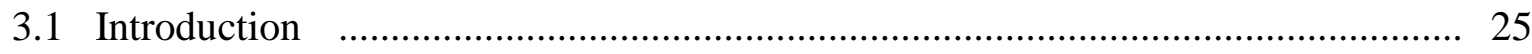

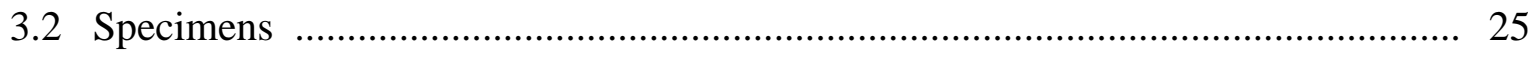

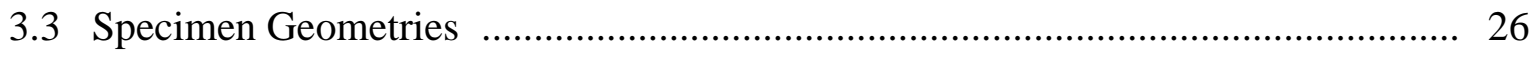

3.4 Experimental Apparatuses ...................................................................... 27

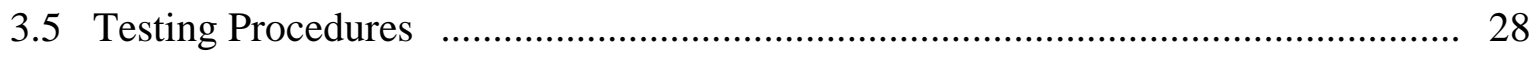

CHAPTER 4： EXPERIMENTAL RESULTS $\ldots$

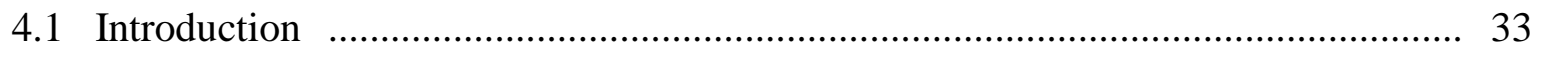

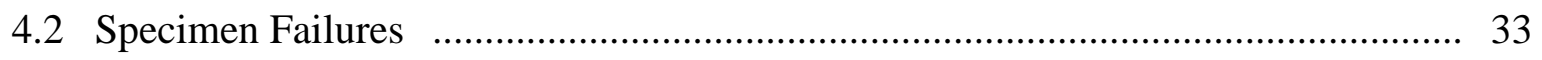

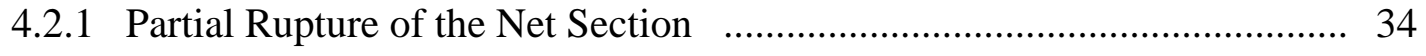

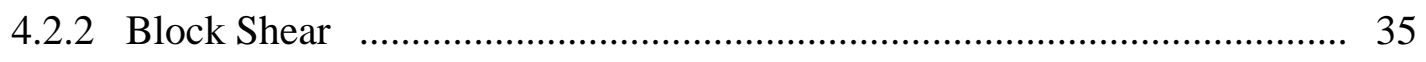

4.2.3 Full Rupture of the Net Section …................................................ 36

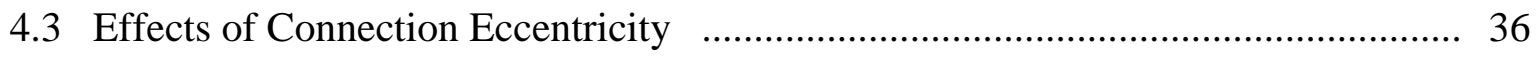

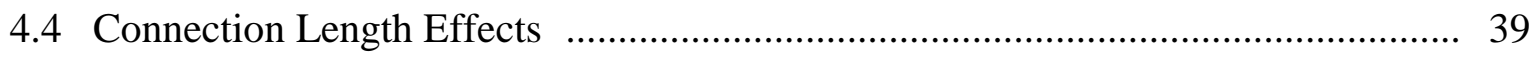




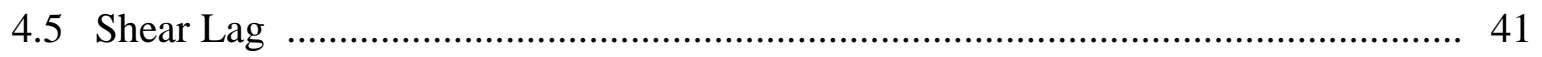

4.6 Hole Fabrication Effects ..................................................................................... 43

4.7 AISC LRFD Predictions ………………………......................................... 44

CHAPTER 5: MODEL DEVELOPMENT _...................................................................... 61

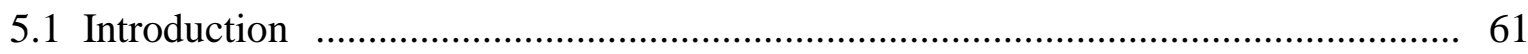

5.2 Linear Regression Analysis ........................................................................ 62

5.3 Comparison of Model Predictions with Current Specifications................................ 63

5.4 Fabrication Factor for Punched Holes ………………....................................... 65

CHAPTER 6: SUMMARY AND RECOMMENDATIONS ............................................ 72

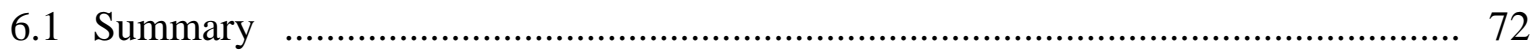

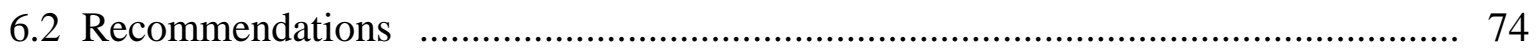

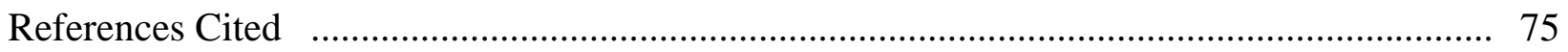

\section{APPENICIES}

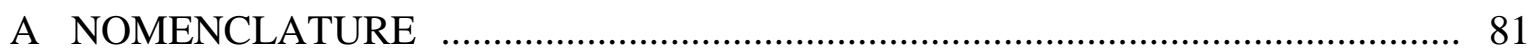

B WT SPECIMEN GEOMETRY _................................................................... 83

C BAR STOCK GRIP GEOMETRY ………………….................................. 87

D EXCEL SPREADSHEETS USED FOR MULTIPLE LINEAR

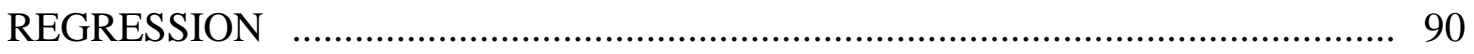

E KULAK AND WU SPECIMEN TEST SETUPS ……………………………...... 93 
F AISC LRFD ACCOMODATION FOR PUNCHING EFFECTS .......................... 95

G AISC LRFD LIMIT STATE CALCULATION EXAMPLES .............................. 97 


\section{LIST OF TABLES}

Table 3.1 Specimen Dimensions and Material Strengths $\quad$.................................................... 29

Table 4.1 Specimen Failure Loads and Predicted Capacities .............................................. 46

Table 5.1 Specimen Professional Factors ………….................................................... 66 


\section{LIST OF FIGURES}

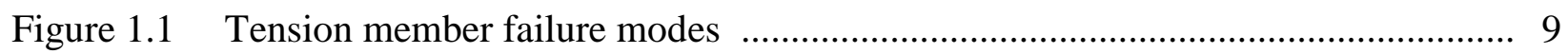

Figure 1.2 Effective hole diameter …………........................................................ 10

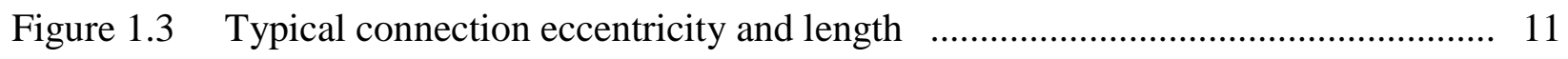

Figure 1.4 Hardash and Bjorhovde gusset plate sketch ………………............................... 12

Figure 2.1 Unbalanced and balanced weld designs f....................................................... 24

Figure 3.1 Typical WT specimen configuration …….................................................... 30

Figure 3.2 Typical WT specimen-grip assembly f.......................................................... 31

Figure 3.3 Typical WT specimen in UTM …………................................................ 32

Figure 4.1 Partial net section rupture, with medium eccentricity (specimen 4) ................... 47

Figure 4.2 Partial net section rupture, with large eccentricity (specimen 1) ........................ 48

Figure 4.3 Block shear failure (specimen 8) ………................................................... 49

Figure 4.4 Full net section rupture (specimen 7) ……….............................................. 50

Figure 4.5 WT 155x 10.55 bolt connection net section efficiency versus eccentricity $\quad . . . . . . .51$

Figure 4.6 WT 155x10.5 4 bolt connection net section efficiency versus eccentricity $\quad . . . . . . .52$

Figure 4.7 WT 100x 183 bolt connection net section efficiency versus eccentricity $\quad . . \ldots \ldots \ldots . . .53$

Figure 4.8 WT 155x 10.55 bolt connection LRFD predictions $\quad$........................................ 54

Figure 4.9 WT 155x 10.54 bolt connection LRFD predictions $\quad$........................................ 55

Figure 4.10 WT 100x 183 bolt connection LRFD predictions $\quad$............................................ 56 
Figure 4.11 Primary bending moments resulting from connection eccentricity

Figure 4.12 Restoring moment developed as a function of connection restraint

Figure 4.13 Net section efficiency versus eccentricity for all specimens tested

Figure 4.14 Comparison of the effects of punching versus drilling on section capacity $\quad . . . . .60$

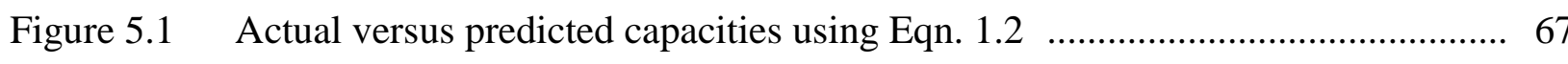

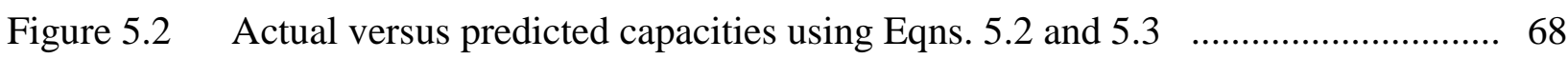

Figure 5.3 Specification predictions and proposed predictions for 5 bolt connections $\quad$....... 69

Figure 5.4 Specification predictions and proposed predictions for 4 bolt connections $\quad . . . . . \quad 70$

Figure 5.5 Specification predictions and proposed predictions for 3 bolt connections $\ldots . . . .71$

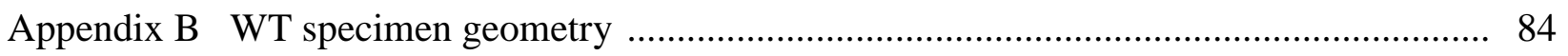

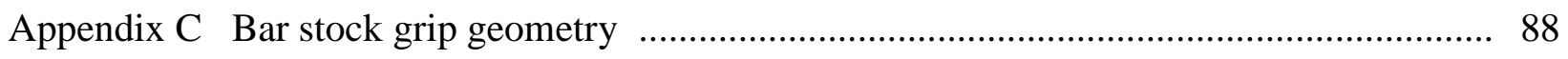

Appendix E Kulak and $\mathrm{Wu}$ specimen test setups ......................................................... 94 


\section{Chapter 1}

\section{INTRODUCTION}

\subsection{Background}

The present study is focused on examining the effects of connection eccentricity and connection length on bolted WT tension member capacities. To date connection eccentricities are only considered with regards to reducing the net section capacity of a tension member as it relates to shear lag effects, with no reduction of the effective net area due to connection eccentricity bending effects. It will be shown by the test results of this study as well as a discussion of work conducted by others that connection eccentricity, which induces bending in tension members, should be considered in all design situations.

\subsubsection{Present Design Considerations}

Tension members used in building construction are designed according to the American Institute of Steel Construction building specifications LRFD [LRFD] and ASD (1995, 1989). LRFD (1995) requires that the designer make three calculation checks to determine the capacity of a tension member: yielding of the gross cross-sectional area, net section rupture of the critical cross-sectional area and block shear (see Fig. 1.1). The lower of the three controls the allowable load capacity of a specified member. 
Gross Section Yielding:

Yielding of the cross-section at service loads is considered so as to prevent large elongations of a member, which is considered serviceability criteria. Yielding of the net section area is not considered because the length over which its gross area is reduced, due to connection details, is small. Therefore, significantly larger elongations than yielding of the gross area would not occur (Gaylord et al. 1992). Gross section yielding is calculated in LRFD (LRFD Eqn. D1-1) as follows

$P_{n}=F_{y} A_{g}$

Net Section Rupture:

The net section rupture strength of a member is calculated using the effective net area, $A_{e}$, multiplied by the material's ultimate tensile strength, $F_{u}$. The net section rupture equation as given by Chapter D of LRFD is shown below (Eqn. D1-2)

$$
P_{n}=F_{u} A_{e}
$$

The effective net area is equal to the critical net section area, $A_{n}$, multiplied by the shear lag reduction factor, $U$, which yields (LRFD Eqn. B3-1)

$$
A_{e}=U A_{n}
$$

A section's net area is equal to the gross area of the critical cross-section minus the area of bolt holes in the critical cross-section. The nominal hole diameter for standard size bolt holes are specified to be fabricated $2 \mathrm{~mm}\left(1 / 16^{\text {th }}\right.$ of an inch) larger than the nominal bolt diameter. The nominal hole diameter is then generally required to be 
increased in design calculations to account for damage effects due to hole fabrication methods. Bolt holes can be fabricated using any of the following techniques: drilling, sub-punching and reaming, and punching. Of the three, the most common fabrication technique is to punch bolt holes. This method, however, damages the material surrounding the bolt hole sufficiently to cause a reduction in the equivalent drilled hole capacity.

LRFD accounts for any damage due to punching in Sec. B2. It specifies that the designer is to increase the nominal bolt hole diameter by $2 \mathrm{~mm}\left(1 / 16^{\text {th }}\right.$ of an inch) (see Fig. 1.2). This is set as a general rule in the designing of net section areas because as often is the case the fabricator will find it more efficient to punch rather than drill holes. An increase in the nominal diameter by $2 \mathrm{~mm}$ assumes that the effects due to punching only extend $1 \mathrm{~mm}\left(1 / 32^{\text {nd }}\right.$ of an inch) beyond the nominal hole diameter.

Equations 1.1 and 1.2 assume that the stresses at a given cross-sectional area are normally distributed. This is a reasonably accurate assumption for sections that are away from the member's connections. However, as is the case at the connection area of a member, this assumption of equal distribution of stresses across the net area is not accurate. This is due primarily to changes in geometry of the connection (i.e., bolt holes) and shear lag effects.

The changes in geometry along the cross-section produce stress concentrations in some areas, while producing lower stresses in other areas of the cross-section. This might limit an average of the material's ultimate tensile strength to only developing over a portion of the net section area, the effective net area (Gaylord et al., 1992). For most ductile steels used in construction practices today the stress concentrations in the net 
section area due to bolt holes are neglected because of the ability of the steels to distribute stresses uniformly when the material is at its plastic stage (Gaylord et al., 1992). However, Munse and Chesson (1963) suggest that the effects of shear lag cannot be ignored. Hence the inclusion of the shear lag reduction factor, $U$, in the calculation of the effective net area (as shown in Eqn. 1.3).

Shear lag is a loss in efficiency of a member's net area as a function of not all its elements transferring load at the connection region. As the stress flows from areas of near uniform stress (i.e., locations away from connection regions) to areas of nonuniform stress (i.e., connection regions) it is required to move from elements not transferring load to elements transferring load. This results in a discontinuity of stresses at the connection region, i.e. shear lag. The severity of shear lag effects are a function of: amount of unconnected material, length of the connection, and the eccentricity between the cross-section centroidal axis and the line of fasteners in the connected elements.

The reduction effects due to shear lag need only be considered when not all of the elements of a member transfer load (LRFD 1995). The calculation of the shear lag factor according to LRFD (1995) is shown below (Eqn. B3-2).

For a member with all of its elements transferring load, $U=1.0$ else, $U=1-(\bar{x} / L) \leq 0.9$

As seen by Eqn 1.4, an increase in connection eccentricity will result in a less effective net area, but an increase in connection length increases the effective net area. An upper bound of the net section efficiency is specified, this is $U=0.9$. This suggests that shear 
lag, regardless of connection length or eccentricity will always influence net section capacity if all of member's elements are not transferring load (see Fig. 1.3).

Also, the LRFD Commentary on shear lag (Sec. CB-3 of LRFD) provides design aids that may be used in lieu of the shear lag reduction factor calculated by Eqn. 1.4. As is sometimes the case, use of Eqn. 1.4 will result in a small or negative number.

These design aid coefficients are based on section type, section size and number of bolts in a connection. The Commentary's U factor that has bearing on the present study is shown below

$W, M$, or $S$ shapes not meeting the conditions of subparagraph a, structural tees cut from these shapes, and all other shapes including builtup cross sections, provided the connection has no fewer than three fasteners per line in the direction of stress, $U=0.85$. (Sec. C-B3.b, LRFD, 1995)

\section{Block Shear:}

The block shear phenomena became a known possible mode of failure when allowable material bearing and bolt shear strengths for design were increased. These increases led to fewer bolts being required in a connection, 20-30\% fewer bolts (Birkemoe and Gilmor, 1978). Decreasing the number of bolts per connection allowed for smaller connections and, hence, the possibility of a block shear failure. Later, Hardash and Bjorhovde (1985) conducted a study of gusset plates. It showed that the development of the shear plane is a function of connection length. From their observations, block shear was the controlling mode of failure. The most accurate model 
of the failures seen is a rupturing of the net tension plane and yielding on the gross shear plane, which increases towards a rupturing of the shear plane as connection lengths become shorter (see Fig. 1.4). This study led to the development of the present LRFD equations provided in Chapter J (Epstein, 1992).

The LRFD block shear provisions incorporate two possible modes of failure: rupture of the net tension area combined with simultaneous yielding of the gross shear area (Eqn. 1.5) or yielding of the gross tension area combined with simultaneous rupture of the net shear area (Eqn. 1.6). The controlling equation is that equation whose net area rupture term is the larger, i.e., if $F_{u} A_{n t} \geq 0.6 F_{u} A_{n v}$ then Eqn. 1.5 controls, else Eqn. 1.6 controls and is used to calculate the allowable block shear capacity. The two LRFD block shear equations are shown below (LRFD Eqns. J4-3a and J4-3b respectively).

$$
\begin{aligned}
& R_{n}=F_{u} A_{n t}+0.6 F_{y} A_{g v} \\
& R_{n}=F_{y} A_{g t}+0.6 F_{u} A_{n v}
\end{aligned}
$$

It is interesting to note that in design typically Eqn. 1.6 will govern, while experiments in which block shear is evident tend to exhibit a failure mode similar to that described by Eqn. 1.5.

The LRFD's block shear equations are slightly different than the ASD block shear equation, which assumes a simultaneous rupturing of both the net tension and shear areas. The ASD (1989) block shear equation is shown below (ASD Eqn. J4-1).

$$
R_{n}=F_{u} A_{n t}+0.6 F_{u} A_{n v}
$$

This equation was suggested by Birkemoe and Gilmore (1978) when the block shear mode of failure was first observed by them. However, similar to Eqn. 1.6, Eqn. 1.7 is typically not evident in block shear failures. 


\subsubsection{Design Practices}

An integral part of some buildings are lateral bracing and truss members, which are frequently subject to tension loads. Their allowable design capacities are governed by the conditions mentioned in the former section. Lateral bracing is generally designed using single angles, double angles, or WT sections connected with high strength bolts. As a function of geometries constraints of the connections, these members are not generally connected through all elements. Therefore, the consideration of shear lag in net section rupture capacities will be included.

Ideally, in these situations placement of the connectors (or centroid of the connectors if multiple gage lines are used) should be along the centroidal axis of the member. However, often the location of the bolt gage line does not lie along the centroidal axis of the member. This can be due to the geometry and location of members framing into a connection. It is also possible that the location of the neutral axis of a member, with respect to its member elements, will not permit the fabrication of bolt holes or allow for minimum clearances required by wrenches. The difference between the centroid of the bolt group and the neutral axis of the member is the eccentricity of the connection. In present specifications, the detrimental effects of connection eccentricities are accounted for through the $\mathrm{U}$ factor. Though not explicitly stated, the current $\mathrm{U}$ factor is empirically based on experimental tests that were inherently subject to a combination of shear lag and bending effects.

According to LRFD (1995) Section J1.8 and the Section J1.8 Commentary, tension members such as single and double angles and similar members that are not 
subjected to fatigue loading, need not be designed for bending induced by connection eccentricity. Therefore, bending effects, induced by connection eccentricity, are not considered to result in reduction of member capacity.

\subsection{Objective}

The purpose of this study is to examine the following parameters with respect to their effects on WT tension member capacities: in-plane eccentricity, connection length and hole fabrication methods. As present strength predictions are shown to produce unconservative results, a new net section efficiency factor is developed to better account for the effects of eccentricity and connection length in WT net section rupture capacities. Additionally, recommendations are made concerning the influence of bolt hole fabrication methods on WT section capacities.

\subsection{Organization}

The thesis is organized in six chapters. The first presents the scope and objectives. Chapter two contains a critical literature review of work conducted on studies relevant to block shear and net section capacity of tension members. The third chapter presents the experimental setup, including: specimen configurations, testing apparatus and testing procedures. Chapter four discusses trends observed in the tests and compares the specimen failure load results with LRFD predictions. The development of a proposed prediction equation and fabrication factor for WT sections in tension is shown in chapter five. Lastly, chapter six presents a summary of the findings and recommendations. 

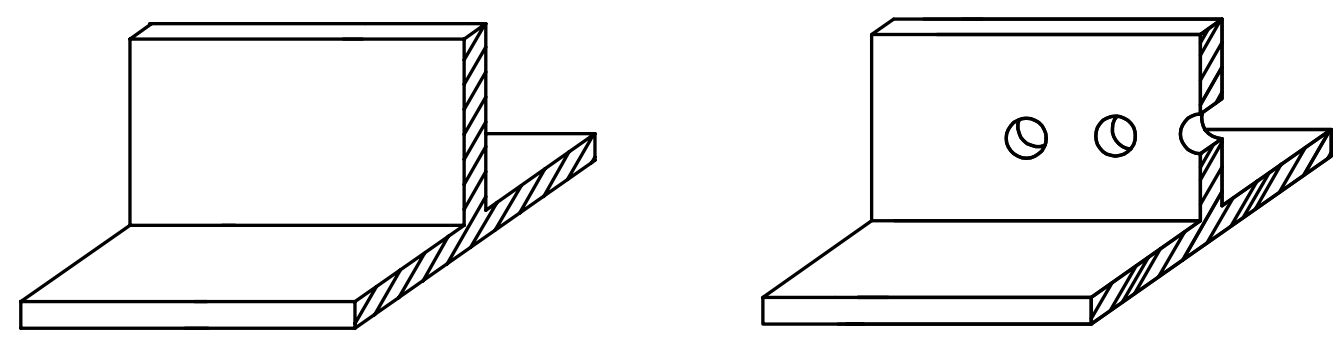

(a) Gross Cross-Sectional Area

(b) Net Cross-Sectional Area
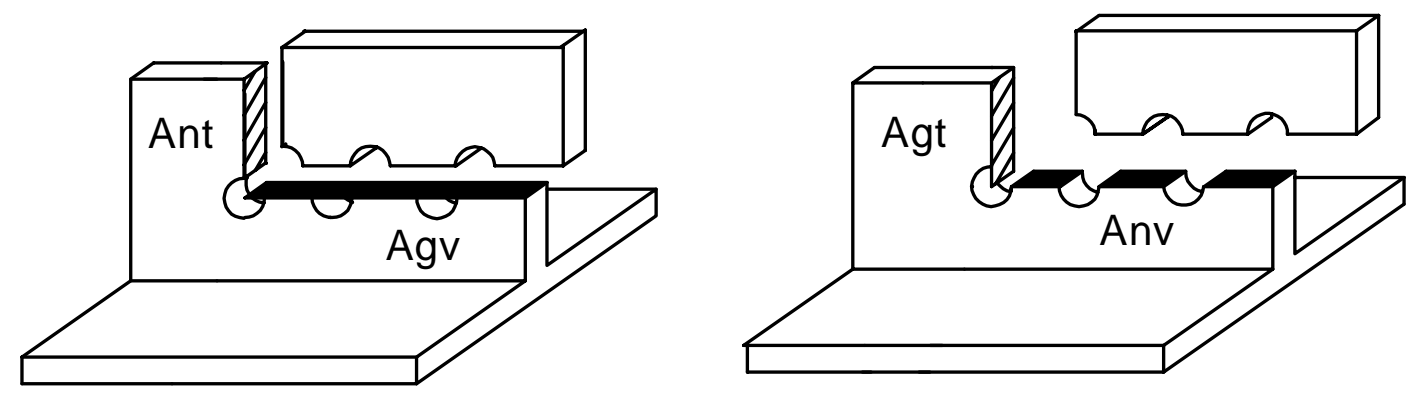

(c) Block Shear Eqn. 1.5

(d) Block Shear Eqn. 1.6

Figure 1.1: Tension member failure modes (a) gross cross-sectional area (b) net cross sectional area (c) block shear Eqn. 1.5 (d) block shear Eqn. 1.6 


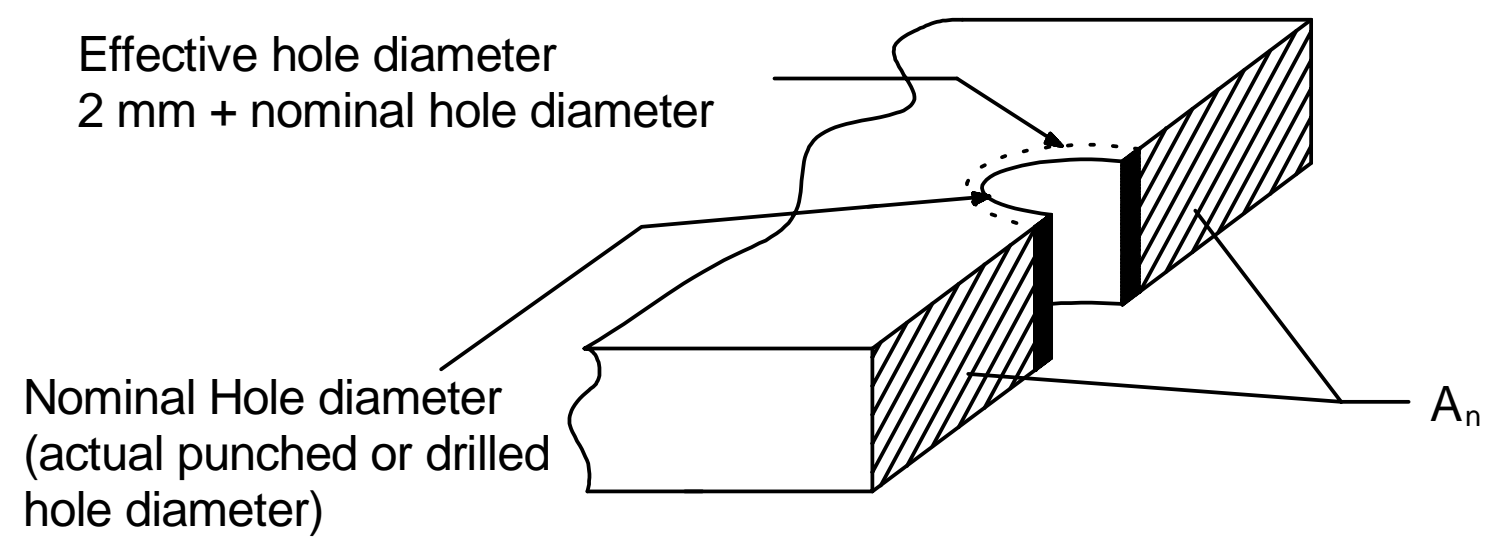

Figure1.2: Effective hole diameter 


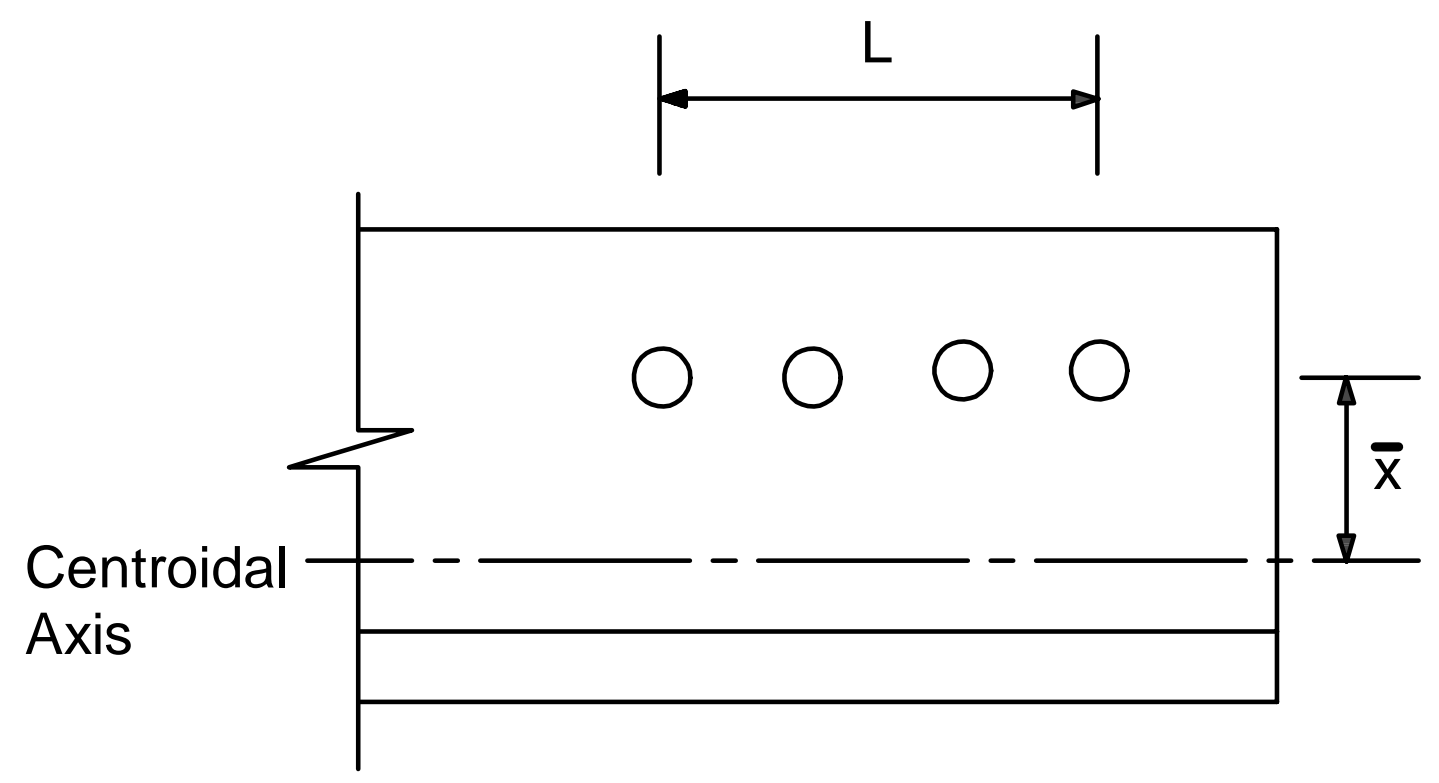

Figure1.3: Typical connection eccentricity and length 


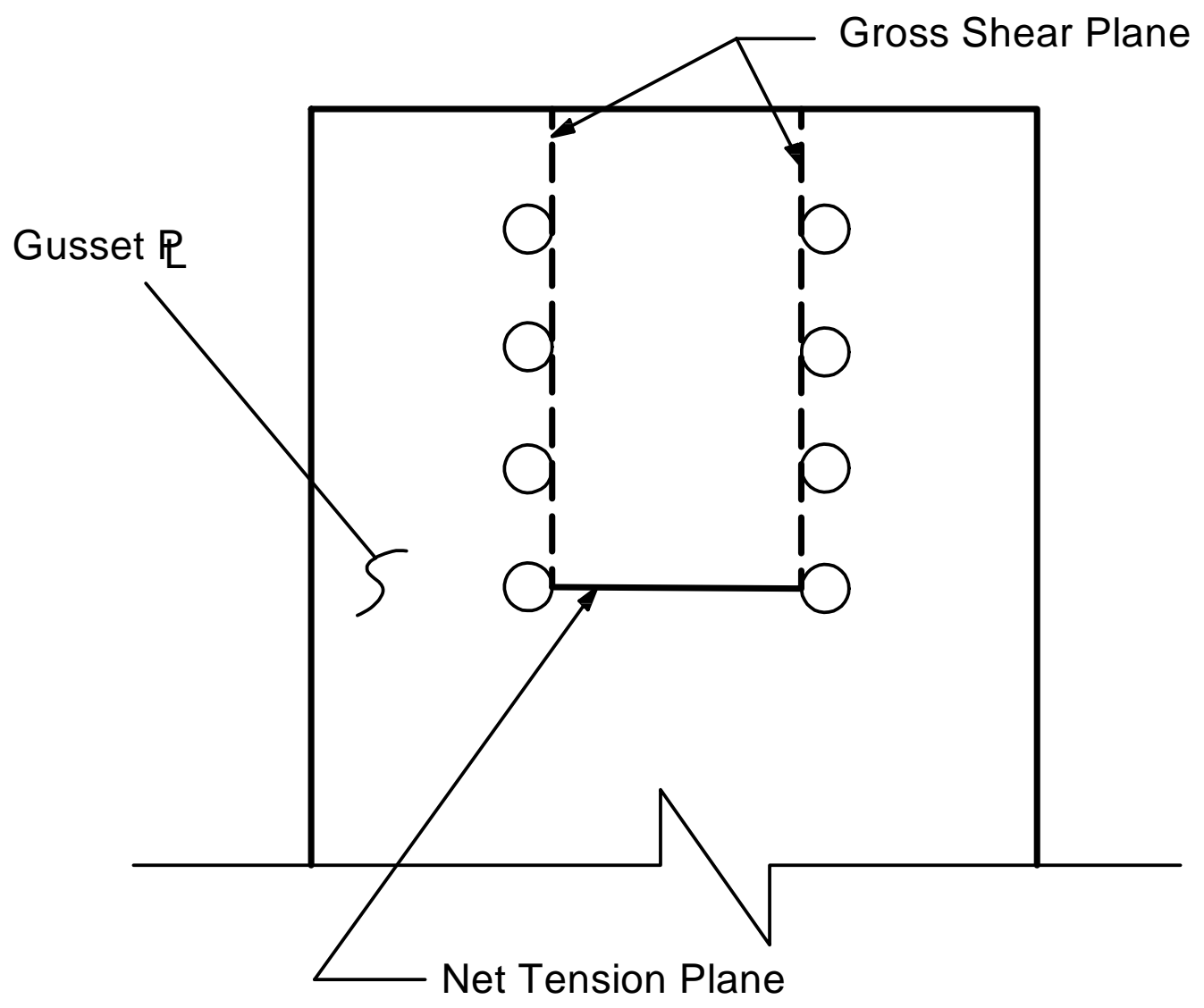

Figure1.4: Typical gusset plate failure as observed by Hardash and Bjorhovde (1985) 


\section{Chapter 2}

\section{LITERATURE REVIEW}

\subsection{Introduction}

There has been a significant amount of work previously conducted that relates to the ultimate capacity of tension members. A majority of these efforts, however, are not directly relevant to the present study. This literature review is divided into two sections: prior studies of tension member failures and relevant studies to the current project.

\subsection{Prior Studies of Block Shear and Net Section Rupture}

There have been several recent studies focused on the adequacy of present specification block shear equations.

Epstein (1996) tested a series of WT tension members in an effort to determine how the outstanding web of a WT, fastened through its flanges, corresponds to the block shear predictions of LRFD. He found that some of the tests failed as net section failures, while others failed in an alternate path failure (tensile rupture of the flanges through the critical section and rupture of the flange-web intersection, then shear rupture of the web area to the end of the member). The members of Epstein's study are fastened through the flanges whereas the tests conducted in the present study were fastened through their 
webs. Also, based on a WT that he examined in his report the connection eccentricities were below $44.5 \mathrm{~mm}(1.75$ "), but the eccentricities examined in the present work, in some cases exceeded $44.5 \mathrm{~mm}$. Epstein (1992), also, conducted tests of bolted single angles in tension attached by the longer leg. All the specimens had a double row of bolts, with some of the bolt rows having a staggered configuration. It was the goal of the present study to examine how the outstanding angle leg and stagger affect the block shear predictions given in current specifications. He found that as the outstanding leg decreased in size more conservative results were produced by LRFD predictions. The effects of a double row of bolts has not been examined in the present study and many of members in Epstein's study failed in block shear, not partial net section rupture.

Orbison et al. (1998) performed tests on WTs and single angles and Gross et al. (1996) performed single angles. Both stated that the failures observed were block shear; a yielding of the gross shear area and rupture of the net tension area. LRFD block shear predictions were on the average conservative for the WT tests. Equation 1.6 governed for all but one of the specimens, which was governed by Eqn. 1.5. The specification prediction results produced were slightly unconservative for the Gross et al. (1996) angle tension tests. Again, Eqn. 1.6 governed the LRFD block shear predictions for the angle specimens. However, the specimen failures with large eccentricities from the present study did not show signs of extended yielding along the gross shear plane, but only local yielding of the shear plane in the vicinity of the lead bolt.

Gibson and Wake (1942) conducted a series of experimental tension tests on single and double angles having welded connections. The connections were fabricated 
with either balanced or unbalanced fillet weld to gusset plate details. Weld balancing consists of placing the weld metal such that there is no resulting eccentricity between the applied force and the resulting weld reactions. Figure 2.1 shows a comparison between unbalanced and balanced weld design. Note that in both cases the total length of fillet weld is the same. The only difference is the placement.

Their study indicated that there was no influence on ultimate section capacity in double angle specimens as a result of balancing the weld. Single angles did however demonstrate a slight increase in section capacity when a balanced detail was incorporated.

Further work by Gibson and Wake concluded that out-of-plane eccentricity did have a significant influence on section capacity. The observation that an outstanding leg effects decrease section capacity is presented by Epstein (1992), as well. However, Orbison et al. (1998) suggests that out-of-plane eccentricity has little effect on connection strength. They compared WT tests and angle tests with the same connection geometries (except that the angle specimens have out-of-plane eccentricity and WT specimens do not) and found that the block shear professional factors produced by the WTs and single angles was nearly identical.

A more recent study of welded connections and the ability of the present shear lag reduction factor for welded members was conducted by Easterling and Giroux (1993). It was found that shear lag controlled specimen failure capacities. Also, the authors recommended that, similar to the $90 \%$ maximum net section efficiency for bolt tension members subjected to shear lag, welded tension members should be subject to the same net section efficiency limitation of $90 \%$. 


\subsection{Other Relevant Studies to Current Project}

\subsubsection{Development of Effective Net Area, the Shear Lag Factor U}

Munse and Chesson (1963), in an effort to examine factors that reduce net section capacity, conducted numerous experiments on various specimens and connection details.

In addition to their own experiments they examined test results from extensive bolted and riveted tests performed by others (Chesson, 1959; Chesson and Munse, 1958; Schulz, 1952; Munse, 1959; Wilson et al. 1952). These tests included flat plates, single angles, double angles connected on the same side of the gusset plate, double angles connected on opposite sides of a gusset plate, single and double angles with lugs, four angles back-toback, built-up I-sections with webs made with lacing, battens or solid material, built-up box sections, single channel sections and double channel sections.

Prior to the Munse and Chesson studies, tension member capacity was based solely on gross section yielding or net section rupture. The net section rupture capacity calculations incorporated no allowance for net section efficiency or hole fabrication.

Based on the results of their studies and an investigation of the data from other studies, Munse and Chesson (1963) were the first to propose an equation representing the "effective" net section. Their expression suggests that the net section effective area is a function of: material ductility, shear lag effects, net section area, and the ratio of the net to gross cross-sectional area. This expression has the form

$$
A_{e}=A_{n}\left(1.60-0.7 \frac{A_{n}}{A_{g}}\right)\left(1-\frac{\bar{x}}{L}\right)
$$


The term $1.60-0.7 \frac{A_{n}}{A_{g}}$ is referred to as the efficiency coefficient. It is a measure of the effectiveness of a given bolted connection configuration. As the net area to gross area ratio decreases connections were observed to develop higher net section efficiencies. The efficiency coefficient is an empirical equation that has been shown to take into account gage distance, $g$, to bolt hole diameter, $d$, ratio effects (Munse and Chesson 1963). A smaller $g / d$ ratio will provide increase connection efficiency. This is to be due to biaxial forces, which develop when connectors are located near each other (Munse and Chesson, 1963). However, Kulak and Wu (1997) stated that for "most practical connections" this can be taken as unity. The term $1-\frac{\bar{x}}{L}$ is the shear lag factor.

Further, they suggest Eqn. 2.1 is only valid when applied to connections fabricated from steels with a similar ductility as the specimens used in the equation development. Present day steels are less ductile than the steels used to fabricate the specimens examined by Munse and Chesson, however, the difference in ductility is not enough to cause to significant influence this parameter (Kulak and Wu, 1997). Lastly, reduction in member capacity due to punching connector holes should be accounted for by multiplying the effective area of a similar member with drilled holes by 0.875 . This is an average based on findings that show punching effects reduce net section capacities by $10-15 \%$.

It may be noted that the Munse and Chesson data (1963) is comprised of experiments with a wide range of connection geometries. Different connections permitted varying amounts of both in-plane and out-of-plane bending. However, Eqn. 
2.1 does not specifically account for loss in section capacity due to the additional normal stress resulting from flexure that is inherently present in many of the specimens they evaluated.

Gaylord et al. (1992) present a similar equation as Munse and Chesson (1963).

They suggest that the effective net area of a tension member is a function of four factors: steel ductility, fabrication methods, connection efficiency, and shear lag effects. Their expression is as follows

$$
A_{\text {eff }}=K_{1} K_{2} K_{3} K_{4} A_{n}
$$

where:

$K_{1} \equiv$ ductility factor $=0.82+0.0032 R \leq 1.0$

$K_{2} \equiv$ fabrication factor $=0.85$ for punching effects and 1.0 for drilling effects

$K_{3} \equiv$ efficiency coefficient

$K_{4} \equiv$ shear lag factor

The efficiency coefficient and the shear lag factors are similar to that presented by Munse and Chesson (1963). Gaylord et al. (1992) suggests that the effect of punched bolt holes reduces net section capacity by $15 \%$. Also, they suggest that the inclusion of the ductility factor has an effect on connection efficiency. The $R$ value shown in the ductility factor is determined experimentally from tensile coupon tests. It is the percent reduction in the cross-sectional area of a tensile coupon at failure. More ductile steels will allow for a better distribution of stress concentrations along a cross-section than will lower ductile steels (a higher $R$ value suggests this by producing a higher ductility factor and therefore a more efficient connection). Thus, equalizing stresses more when the steel 
is in its plastic region and making more accurate the assumption that an average of the tensile stress develops across the net section. Kulak and Wu (1997) suggest that with the use of present steels the ductility factor can be considered as having a value of one.

\subsubsection{Shear Lag Effects on Net Section Rupture}

Kulak and Wu (1997), in an attempt to examine shear lag effects and present accountings for shear lag in American and Canadian design specifications (which are based on AISC LRFD specifications), conducted a number of tension tests of single and double angles with punch bolt holes, considering only net section rupture. The failure of these single and double angle specimens was preceded by a necking down of the net area between the leg edge and lead bolt hole. Rupturing of the specimen initiated at the leg edge and propagated through to the bolt hole and then on through the rest of the specimen.

\section{Connection Length:}

Their study indicates that connection length affects section efficiency as a function of its influence on shear lag effects. Note that section efficiency is defined as $U=P_{\text {experimental }} /\left(F_{u} A_{n}\right)$. A single angle specimen fastened with six bolts and a similar single angle fastened with four bolts, having all other connection parameters held constant, exhibited little difference in failure loads. The six bolt specimen had a net section efficiency of $96.4 \%$, while the four bolt specimen had an efficiency of $100 \%$. However, a single angle of similar size fastened with only two bolts had an efficiency of $82.5 \%$; a difference in the section's efficiency of approximately $17 \%$. This is in 
agreement with present specification predictions. The connection length term is in the denominator of Eqn 1.4, hence, an increase in connection length yields an increase in net section efficiency. This is attributed to the fact that a longer connection may more easily and evenly distribute the applied stress. They found connection length to be most significant in affecting the efficiency of a connection. LRFD limits net section efficiency in a member subject to shear lag (i.e. a member that is not fastened through all of its elements) effects to $90 \%$. However, two specimens failed at or within $4 \%$ of having a net section efficiency of $100 \%$. This suggests that the effects of shear lag might be neglected for some connection geometries, regardless of the fact that an element of a member is not connected and there is connection eccentricity. The specimens used to examine the influences of connection length on shear lag effects had in-plane connection eccentricities of $19.9 \mathrm{~mm}$ (0.78 inches) (Wu and Kulak, 1993).

Similar trends were also observed in double angle specimens. A double angle specimen with a six bolt connection had an net section efficiency of $86.3 \%$ while a similar type of double angle specimen with a four bolt connection had a $89.7 \%$ net section efficiency. The two bolt connection for a similar double angle section had an efficiency of $71.8 \%$, an decrease in efficiency of about $18 \%$. A similar gage line and angle size was used as in the single angle comparisons, which gives an in-plane connection eccentricity of $19.9 \mathrm{~mm}$ (Wu and Kulak, 1993). 
Other Influencing Variable:

Kulak and $\mathrm{Wu}(1997)$ commented that the angle disposition has an effect on specimen ultimate capacity. This has been well documented by others. Using similar angles but changing which leg was connected Kulak and Wu (1997) found an increase in net section efficiency. Epstein (1992) observed that as the outstanding leg of angles decreased, while the connected leg size remained the same, resulted in increased failure loads. Also, Gibson and Wake (1942) found that angle efficiencies are reduced by outstanding leg effects.

Kulak and Wu set up a series of tests which examined outstanding leg effects by changing which leg, the long or the short, was connected. Comparing a single angle specimen with the long leg connected and a similar size angle connected by the short leg showed a $10 \%$ increased efficiency for when the long leg was connected. Double angles demonstrated a 7\% increase in efficiency when the long leg of each angle was attached instead of the short legs. A change from the long leg being connected to the short leg being connected changed the in-plane connection eccentricity from $32.0 \mathrm{~mm}(1.25$ inches) to $25.8 \mathrm{~mm}$ (1 inch). Therefore, this effect on section efficiency is not likely due to in-plane bending. See Appendix E for a diagram of single and double angle set-ups used by Kulak and Wu (1997). Note that the double angles are not back-to-back, but rather, are separated by a gusset plate.

Also, it was noted (Kulak and $\mathrm{Wu}, 1997)$ that using LRFD provisions for punching effects reduced capacities of the sections examined by less than $2 \%$ and by less than $4 \%$ in a wide range of angles. Whereas, it has been noted (Munse and Chesson, 
1963; Gaylord et al., 1992) that a reduction in capacity of 12.5 to $15 \%$ is not unreasonable in accounting for losses in capacity due to punching. Kulak and Wu only tested specimens with punched holes and, therefore, no examination of experimental losses in capacity due to punching can be made.

\section{Predictions of $U$ factor:}

Kulak and Wu (1997) compared their test results and those of others with the specification predicted capacities. The test results of others (Nelson, 1953; Mueller and Wagner, 1985; McKibbon, 1906 and 1907) that they used in the examination included double and single angles, with both punched and drilled holes. The predicted strength values were developed on the basis of net section rupture, calculating the effective net area of the critical cross section based on Eqns. 1.4 and 2.2.

In the examination of Eqn. 2.2, assuming $K_{1}$ and $K_{3}$ are equal to one, unconservative results were obtained. The average professional factor was 1.05 (above unity is unconservative) and the standard deviation was 0.13 . Over prediction of a specimen's capacity was especially true for those specimens with drilled holes and for those specimens with fewer than four bolts.

Comparing actual specimen capacities with the LRFD predictions, Eqn 1.2, which includes the $2 \mathrm{~mm}$ diameter increase to the nominal hole to account for punched holes, produced very unconservative results. The professional factor had an average of 1.19 and a standard deviation of 0.13 .

Lastly, comparing specimen failures strengths against the LRFD predictions, using a $\mathrm{U}$ value as allowed for by the Commentary on Chapter $\mathrm{B}$ ( $U=0.85$ for a 3 or 
more bolt connection and $U=0.75$ for a two bolt connection) and, again, the $2 \mathrm{~mm}$ hole diameter increase, produced professional factors with an average of 1.12 and a standard deviation of 0.17 . It was noted that in a few cases the predicted failure load over estimated the actual failure load by $50 \%$.

On the basis of the above results Wu and Kulak (1997) concluded that the calculated U value might produce unconservative predictions. They suggest that to produce a more conservative prediction the present shear lag equation should be multiplied by the fabrication factor of 0.85 , regardless of whether or not bolt holes are fabricated using punching or drilling methods. 


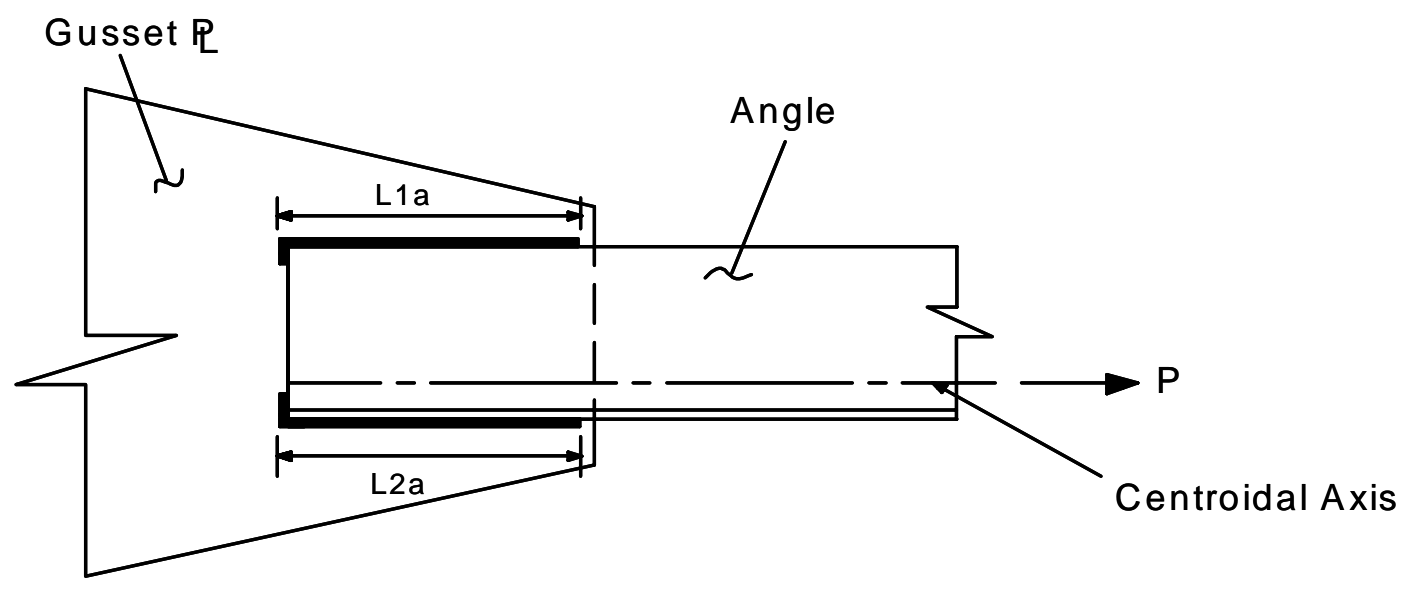

(a) unbalanced

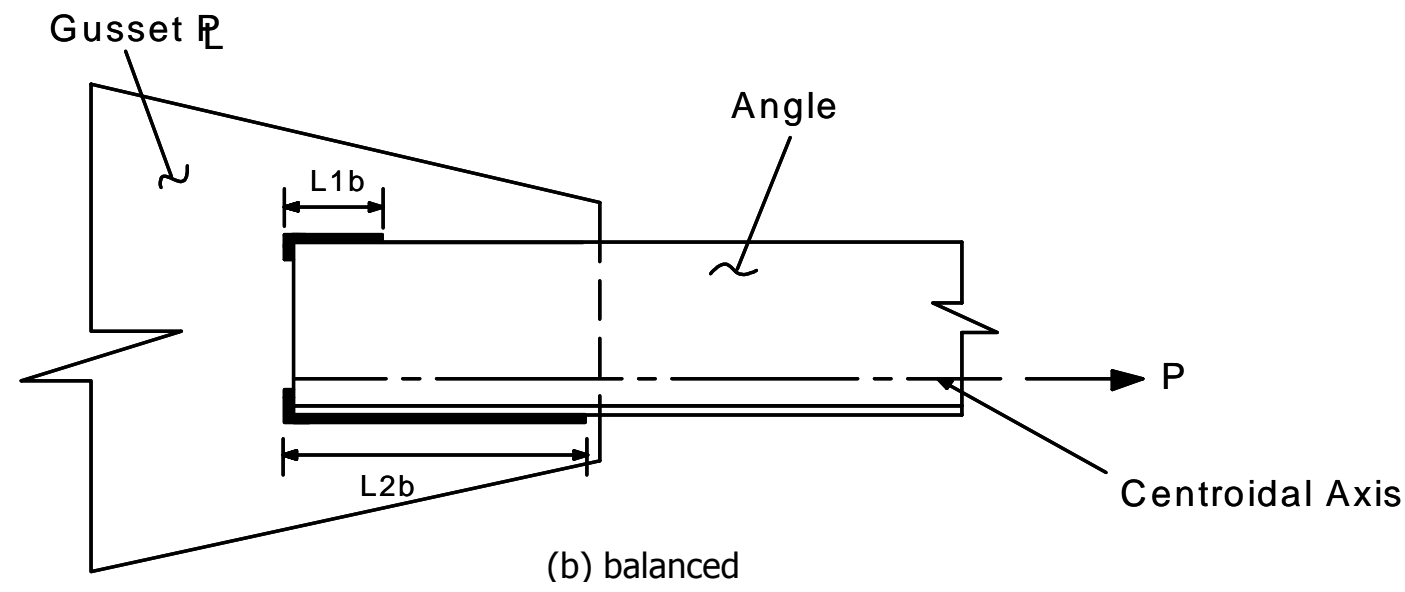

Note: $\mathrm{L} 1 \mathrm{a}+\mathrm{L} 2 \mathrm{a}=\mathrm{L} 1 \mathrm{~b}+\mathrm{L} 2 \mathrm{~b}$

Figure 2.1: Unbalanced and balanced weld designs (a) unbalanced (b) balanced 


\section{Chapter 3}

\section{EXPERIMENTAL STUDY}

\subsection{Introduction}

This chapter is a presentation of the experimental tests performed. Specimen fabrication and testing are discussed. LRFD also specified limits for connection geometries and an explanation of testing apparatuses are presented in this chapter.

\subsection{Specimens}

The experimental testing program consists of three sets of short WT tension specimens fabricated from duel certified steel for ASTM A36 and ASTM A572 Grade 50 steels. All specimens are $914 \mathrm{~mm}$ (36 inch) length. All specimens are fastened, with a single row of $19 \mathrm{~mm}$ (3/4 inch) A490-x bolts, through their webs at both ends (see Fig. 3.1, Table 3.1 and Appendix B). The tests consist of the following types of specimens: 2 sets of 8 WT 155x10.5s (WT 6x7) and 1 set of 6 WT 100x18s (WT 4x12). The WT $155 \times 10.5$ sets have the same eccentricities, but differing connection lengths $228.6 \mathrm{~mm}$ ( 9 inches) and $304.8 \mathrm{~mm}$ (12 inches). Connection length was increased or decreased by varying the number of bolts, not the pitch distance, in a connection. The WT 100x18 specimens have different eccentricities (gage dimensions) than those of the WT $155 \times 10.5 \mathrm{~s}$ and connection lengths of $152.4 \mathrm{~mm}$ ( 6 inches). There are four specified gage 
dimensions for the WT $155 \times 10.5$ s and three gage dimensions specified for the WT 100x18s. Each gage dimension has a pair of specimens associated with it; one has punched holes while the other has drilled holes (with the exception of specimen $4 \mathrm{a}$ which has drilled rather than punched bolt holes due to a fabrication error). The pitch and end distance for each specimen are held constant at $76.2 \mathrm{~mm}$ (3.0 inches) and $63.5 \mathrm{~mm}$ (2.5 inches), respectively. Holes for the $19 \mathrm{~mm}$ A490-x bolts were specified to be drilled or punched to a $21 \mathrm{~mm}\left(13 / 16^{\text {th }}\right.$ inch $)$ diameter.

\subsection{Specimen Geometries}

The literature review showed studies that examined shear lag effects on the net section rupture capacities of tension members. However, the present study has particular focus placed upon the effects of connection eccentricities with regards to induced bending moments. For this reason the specimens' eccentricities were specified such that a broad range of eccentricities could be examined. Past studies have not considered the induced bending effects from eccentricities. Additionally, there have not been any previous studies focused on studying a comprehensive range of eccentricities. All specimens met present specification limits on both end distance and edge distance.

LRFD limits the placement of bolts to within $25.4 \mathrm{~mm}$ (1 inch) of any edge for specimens that are connected with $19 \mathrm{~mm}(3 / 4 \mathrm{inch})$ bolts and have non-sheared edges.

Connection lengths are also examined. As past results have shown, connection length has significant influence in the development of the effective net area. Connection length was varied by increasing or decreasing the number of bolts in connection (bolt 
pitch was held constant). The specification requires that a pitch no less than $2^{2} /{ }_{3} \mathrm{~d}$ (where "d" is the nominal bolt hole diameter) is to be used in design and that a pitch distance of $3 \mathrm{~d}$ is more appropriate for connections (J3.3, p. 6-80). Typically, a $76.2 \mathrm{~mm}$ (3 inch) pitch is used in construction practices for $19 \mathrm{~mm}$ diameter bolts.

Punched effects have been examined in the past and their results have been present. In an effort to continue to examine present LRFD accommodations for punched holes effects specimens were fabricated with punched or drilled bolt holes. Also, punching effects in combination with minimum edge distances have not been considered. Hence, the reason for testing specimens with minimum edge distances and punched holes.

As shown by Kulak and Wu (1997), increases in out-of-plane eccentricities have resulted in decreased efficiencies, $7 \%$ for double angle specimens (non-back-to-back, see App. E). WTs were chosen as opposed to angles for the primary purpose of limiting the number of parameters to not including out-of-plane eccentricities. Later, the effects of out-of-plane bending will need to be examined, but for the present study their elimination was desired. Also, for the reason of eliminating out-of-plane eccentricities the specimens were fastened at both ends between two bar stock grips, one on either side of a specimen.

\subsection{Experimental Apparatuses}

Bar stock grips, simulating gusset plate effects, are used to transfer the load from a Baldwin $890 \mathrm{KN}$ (200 kip) universal testing machine (UTM) to a WT specimen. They are fabricated from $76 \mathrm{~mm}$ by $19 \mathrm{~mm}$ (3 by 3/4 inch) ASTM 1080 cold rolled bar stock 
and had $21 \mathrm{~mm}\left(13 / 16^{\text {th }}\right.$ inch) diameter holes drilled at the appropriate pitch. Two sets of bar stock grips were used in this study. One set of grips had four holes drilled in each bar, while the other set had five holes per bar. A set of grips consists of four lengths of bar stock; the five hole bar stock grips have a length of $635 \mathrm{~mm}$ ( 25 inches) and the four hole grips have a length of $558.8 \mathrm{~mm}$ (22 inches). Appendix C contains sketches with appropriate dimensions of the two types of grips used.

To prevent bending of the grip ends and, thus, enabling the UTM wedge-grips to have a truer contact surface with the bar stock grips, spacer plates of the same thickness as a specimen's web were placed between the ends of the grips. Figure 3.2 shows a typical WT specimen with attached grips, a specimen-grip assembly. The bolts were tightened to the snug-tight condition, which allowed the specimens to go into bearing after the initial loading of a specimen. Bolts were reused for tests if they were visually undamaged from previous tests.

\subsection{Testing Procedure}

After the appropriate grips were fastened to a WT the specimen-grip assembly was then placed and centered in the UTM and then secured fast with the wedge-grips in the UTM crossheads (see Fig. 3.3). Each specimen was tested to failure (at which point the load applied by the UTM would drop off considerably) by steadily increasing the applied load. 
Table 3.1: Specimen Dimensions and Material Strengths

\begin{tabular}{|c|c|c|c|c|c|c|c|c|c|c|}
\hline $\begin{array}{l}\text { Spec. } \\
\text { No. }\end{array}$ & $\begin{array}{l}\text { WT } \\
\text { Sect. }\end{array}$ & $\begin{array}{l}\text { No. of } \\
\text { Bolts }\end{array}$ & $\begin{array}{l}\text { Conn. } \\
\text { Length }\end{array}$ & $\begin{array}{c}\text { Gage } \\
\text { Distance, } \mathbf{g}\end{array}$ & $\begin{array}{c}\text { Bolt Line } \\
\text { Eccentricity, } \bar{x}\end{array}$ & $\begin{array}{l}\text { Spec. } \\
\text { Depth, d }\end{array}$ & $\begin{array}{c}\text { Web } \\
\text { Thickness, tw }\end{array}$ & $\begin{array}{l}\text { Hole } \\
\text { Diam. }\end{array}$ & $\begin{array}{l}\text { Yield } \\
\text { Strength }\end{array}$ & $\begin{array}{l}\text { Tensile } \\
\text { Strength }\end{array}$ \\
\hline $1(p)^{b}$ & $155 \times 10.5$ & 4 & 228.6 & 127.0 & 82.3 & 150.2 & 5.0 & 19.8 & 405 & 518 \\
\hline $2(d)$ & $155 \times 10.5$ & 4 & 228.6 & 127.0 & 82.3 & 150.7 & 5.0 & 20.9 & 405 & 518 \\
\hline $3(p)$ & $155 \times 10.5$ & 4 & 228.6 & 88.9 & 44.2 & 150.6 & 5.0 & 19.8 & 405 & 518 \\
\hline $4(d)$ & $155 \times 10.5$ & 4 & 228.6 & 88.9 & 44.2 & 150.0 & 5.0 & 20.8 & 405 & 518 \\
\hline $5(d)$ & $155 \times 10.5$ & 4 & 228.6 & 63.5 & 18.8 & 150.6 & 4.9 & 20.4 & 405 & 518 \\
\hline $6(p)$ & $155 \times 10.5$ & 4 & 228.6 & 63.5 & 18.8 & 151.6 & 5.1 & 19.8 & 405 & 518 \\
\hline $7(p)$ & $155 \times 10.5$ & 4 & 228.6 & 46.5 & 1.8 & 151.8 & 5.0 & 20.7 & 405 & 518 \\
\hline $8(d)$ & $155 \times 10.5$ & 4 & 228.6 & 46.5 & 1.8 & 150.5 & 4.9 & 20.7 & 405 & 518 \\
\hline $1 a(d)$ & $155 \times 10.5$ & 5 & 304.8 & 127.0 & 82.3 & 150.4 & 5.2 & 20.7 & 427 & 526 \\
\hline $2 a(p)$ & $155 \times 10.5$ & 5 & 304.8 & 127.0 & 82.3 & 150.0 & 5.2 & 20.6 & 427 & 526 \\
\hline $3 a(d)$ & $155 \times 10.5$ & 5 & 304.8 & 88.9 & 44.2 & 149.9 & 5.2 & 20.7 & 427 & 526 \\
\hline $4 a(d)^{c}$ & $155 \times 10.5$ & 5 & 304.8 & 88.9 & 44.2 & 150.7 & 5.2 & 20.6 & 427 & 526 \\
\hline $5 a(d)$ & $155 \times 10.5$ & 5 & 304.8 & 63.5 & 18.8 & 151.8 & 5.2 & 20.8 & 427 & 526 \\
\hline $6 a(p)$ & $155 \times 10.5$ & 5 & 304.8 & 63.5 & 18.8 & 151.6 & 5.1 & 20.6 & 427 & 526 \\
\hline $7 a(d)$ & $155 \times 10.5$ & 5 & 304.8 & 46.5 & 1.8 & 150.0 & 5.2 & 20.7 & 427 & 526 \\
\hline $8 a(p)$ & $155 \times 10.5$ & 5 & 304.8 & 46.5 & 1.8 & 150.8 & 5.2 & 20.6 & 427 & 526 \\
\hline $1 \mathrm{~b}(\mathrm{~d})$ & $100 \times 18$ & 3 & 152.4 & 76.2 & 58.7 & 101.2 & 7.3 & 20.6 & 402 & 474 \\
\hline $2 b(p)$ & $100 \times 18$ & 3 & 152.4 & 76.2 & 58.7 & 101.7 & 7.3 & 20.5 & 402 & 474 \\
\hline $3 b(d)$ & $100 \times 18$ & 3 & 152.4 & 63.5 & 46.0 & 101.3 & 7.3 & 20.7 & 402 & 474 \\
\hline $4 b(p)$ & $100 \times 18$ & 3 & 152.4 & 63.5 & 46.0 & 101.0 & 7.3 & 20.5 & 402 & 474 \\
\hline $5 b(d)$ & $100 \times 18$ & 3 & 152.4 & 50.8 & 33.3 & 103.7 & 7.4 & 20.8 & 402 & 474 \\
\hline $6 b(p)$ & $100 \times 18$ & 3 & 152.4 & 50.8 & 33.3 & 101.9 & 7.3 & 20.6 & 402 & 474 \\
\hline
\end{tabular}

a. Dimensions are in $\mathrm{mm}$ and strengths are in $\mathrm{MPa}$.

b. (p) designates a specimen with punched holes and (d) a specimen with drilled holes.

c. Due to a fabrication error specimen $4 a$ 's bolt holes were drilled rather than punched. 


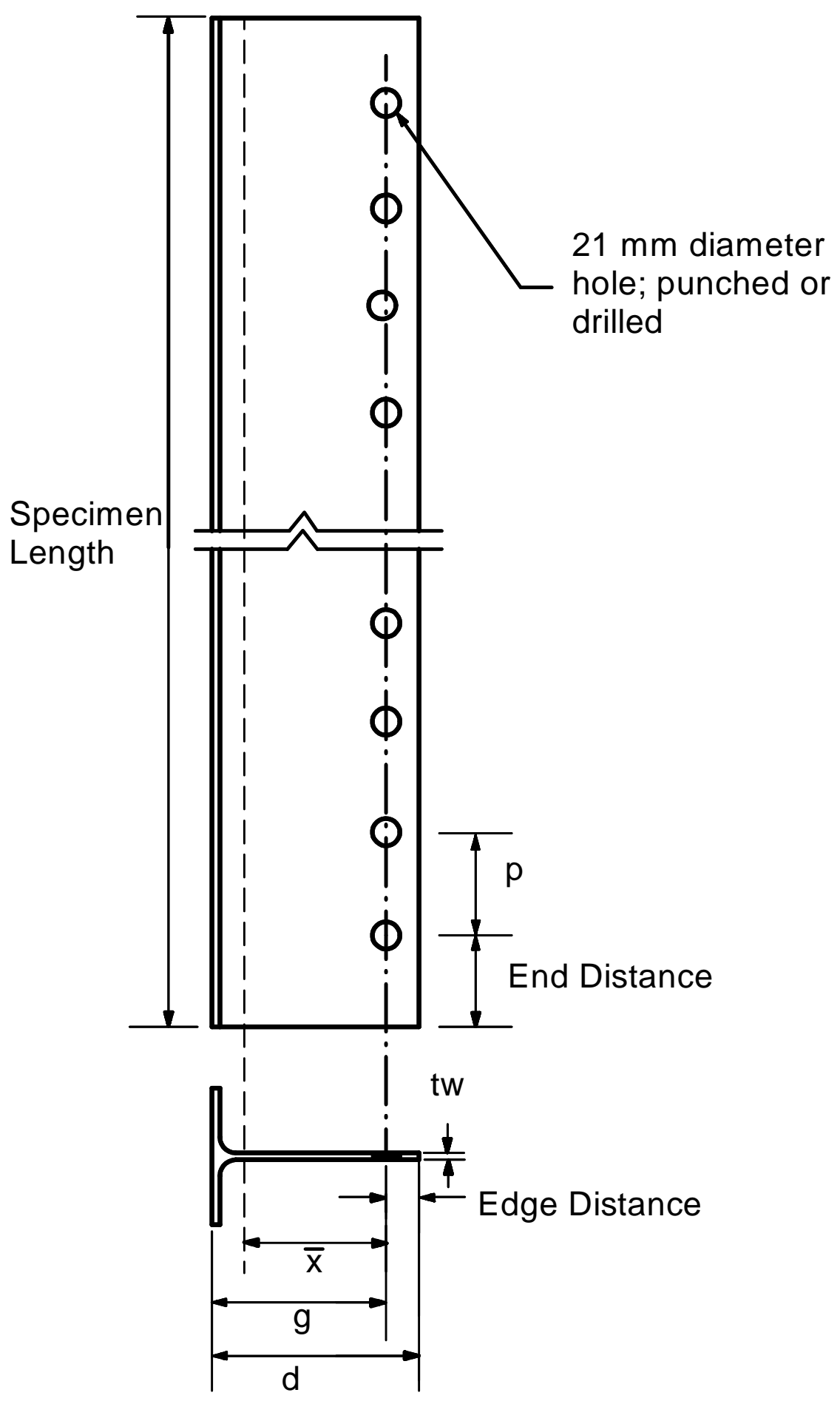

Figure 3.1: Typical WT specimen configuration 


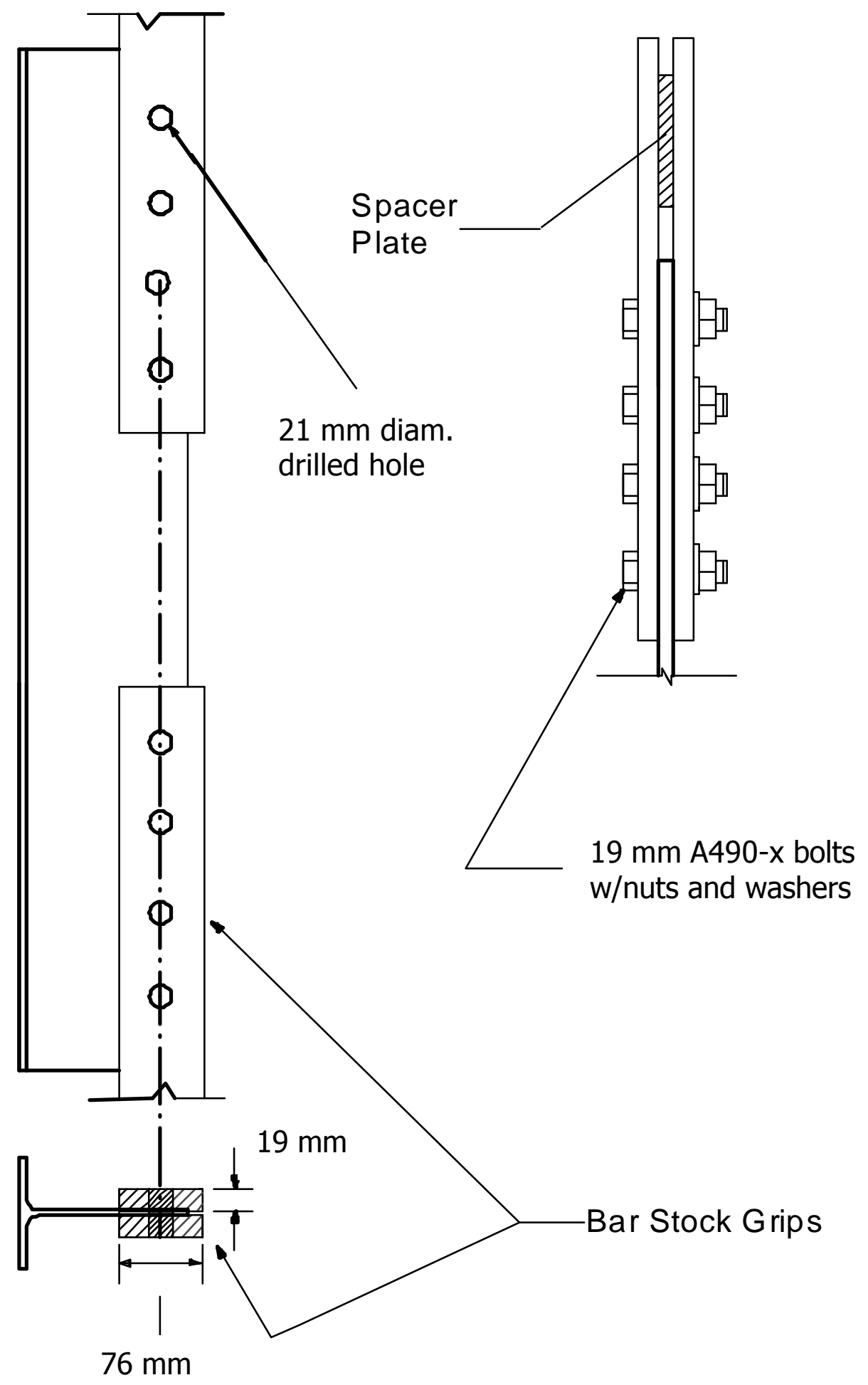

Figure 3.2: Typical WT specimen- grip assembly 


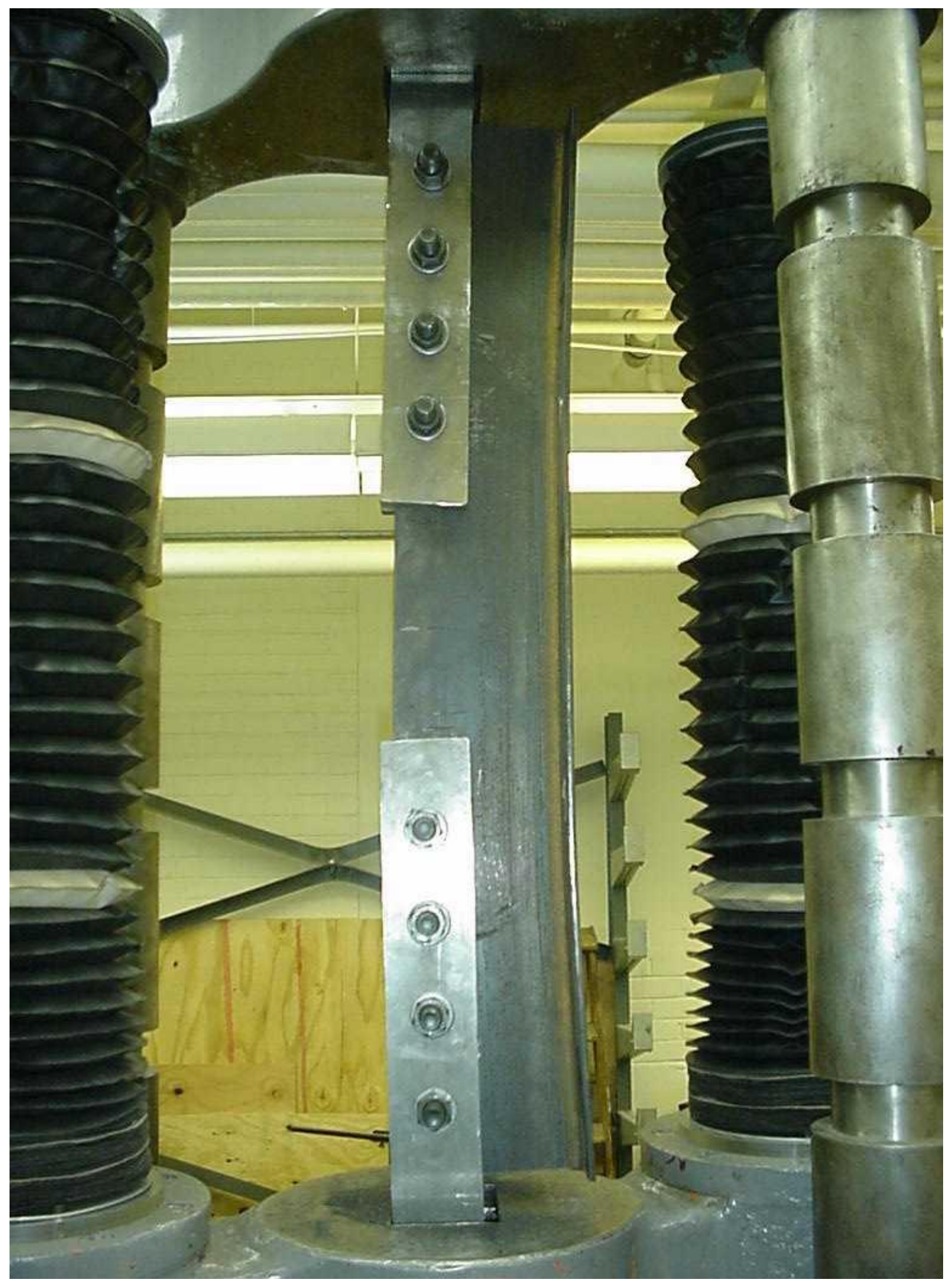

Figure 3.3: Typical WT specimen in UTM 


\section{Chapter 4}

\section{EXPERIMENTAL RESULTS}

\subsection{Introduction}

This chapter examines failure modes exhibited by the specimens tested. Also, the trends exhibited by the tests will be examined and failure loads will be compared to LRFD predictions and provisions.

\subsection{Specimen Failures}

Three modes of failure were observed among the tests. The first mode, exhibited by most specimens with non-zero connection eccentricities, involved necking down and subsequent rupture of the net section from the lead bolt hole to the edge of the web. The second failure mode observed was a block shear failure evidenced by rupture of the net tension area and either partial or full rupture of the gross shear area. The third failure mode consisted of full net section rupture, with near-simultaneous rupture of both the web and flange areas. These modes are described as partial rupture of the net section, block shear rupture, and full rupture of the net section respectively and are described in the following subsections. 


\subsubsection{Partial Rupture of the Net Section}

The typical specimen failure (specimens: 1, 2, 3,4, 5, 6, 1a, 2a, 3a, 4a, 5a, 6a, 1b, $2 \mathrm{~b}, 3 \mathrm{~b}$, and $4 \mathrm{~b}$ ) consisted of a partial rupturing of the net section. Note that tests were stopped when the peak load was reached. The peak load was reached before fracturing of the full net section, but after rupture of the partial net section. Fracturing of a specimen's web initiated at the lead bolt hole and propagated to the web's outside edge. Necking down of the tension plane area preceded fracture. Specimens with small eccentricities exhibited a significant amount of bolt hole deformation (see Fig. 4.1). However, it was observed that the amount of deformation decreased with increasing eccentricity. Those specimens with the largest eccentricities demonstrated very minor hole deformation except at the lead and last bolts (see Fig. 4.2).

Additionally, some yielding was observed in the web as witnessed by mill scale flaking. Again, this observed flaking was localized to the area surrounding the lead bolt hole for large eccentricities but extended further along the shear plane as eccentricity was decreased.

Specimens also exhibited in-plane bending. Specimens with larger eccentricities had larger degrees of in-plane bending. Figure 3.3 shows in-plane bending of a specimen while being loaded. After partial net section rupture had occurred the specimens experience significantly more in-plane bending compared with bending prior to fracture. This is due to a plastic hinge being formed in the web opposite the fracture. 
Rotation of a connection is easily visible in the bolt hole deformation patterns shown in the lead and last bolt holes in a connection. As a result of in-plane eccentricity, moments produced in a specimen were resisted by the specimen's connections and thus the deformation patterns observed. The resisting moment of the connection was centered about the connection length's center. The evidence of this connection rotation, as given by bolt hole deformation patterns, decreased with decreased eccentricity.

\subsubsection{Block Shear}

Block shear failure occurred in specimens $8,5 \mathrm{~b}$, and $6 \mathrm{~b}$. Specimen 8 had a near zero eccentricity, $1.8 \mathrm{~mm}$ (0.07 inches), and the block shear failure consisted of a rupturing of both the net tension and net shear areas. An interesting note is that its punched match, specimen 7 , failed in net section rupture. This may be attributed to a significant enough loss in net section efficiency, due to punching effects, to decrease the net section rupture capacity below the block shear capacity. The other two specimens, $5 \mathrm{~b}$ and $6 \mathrm{~b}$, failed in block shear by a partial rupturing of the net shear area and a complete rupturing of the net tension area. These two specimens had eccentricities of $33.3 \mathrm{~mm}$ (1.31 inches) and exhibited in-plane bending with similar connection rotation patterns as noted above. Figure 4.3 is a photo of a specimen 8. 


\subsubsection{Full Rupture of the Net Section}

Full rupture of the net section occurred in specimens 7, 7a, and 8a. All of these specimens had an eccentricity of $1.8 \mathrm{~mm}(0.07$ inches $)$. There occurred a rupturing of the web on either side of the lead bolt hole, which propagated thorough the rest of both the flange and web areas simultaneously. Figure 4.4 shows specimen 7 a failed in full net section rupture.

\subsection{Effects of Connection Eccentricity}

Eccentricity is readily observed to have a direct impact on a connection's net section efficiency. Figures 4.5 through 4.7 show only the drilled specimen net section efficiencies versus connection eccentricity for the five, four and three bolt connections, respectively. These figures clearly show that as connection eccentricity decreases, there is a near linear increase in member efficiency for the four and three bolt connection specimens. However, the five bolt connection specimens show a non-linear increase in efficiency as connection eccentricities approach zero and net section efficiencies are approaching 100\%; specimens are nearing their maximum tensile capacity.

Kulak and Wu (1997) suggest that to provide more conservative results than are presently obtained by Eqn. 1.2 the fabrication factor $K_{2}$ should be multiplied by the shear lag factor, regardless of whether the bolt holes are fabricated using drilling or punching methods. Kulak and $\mathrm{Wu}$ observed that the unconservative results produced were especially true for drilled holes and specimens with fewer than four bolts. Therefore, the effective net area of a member is not correctly determined by the present 
shear lag reduction factor. This strongly suggests that the present LRFD effective net section reduction factor (the shear lag reduction factor) does not account for the bending effects induced by connection eccentricities or the degree to which the connection length influences bending effects. Connection length effects will be discussed in the following subsection.

Specimens with the largest eccentricities, $82.3 \mathrm{~mm}$ (3.25 inches) for the WT $155 \times 10.5 \mathrm{~s}$ and $58.7 \mathrm{~mm}$ (2.31 inches) for the WT 100x18s, produce unconservative predictions when compared with failure capacities given by the Eqns. 1.1, 1.2, 1.5 and 1.6. The efficiencies of these equations for the five, four and three bolt connection specimens are presented in Figs. 4.8 - 4.10, respectively. "U equivalent of block shear" and "U equivalent of H1-1a", as shown in the figure legends are net section efficiency equivalents of non-net section failures. This is done in an effort to normalize the predicted capacities of the two types of WT sections tested in this study. The calculation of "U equivalent of block shear" and "U equivalent of H1-1a" is shown below.

$U$ equivalent of block shear $=\frac{\text { LRFDpredicted block shear capacity }}{F_{u} A_{n}}$

$U$ equivalent of $H 1-1 a=\frac{\text { LRFDpredicted } H 1-1 \text { a capacity }}{F_{u} A_{n}}$

The "H1-1a" and other LRFD predicted capacities can be seen in Table 4.1. The calculation of "H1-1a" capacities will be discussed later in this section.

Specimens 2, 1a and $1 \mathrm{~b}$ produced professional factors of $0.69,0.62$, and 0.79 , respectively (less than unity being unconservative). The corresponding punched matches, specimens $1,2 \mathrm{a}$, and $2 \mathrm{~b}$, produced professional factors with less conservative results, 0.62, 0.56, and 0.75, respectively (see Table 4.1). It is observed from the Figs. 4.7 
through 4.9 that LRFD predictions become unconservative for connection eccentricities exceeding $45 \mathrm{~mm}$ (1.75 inches) for specimens with drilled and $25 \mathrm{~mm}$ and $38 \mathrm{~mm}$ (for WT 155x10.5 and 100x18 specimens, respectively) for specimens with punched holes. Note, however, that many of the specification controlling prediction failures (block shear) are not representative of the failures observed in the specimens.

The inconsistencies between LRFD predictions and the failure loads may be attributed to primary bending moments resulting from connection eccentricity, which are not accounted for in present specifications. The effects of an axial load will be increased because of an eccentricity induced flexural load. This will have the greatest affect on the web, causing a premature rupture of the partial net section area. Figure 4.11 shows a specimen subjected to a loading of "P" acting at the connection. Using statics, the resulting internal forces of a body can be reduced to a force and moment acting at some location. The resultant internal force acts through the centroidal axis of the member. However, because the external and resultant internal force are not in the same line of action an internal moment is produced, which is equal to the distance between the two forces (the in-plane eccentricity, " $\bar{x}$ ") multiplied by the magnitude of the moment couple (the applied external load, "P"). As mentioned in Chapter 3, connection eccentricities in the present studies fall within allowable minimum edge distances given in Section J3.4 of LRFD (1995). Therefore, the eccentricities should properly be accounted for in the design equations, but are not.

A more adequate accounting of the combination of axial and flexural effects on a tension specimen might be found by using the present interaction equation listed in Chapter H of LRFD, Eqn. H1-1a. A modified version of the interaction equation 
predictions are shown in Figs. 4.8 through 4.10 and listed in Table 4.1. However, the interaction equation predictions are conservative for specimens with the largest eccentricities and overly conservative for specimens with intermediate eccentricities. The interaction equation's conservativeness of the failure load may be attributed to a restoring moment being developed at the connection (as is witnessed by bolt hole deformation patterns). It is a function of connection length and the in-plane stiffness of the bar stock grips (typical of gusset plates). Acting counter to the in-plane bending of the specimen it reduces the detrimental effects of bending. Hence, the failure load of the specimen exceeds the interaction equation prediction. Figure 4.12 shows the beneficial effect of the restoring moment. The ability, however, to calculate this restoring moment is hampered by the fact that it is due to second order bending effects.

\subsection{Connection Length Effects}

The net section efficiency of the specimens tested increased by an average of $8 \%$ when the connection length was increased from $228.6 \mathrm{~mm}$ (9 inches) to $304.8 \mathrm{~mm}$ (12 inches). Whereas, the average increase in efficiency when going from a $152.4 \mathrm{~mm}$ (6 inches) to a $228.6 \mathrm{~mm}$ connection is $38 \%$. These results are comparable to work presented by Wu and Kulak (1993). They saw a 16\% increase in efficiency between a $76.2 \mathrm{~mm}$ ( 3 inch) and a $228.6 \mathrm{~mm}$ connection length ( 2 bolts to 4 bolts) but they saw no increase in efficiency between a $228.6 \mathrm{~mm}$ and a $381.0 \mathrm{~mm}$ (15 inch) connection length ( 4 bolts to 6 bolts). It should be noted that Kulak and Wu (1997) discuss the results of their study in terms of number of bolts rather than connection length. Similar to this study, they used a pitch distance of $76 \mathrm{~mm}$ (3 inches). Therefore, it is not possible to say 
that an increase or decrease in number of bolts causes net section efficiency to increase or decrease. As stated previously, pitch distance was not a parameter in this study.

The increases in net section efficiency shown here are due possibly to two benefits of increased connection length.

First, a possible benefit to a longer connection length is that it allows shear lag effects to be reduced. This has been shown to be the case in past studies (Munse and Chesson, 1963; Kulak and Wu, 1997; Wu and Kulak, 1993). Wu and Kulak (1993) examined the effect of connection length as it affects shear lag by the use of a finite element analysis [FEA] that they performed, examining the stress on the critical net section. Five specimens from their experimental tests were examined using the FE program ANSYS. A comparison between the FEA ultimate load and the corresponding physical test specimens was good, an average of 0.988 (FEA ultimate load to experimental load) and a standard deviation of 0.059 .

The FEA showed that with increased connection length a specimen with four or more bolts is able to develop an average of the yield stress in the outstanding leg and an average of the ultimate stress in the connected leg. However, a specimen with less than four bolts was not able to develop an average of the yield stress in the outstanding leg, while the connected leg is still able to develop an average of the ultimate stress. These results correspond well with present design considerations, which suggest that increased connection length allows for increased net section efficiency. However, this FEA is similar to Munse and Chesson's (1963) study of shear lag. There is an inherent inclusion of bending effects in the solution due to small connection eccentricities present in each 
modeled specimen. Therefore, as in Munse and Chesson's (1963) study no distinction can be drawn between the effects of bending and shear lag.

Secondly, an increase in the connection length of a specimen allows for a larger restoring moment at the connection. The connection length limits the restoring moment's lever-arm. A longer connection length permits, therefore, a larger restoring moment to develop, increasing net section efficiency. This has been discussed in more detail in the previous section. The restoring moment can be expected to be present in any tension member having connection eccentricity and gusset plate stiffness.

\subsection{Shear Lag}

Concerning present shear lag considerations in design, the current test results indicated that for eccentricities near zero (specimens 7, 8, 7a and 8a) the maximum shear lag coefficient, $U=0.9$, is exceeded for both punched and drilled holes (see Fig. 4.13). Specimen 7a, the drilled WT 6x7 with a $304.8 \mathrm{~mm}$ connection length, had a net section efficiency of $98 \%$. This is higher than the cut-off of $90 \%$ net section efficiency due to shear lag as specified in LRFD. Therefore, this observation would suggest that shear lag causes minimal reduction in net section efficiency for members that have no in-plane, or near zero in-plane, eccentricities. Specimen 8 failed in a complete rupturing of the block shear areas and had a net section efficiency of $95 \%$. The net section rupture capacity was never reached. Hence, if it had been possible for specimen 8 to fail in net section rupture it would have exceeded an efficiency of $95 \%$.

Specimens' 7a and 8 efficiencies indicate that regardless of the fact that only one out of three of the member's elements are connected the member has the potential to 
develop near $100 \%$ net section efficiency for near zero eccentricities. This possibility of developing 100\% efficiency in angles, regardless of the number of member elements not attached, was also witnessed by Kulak and Wu's (1997) test results (see Sec. 2.3.2.1).

Previous specimens that led to the development of the present $\mathrm{U}$ factor had differing amounts of bending due to eccentricity resulting from test setups. Present design specifications suggest that the effective net area is reduced only when shear lag is present. Therefore, the basis for the development of the shear lag reduction factor and its use fail to consider the detrimental connection eccentricity induced bending effects. This is supported by the prediction results of the reduction factor, $U$. As seen, in the Kulak and $\mathrm{Wu}(1997)$ study and the specimens of this present study. For WT $155 \times 10.5$ specimens whose eccentricities exceed $19 \mathrm{~mm}$ ( 0.75 inches), the LRFD efficiency predictions (Eqn. 1.4) are unconservative for punched and drilled specimens (see Figs. 4.8 and 4.9). Note that this comparison of predicted efficiencies and experimental efficiencies is only done considering net section rupture as the predicted mode of failure because the failures of this study are more accurately represented by net section failure.

Specimens with near zero eccentricities exhibit no real losses due to shear lag effects and the shear lag formula is unable to conservatively predict failure loads after 19 $\mathrm{mm}$. It, therefore, seems possible that the losses in efficiencies of the present experimental tests have not been due to any significant effects of shear lag, but rather, eccentricity induced bending effects. 


\subsection{Hole Fabrication Effects}

It has been well documented that punching holes has a detrimental influence on net section capacity when compared to similar members with drilled holes (Munse and Chesson, 1963; Gaylord et al., 1992). The average loss in capacity of the WT $155 \times 10.5$ s due to punching effects is $9 \%$ and the average loss in capacity of the WT $100 \times 18$ s is $7 \%$, a total average loss in section capacity of $8 \%$.

The specification states that $2 \mathrm{~mm}$ should be added to the nominal hole diameter to account for punching effects (LRFD, 1995). However, this increase only decreases the net section capacity by less than $2 \%$ (see Appendix F). This is noted in a past study, too (Kulak and $\mathrm{Wu}, 1997)$.

The detrimental effects of punched fabrication methods, also, increases with decreased edge distance (see Fig. 4.14). The WT 155x10.5s had an average of $11 \%$ loss in capacity due to punching for the $25.4 \mathrm{~mm}$ ( 1 inch) edge distance specimens, while the specimens with an approximate edge distance of $88.9 \mathrm{~mm}$ (3.5 inches) had an average loss due to punching effects of 5\%. The same trend can be seen with the WT 100x18 specimens, though the effects of punching a hole near the edge of the specimen are not as severe. This might be due to more web material being present between the bolt hole and web edge for the WT 4x12 25mm (1 inch) edge distance specimens than the WT $155 \times 10.525 \mathrm{~mm}$ edge distance specimens.

The ratio of material thickness to hole diameter is relatively small in the specimens tested; higher ratios are permitted (LRFD, 1995), which might possibly result in greater load capacity reductions. The Munse and Chesson (1963) recommendation of a $12.5 \%$ reduction in tension member net section capacity is not unreasonable. 


\subsection{AISC LRFD Predictions}

A comparison of these experimental results versus the LRFD predictions was completed. All the values calculated according to the specification, which are presented in Table 4.1, are calculated without the inclusion of any resistance factors. The bearing strengths are calculated on the assumption that bolt hole deformation is not a concern. All bolts, because of the pair of bar stock grips fastened at either end of a specimen, are subjected to double shear. Net section rupture strengths were calculated using Eqn. 1.2. The shear lag reduction factor, $U$, was calculated using both Eqn. 1.4 and the Commentary's allowance of $U=0.85$ for connections with three or more bolts. The increase of $2 \mathrm{~mm}$ in nominal hole diameter was only used for those specimens with punched holes rather then punched and drilled holes. Also, as mentioned previously, because of bending that was seen by all members with in-plane eccentricities, especially those specimens with large eccentricities, the calculation of a form of Eqn. H1-1a is included in the table of predicted strength values. However, it is not included in the “AISC Predicted Capacity" or "Prof. Factor $\mathrm{P}_{\mathrm{exp}} / \mathrm{P}_{\text {aisc }}$ " columns of Table 4.1 because it is not presently considered in tension member design. A sample calculation of specimens 1 and 2 for each of the LRFD limit states and a form of the LRFD interaction equation, Eqn. H1-1a, are given in Appendix G.

As noted previously, block shear Eqn. 1.6 controls the allowable block shear capacity of the member examined. Also, block shear is LRFD's predicted mode of failure for both the four and three bolt connections. However, for most of those

specimens block shear was not observed, especially by the mechanism suggested in Eqn. 
1.6. Also of note is that the shear lag reduction factor only produces a controlling design capacity for specimens 1a and 2a, but even this prediction produces a low professional factor, 0.62 and 0.56 , respectively. 
Table 4.1: Specimen Failure Loads and Predicted Capacities

\begin{tabular}{|c|c|c|c|c|c|c|c|c|c|c|c|c|c|}
\hline \multirow{3}{*}{$\begin{array}{c}\text { Spec. } \\
\text { No. }\end{array}$} & \multirow{3}{*}{$\begin{array}{l}\text { Exper. } \\
\text { Load }^{\mathrm{a}}\end{array}$} & \multirow{3}{*}{$\begin{array}{c}\text { Spec. } \\
\text { Failure } \\
\text { Type }^{b}\end{array}$} & \multicolumn{6}{|c|}{ AISC-LRFD Limit States } & \multirow{3}{*}{$\begin{array}{c}\text { Inter. } \\
\text { Eq. } \\
\text { (H1-1a) }\end{array}$} & \multirow{3}{*}{$\begin{array}{c}\text { AISC } \\
\text { Pred. } \\
\text { capacity }\end{array}$} & \multirow{3}{*}{$\begin{array}{c}\text { Prof. } \\
\text { Factor } \\
\mathbf{P}_{\text {exp }} / \mathbf{P}_{\text {aisc }}\end{array}$} & \multirow[b]{3}{*}{$F_{u} A_{\text {net }}$} & \multirow{3}{*}{$\begin{array}{l}\text { Efficiency } \\
\mathbf{P}_{\text {exp }} / F_{u} A_{\text {net }}\end{array}$} \\
\hline & & & \multicolumn{2}{|c|}{ Rupture ${ }^{c}$} & \multirow{2}{*}{$\begin{array}{c}\text { Yielding } \\
\text { (D1-1) }\end{array}$} & \multirow{2}{*}{$\begin{array}{c}\text { Bolt } \\
\text { Bearing } \\
(\mathrm{J} 3-1 \mathrm{~b})^{\mathrm{d}}\end{array}$} & \multirow{2}{*}{$\begin{array}{c}\text { Bolt } \\
\text { Shear } \\
(\mathrm{J} 3.6)^{e}\end{array}$} & \multirow{2}{*}{$\begin{array}{c}\text { Block } \\
\text { Shear } \\
\text { Capacity }\end{array}$} & & & & & \\
\hline & & & U=Calc & U=Comm. & & & & & & & & & \\
\hline $1(p)$ & 235.0 & PNS & 409 & 543 & 543 & 587 & 1180 & 383 & 178 & 383 & 0.62 & 641 & 0.37 \\
\hline $2(d)$ & 264.8 & PNS & 409 & 543 & 543 & 587 & 1180 & 383 & 178 & 383 & 0.69 & 641 & 0.41 \\
\hline $3(p)$ & 419.6 & PNS & 516 & 543 & 543 & 587 & 1180 & 458 & 263 & 458 & 0.92 & 641 & 0.66 \\
\hline $4(d)$ & 460.6 & PNS & 516 & 543 & 543 & 587 & 1180 & 458 & 263 & 458 & 1.00 & 641 & 0.72 \\
\hline 5 (d) & 560.7 & PNS & 579 & 543 & 543 & 587 & 1180 & 507 & 374 & 507 & 1.11 & 641 & 0.88 \\
\hline $6(p)$ & 526.0 & PNS & 579 & 543 & 543 & 587 & 1180 & 521 & 374 & 521 & 1.01 & 641 & 0.82 \\
\hline $7(p)$ & 578.5 & FNS & 579 & 543 & 543 & 587 & 1180 & 543 & 521 & 543 & 1.07 & 641 & 0.91 \\
\hline 8 (d) & 610.5 & BS & 579 & 543 & 543 & 587 & 1180 & 543 & 521 & 543 & 1.12 & 641 & 0.95 \\
\hline & & & & & & & & & & & & & \\
\hline $1 \mathrm{a}(\mathrm{d})$ & 295.5 & PNS & 476 & 547 & 574 & 788 & 1470 & 507 & 191 & 476 & 0.62 & 650 & 0.45 \\
\hline $2 a(p)$ & 262.6 & PNS & 476 & 547 & 574 & 788 & 1470 & 494 & 191 & 476 & 0.56 & 650 & 0.40 \\
\hline $3 a(d)$ & 542.0 & PNS & 556 & 547 & 574 & 779 & 1470 & 587 & 276 & 547 & 0.98 & 650 & 0.83 \\
\hline $4 a(d)$ & 535.8 & PNS & 556 & 547 & 574 & 774 & 1470 & 574 & 276 & 547 & 0.98 & 650 & 0.83 \\
\hline $5 a(d)$ & 609.7 & PNS & 583 & 547 & 574 & 779 & 1470 & 645 & 392 & 547 & 1.10 & 650 & 0.94 \\
\hline $6 a(p)$ & 582.1 & PNS & 583 & 547 & 574 & 770 & 1470 & 627 & 392 & 547 & 1.05 & 650 & 0.90 \\
\hline $7 a(d)$ & 638.6 & FNS & 583 & 547 & 574 & 783 & 1470 & 685 & 552 & 547 & 1.16 & 650 & 0.98 \\
\hline $8 a(p)$ & 596.7 & FNS & 583 & 547 & 574 & 783 & 1470 & 672 & 552 & 547 & 1.09 & 650 & 0.92 \\
\hline & & & & & & & & & & & & & \\
\hline $1 b(d)$ & 332.0 & PNS & 623 & 859 & 917 & 596 & 886 & 418 & 178 & 418 & 0.79 & 1010 & 0.33 \\
\hline $2 b(p)$ & 307.1 & PNS & 623 & 859 & 917 & 596 & 886 & 418 & 178 & 418 & 0.75 & 1010 & 0.31 \\
\hline $3 b(d)$ & 444.6 & PNS & 703 & 859 & 917 & 596 & 886 & 449 & 218 & 449 & 0.99 & 1010 & 0.44 \\
\hline $4 b(p)$ & 411.2 & PNS & 703 & 859 & 917 & 596 & 886 & 449 & 218 & 449 & 0.92 & 1010 & 0.41 \\
\hline $5 b(d)$ & 544.7 & BS & 788 & 859 & 917 & 596 & 886 & 498 & 276 & 498 & 1.09 & 1010 & 0.54 \\
\hline $6 b(p)$ & 515.3 & BS & 788 & 859 & 917 & 596 & 886 & 485 & 276 & 485 & 1.06 & 1010 & 0.51 \\
\hline
\end{tabular}
a. All capacities are in shown in $\mathrm{KN}$.
b. $\quad$ PNS = Partial net section rupture, FNS = Full net section rupture, $\mathrm{BS}=$ Block shear
c. Net section rupture strengths are calculated using U values as determined by Eqn. (B3-2) of Chapter B and Sec C-B3.
d. Bolt bearing is calculated neglecting hole deformation.
e. Bolts are in double shear.
f. The controlling Block Shear equation was J4-3b for all specimens. 


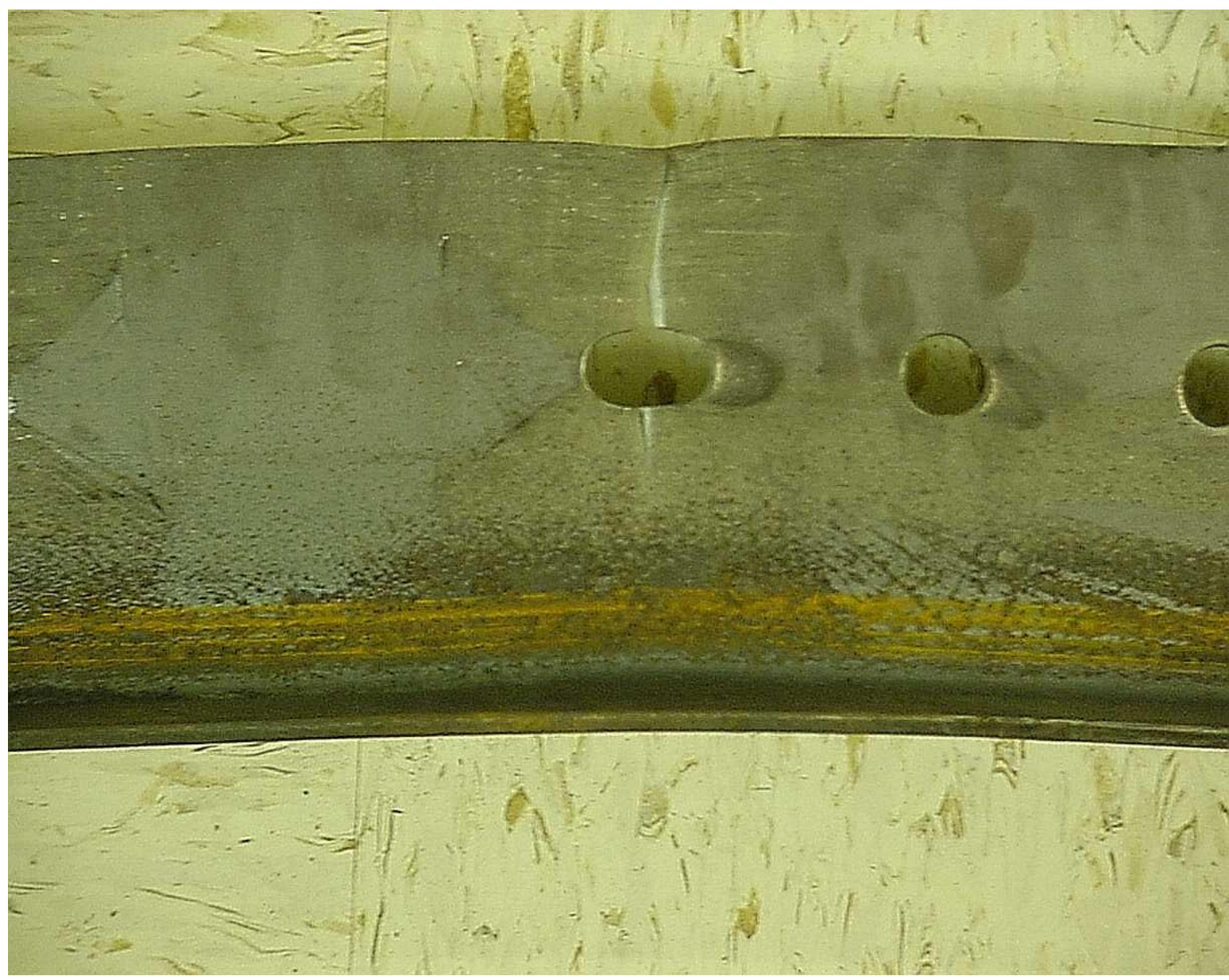

Figure 4.1: Partial net section rupture, with medium eccentricity (specimen 4) 


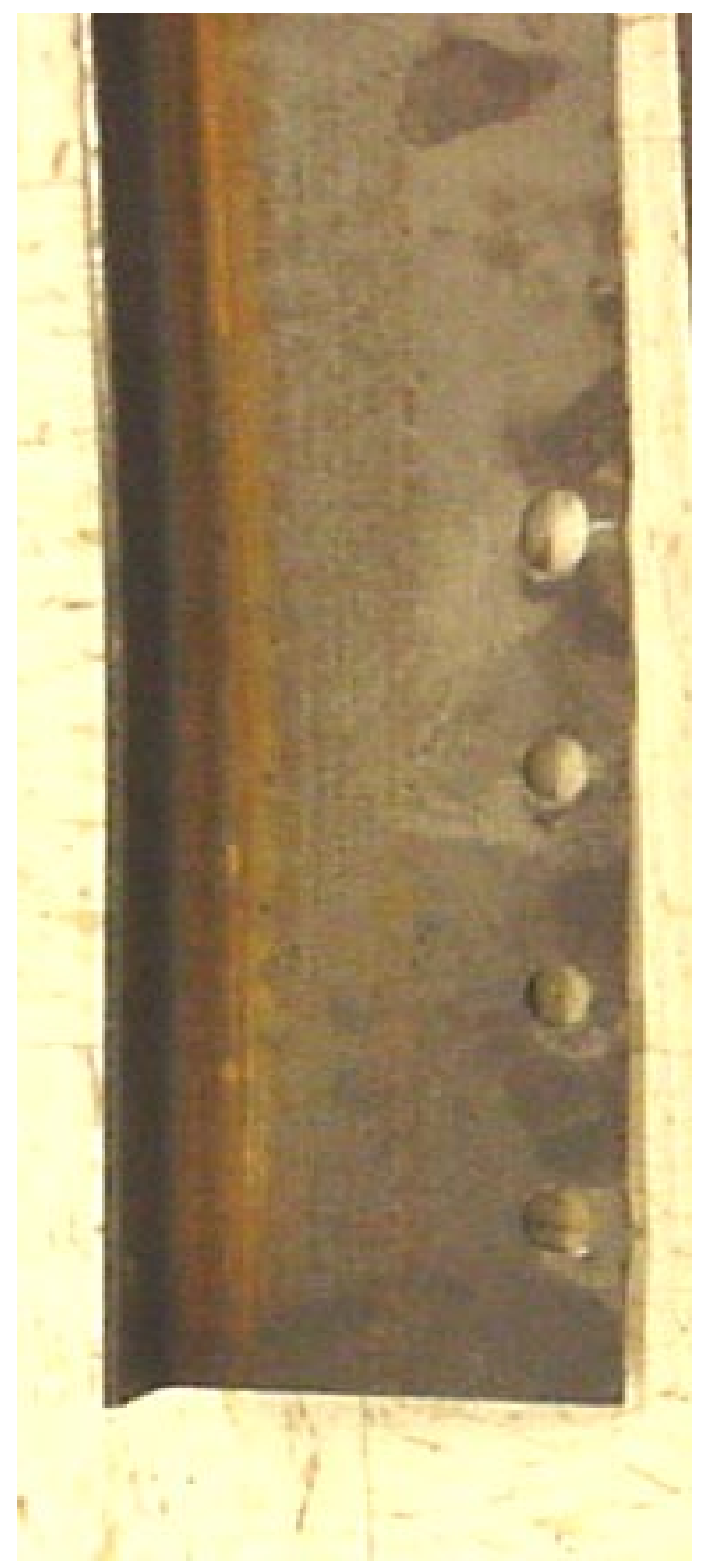

Figure 4.2: Partial net section rupture, with large eccentricity (specimen 1) 


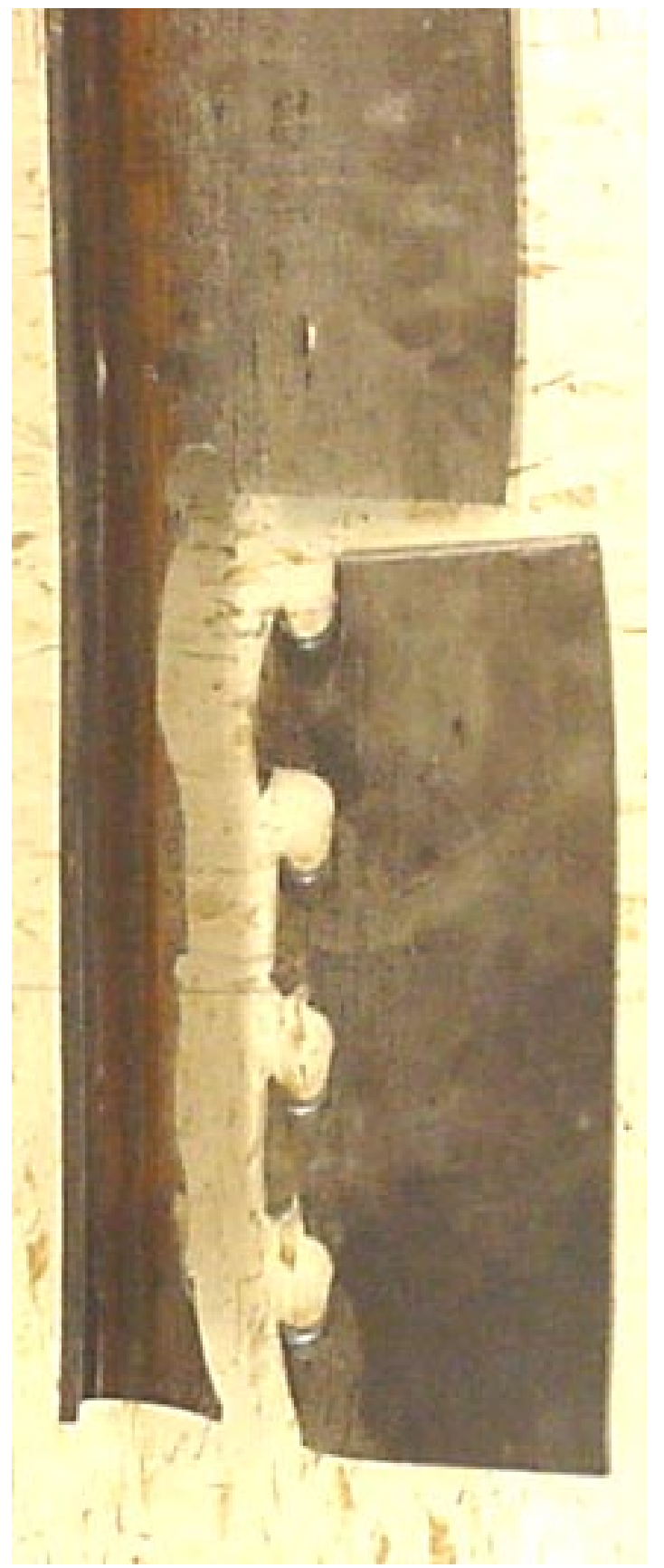

Figure 4.3: Block shear failure (specimen 8) 


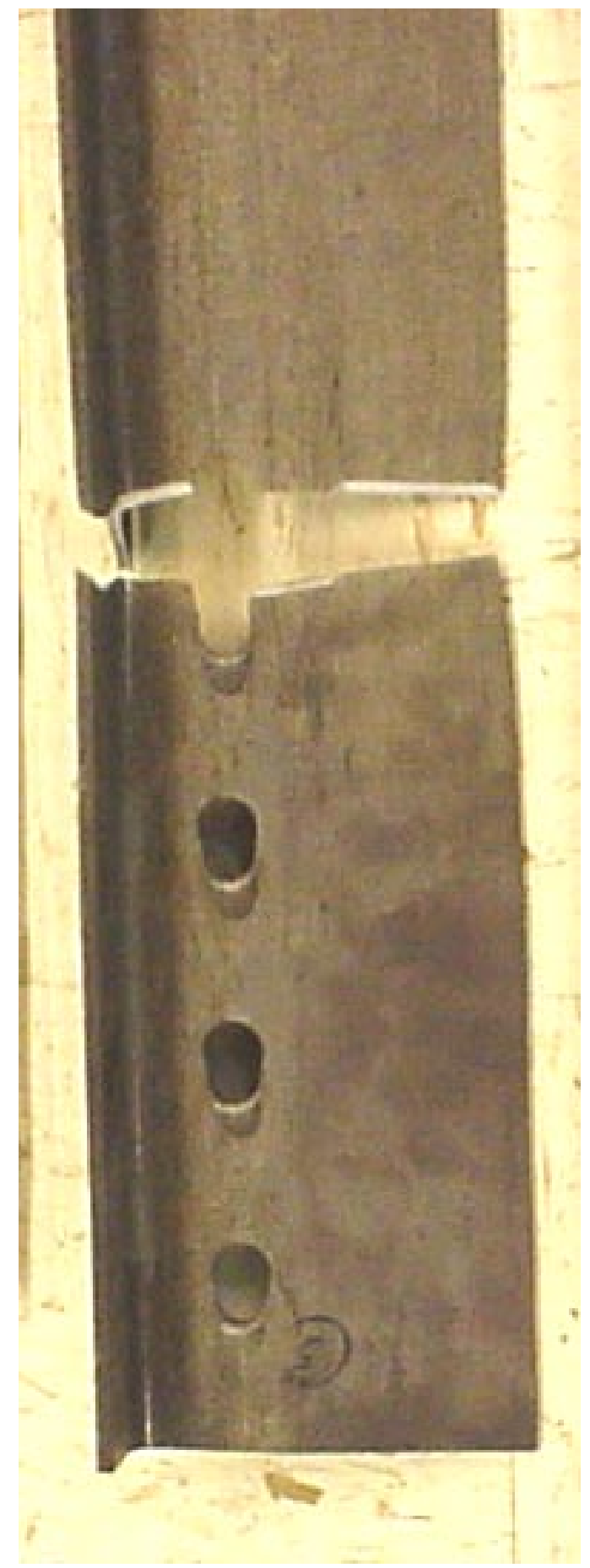

Figure 4.4: Full net section rupture (specimen 7) 


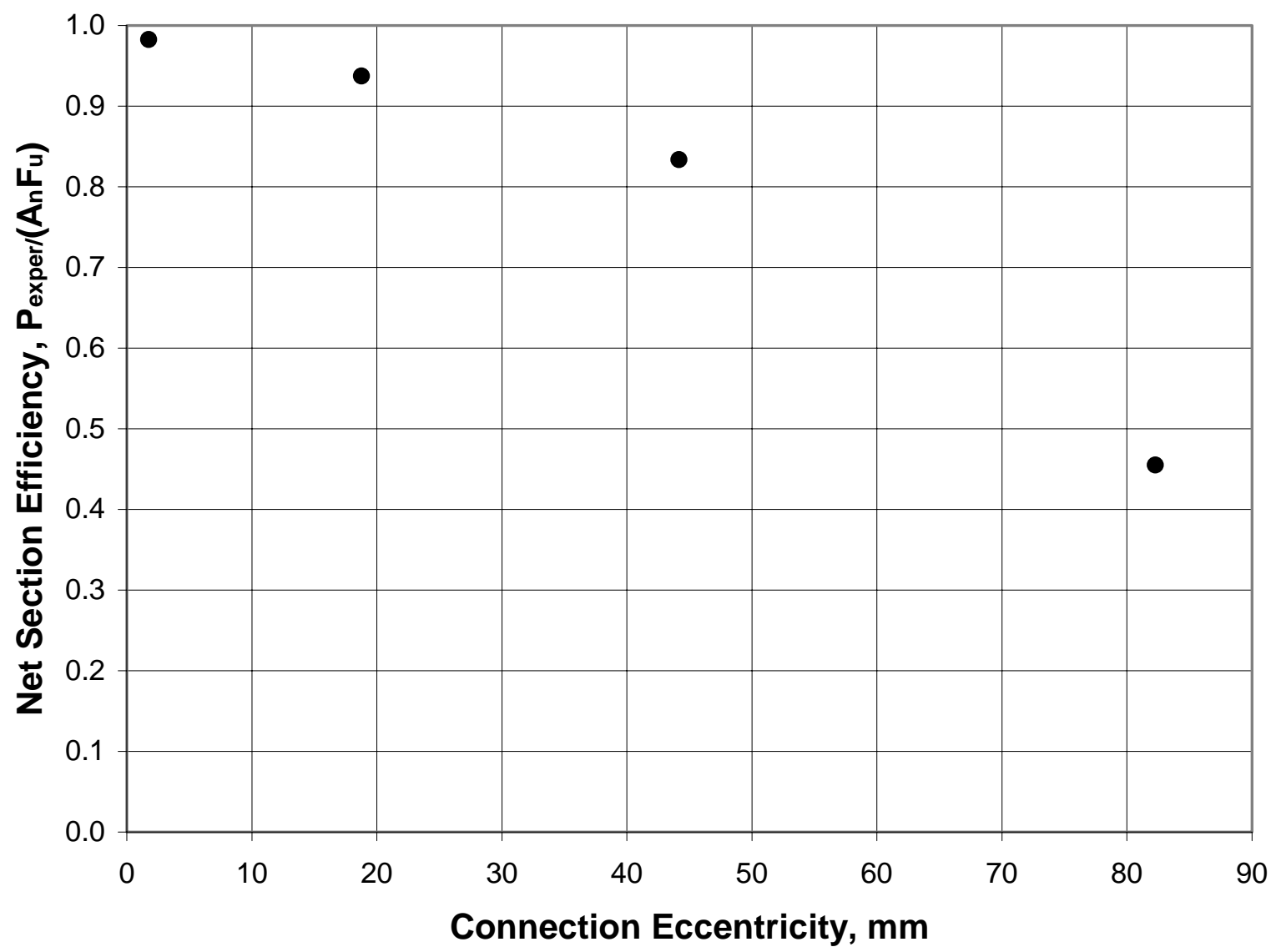

Figure 4.5: WT 155x10.5 5 bolt connection drilled specimens Net section efficiency versus connection eccentricity 


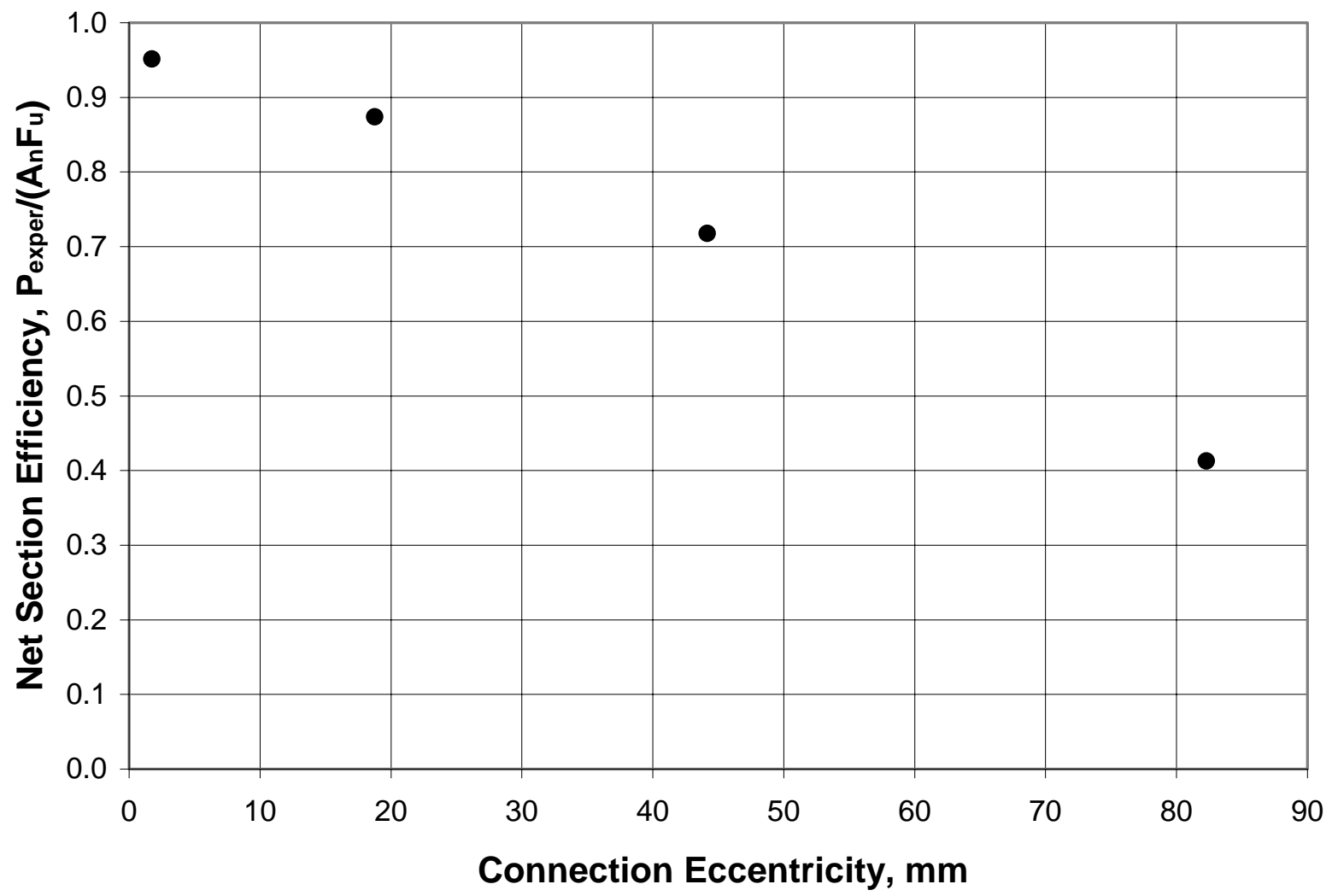

Figure 4.6: WT 155x10.5 4 bolt connection drilled specimens Net section efficiency versus connection eccentricity 


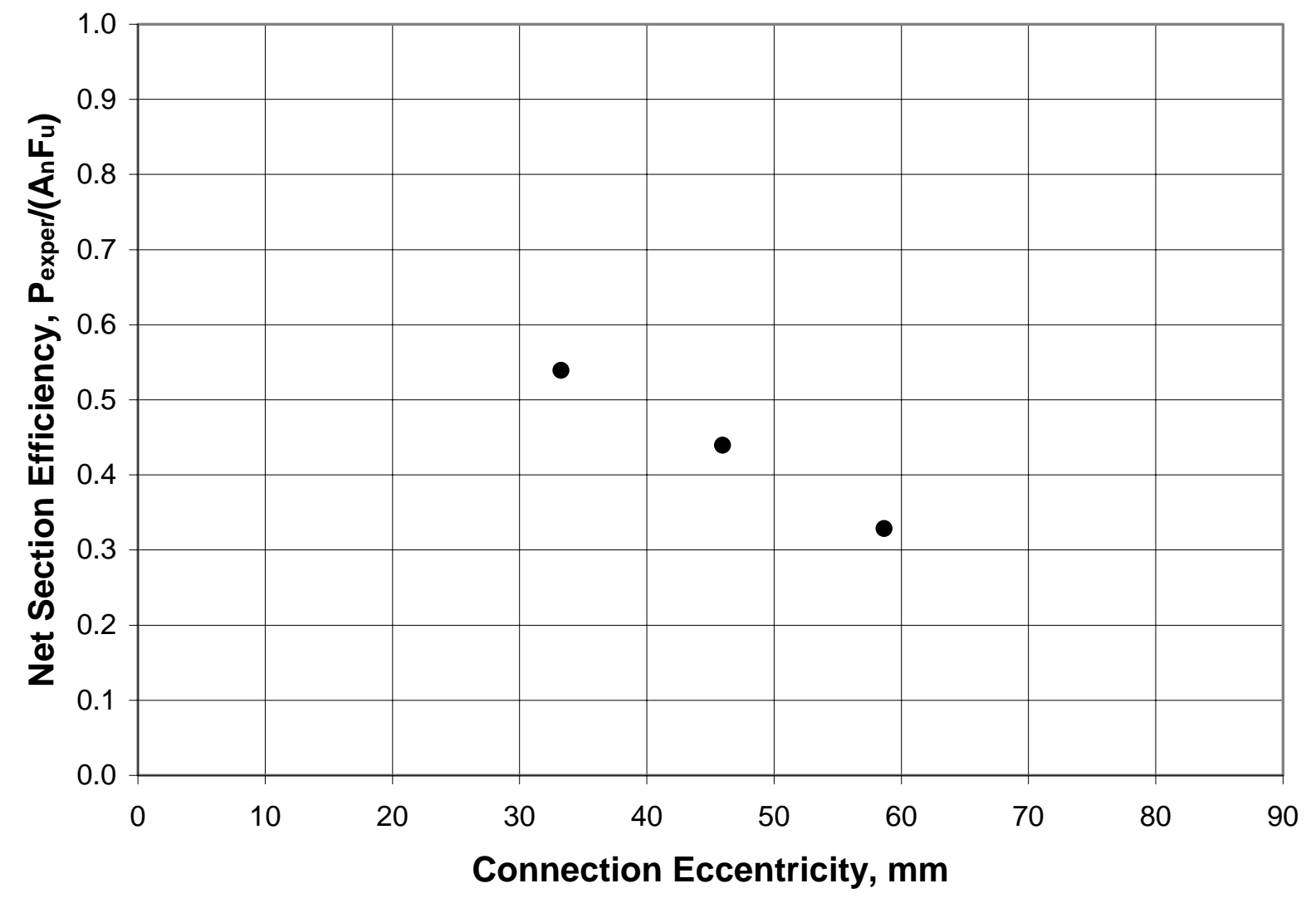

Figure 4.7: WT 100x 183 bolt connection drilled specimens

Net section efficiency versus connection eccentricity 


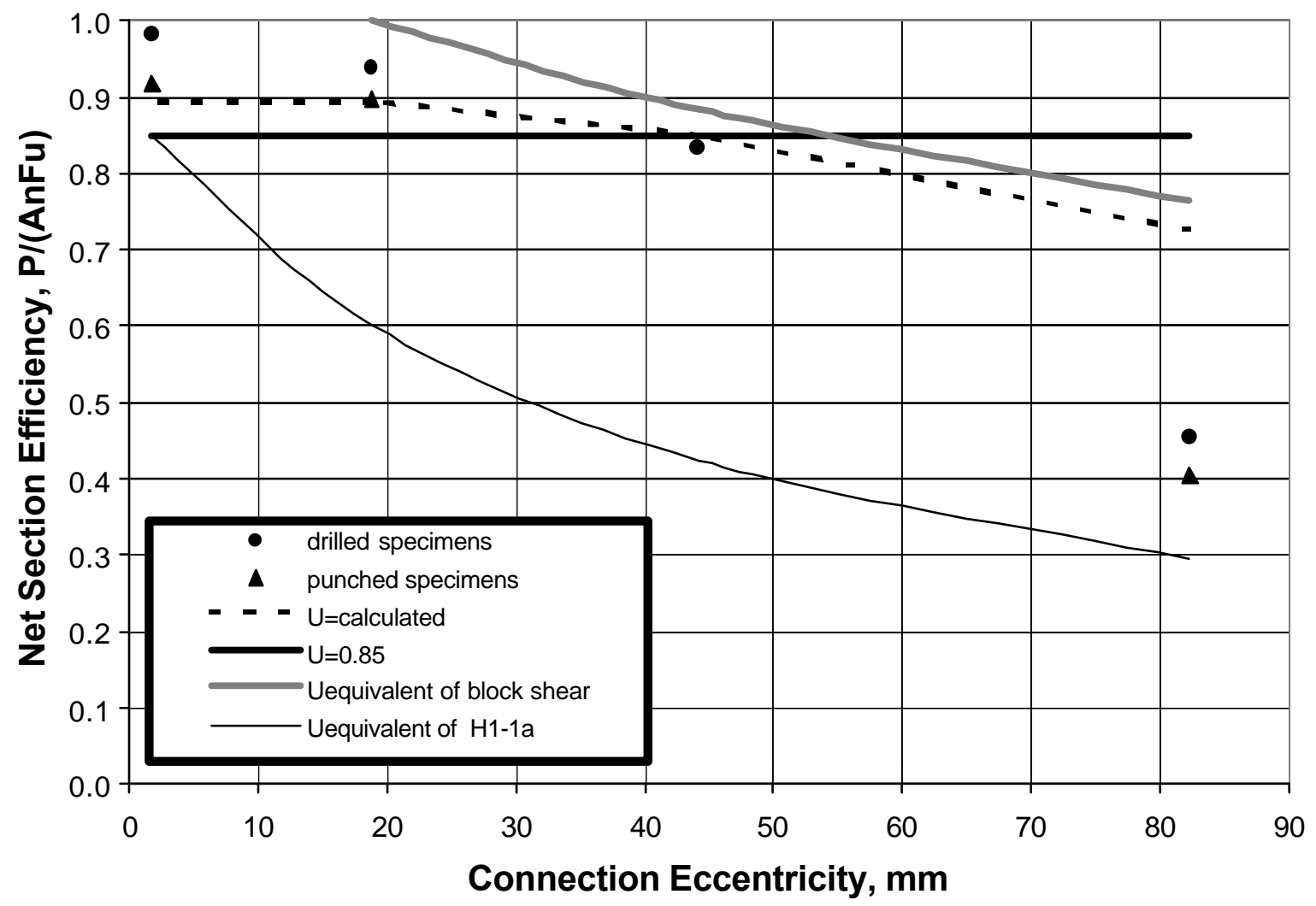

Figure 4.8: WT 155x10.5 5 bolt connection drilled and punched specimens AISC LRFD predicted efficiencies. Net section efficiency versus connection eccentricity 


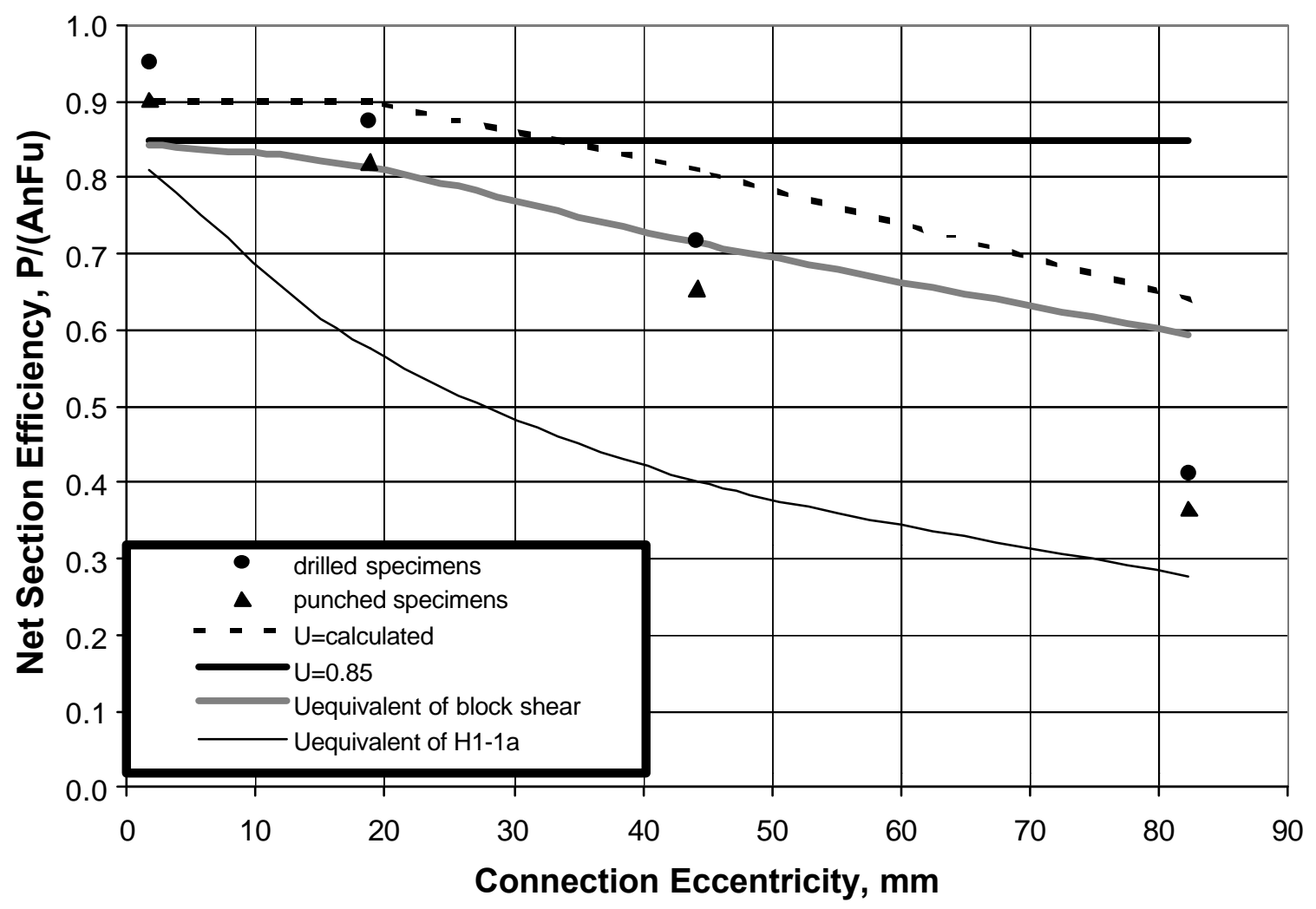

Figure 4.9: WT 155x10.5 4 bolt connection drilled and punched specimens AISC LRFD predicted efficiencies. Net section efficiency versus connection eccentricity 


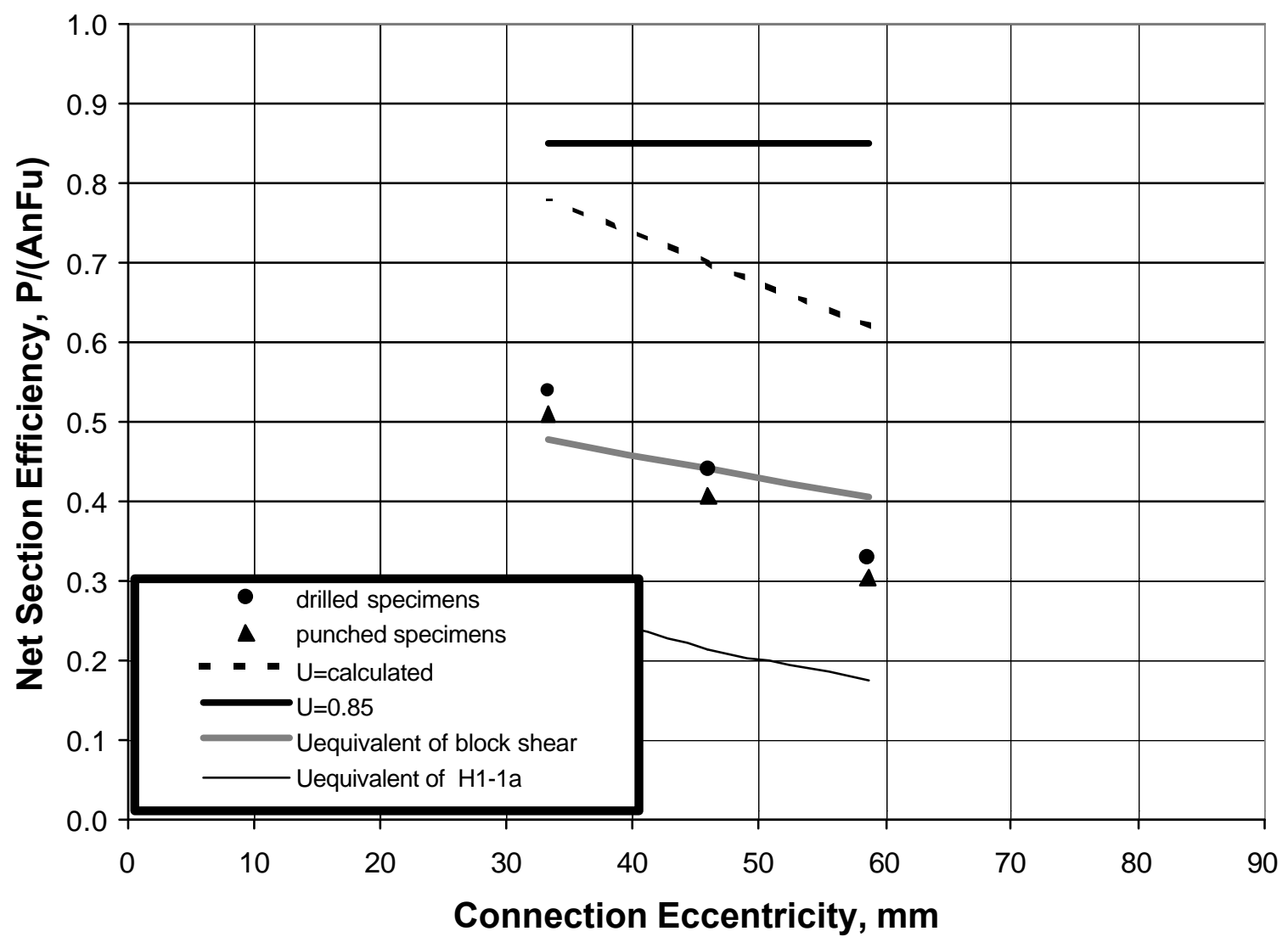

Figure 4.10: WT 100x18 3 bolt connection drilled and punched specimens AISC LRFD predicted efficiencies. Net section efficiency versus connection eccentricity 


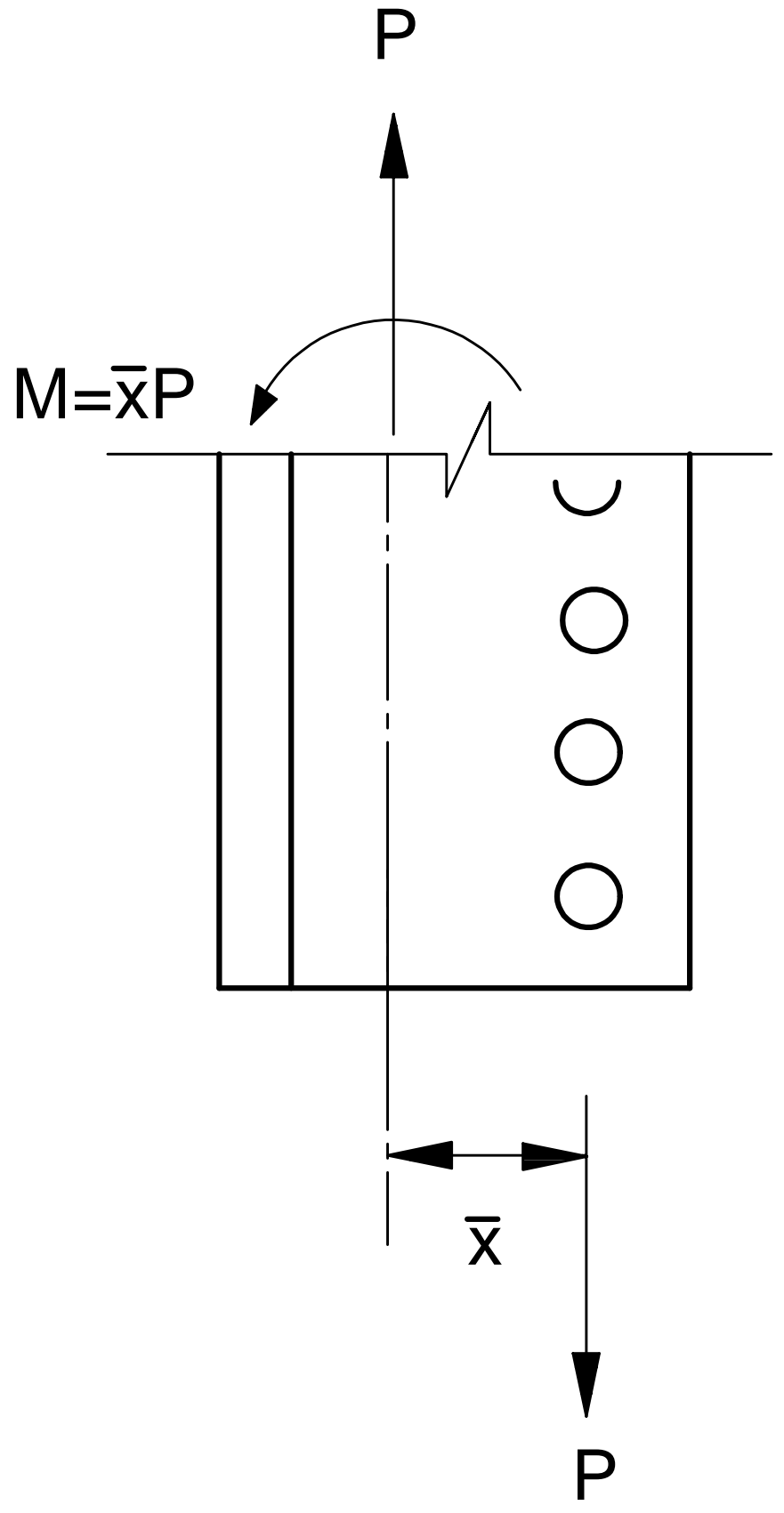

Figure 4.11: Primary bending moments resulting from connection eccentricity 


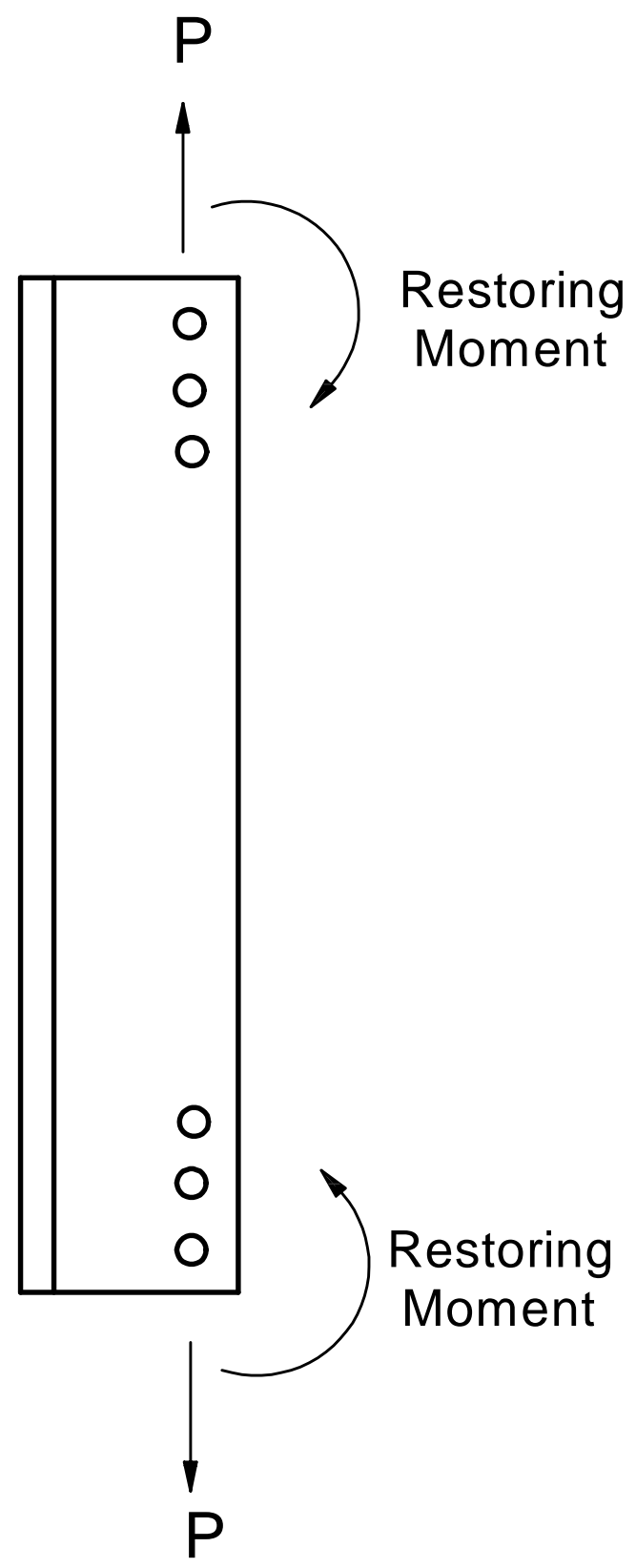

Figure 4.12: Restoring moment developed as a function of connection restraint 


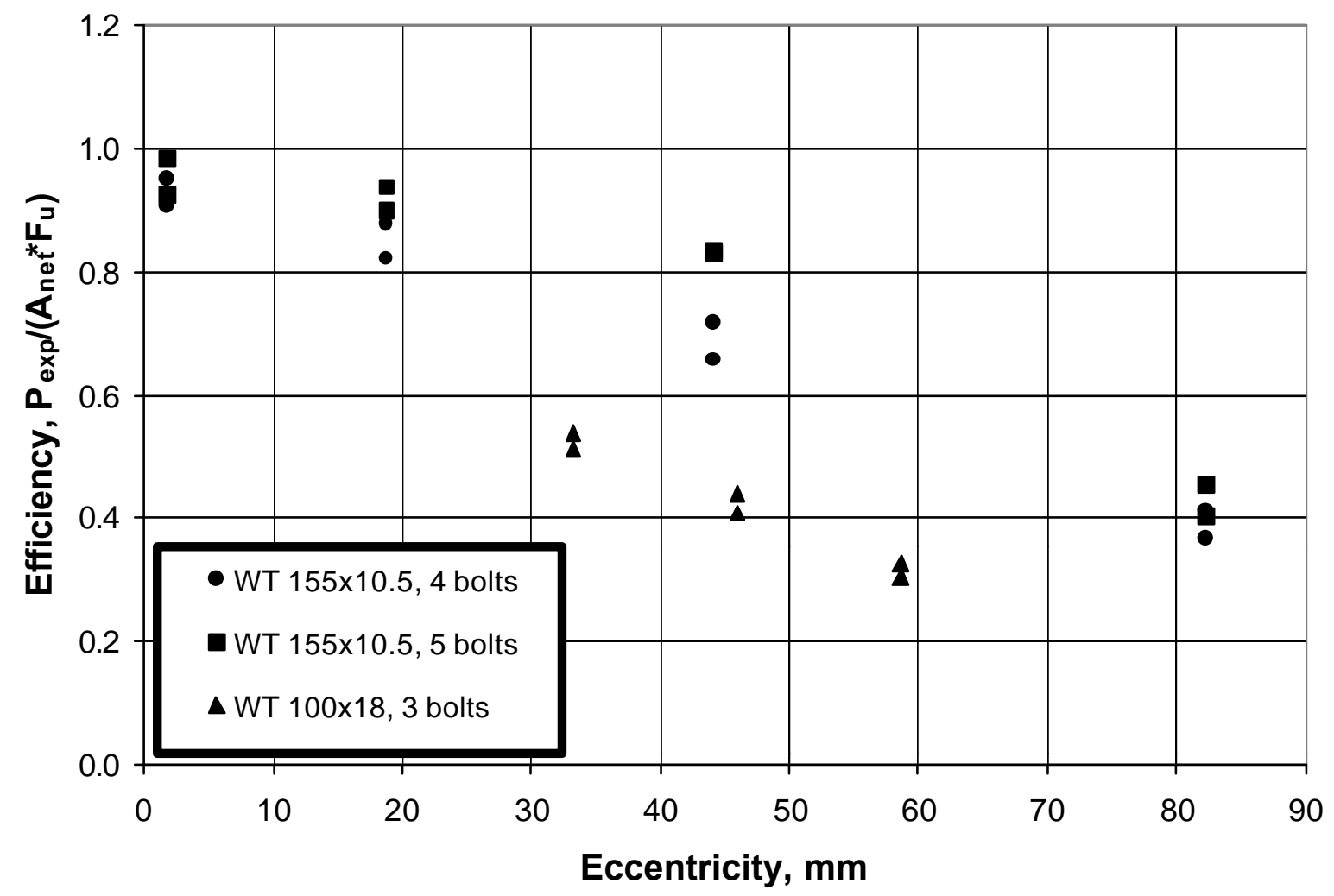

Figure 4.13: Net section efficiency versus eccentricity for all specimens tested 


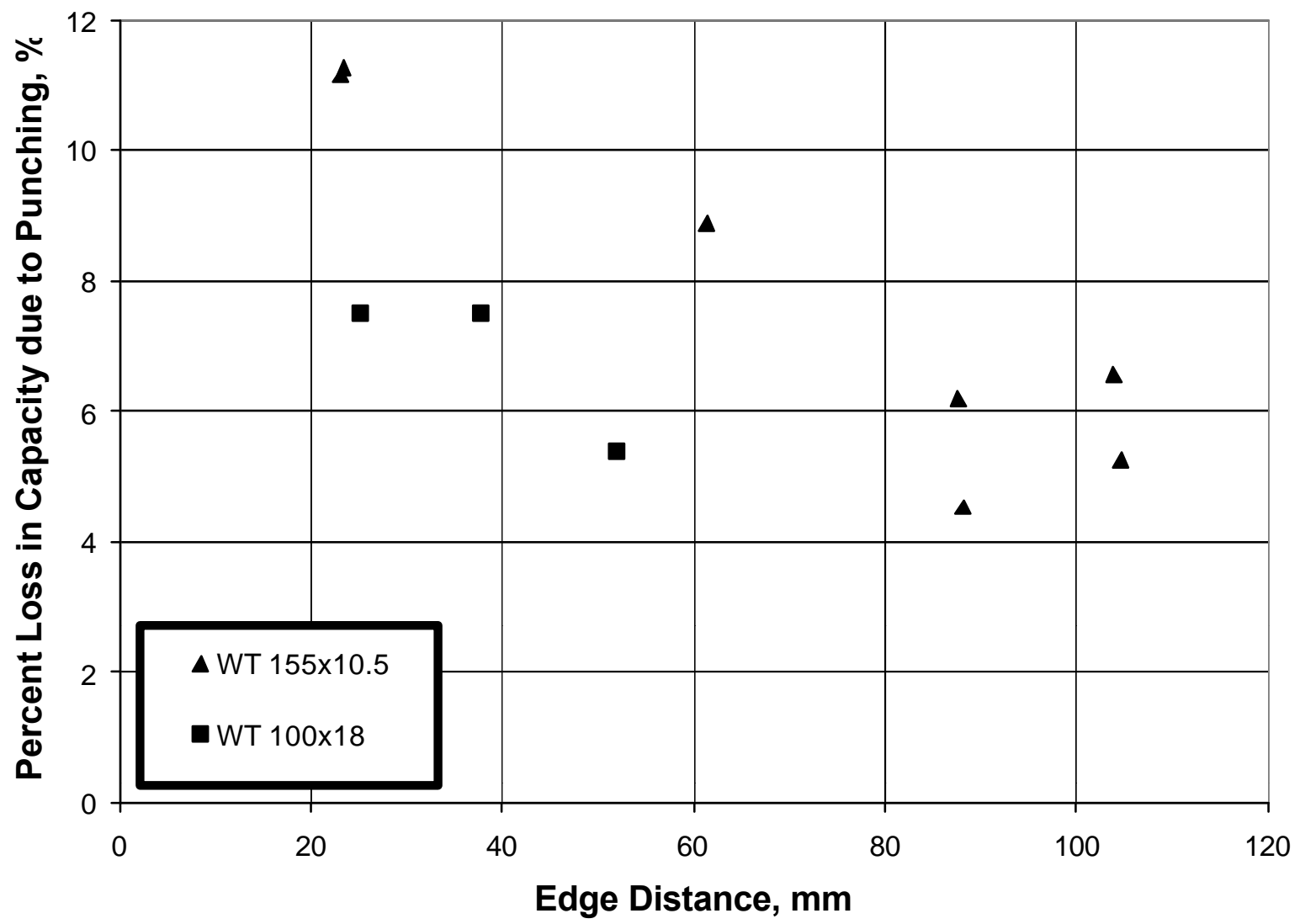

Figure 4.14: Comparison of the effects of punching versus drilling on section capacity 


\section{Chapter 5}

\section{MODEL DEVELOPMENT}

\subsection{Introduction}

As documented in Chapter 4, present LRFD bolted tension member specifications unconservatively predict the net section rupture capacities for members having connection eccentricities exceeding $19 \mathrm{~mm}$. Ideally, a modified moment axial force interaction relationship should be used to account for the observed behavior of the specimens. This was attempted using a plastic mechanism approach. The results, however, were similar to those produced by LRFD Eqn. H1-1a; very conservative results for specimens with less than minimum edge distances. Again, this was attributed to the second order restoring moments developed at a member's connections.

This chapter describes the development of a $U$ factor, similar in concept as the present $U$ factor, using a multiple linear regression analysis. It then compares and contrasts the present LRFD $U$ factor with the proposed $U$ factors developed in this chapter on the basis of capacity predictions. 


\subsection{Linear Regression Analysis}

It has already been shown that increased connection eccentricity leads to deceased section capacity. This has also been documented as being attributed to bending moments produced by the connection eccentricities and the applied axial force. Also, connection length has the possible effect of decreasing shear lag effects and increasing the restoring moment developed. This in turn resists eccentricity in-plane moments, thus increasing member capacity.

These two connection geometry parameters (eccentricity and connection length) are seen to be the two most influential parameters in member net section capacity. It was therefore hypothesized that a modified $U$ factor equation that more accurately accounts for these factors may better predict section capacity.

Two multiple linear regression analyses were conducted for the three sets of WT specimens: one equation is developed for punched hole data and one is developed for drilled hole data. The linear regression program used for the analyses was developed in a Microsoft Excel spread sheet (see Appendix D for the Microsoft Excel program used).

The net section efficiency factor, $U$, was the dependent variable and connection eccentricity and connection length were the independent variables in the analyses.

$U=a+b_{1} \bar{x}+b_{2} L$

Where:

$U=\frac{P_{\text {exp }}}{F_{u} A_{n}}$

$a, b_{1}, b_{2} \equiv$ constant or coefficients of variation 
Only those specimens that failed in partial net section rupture were used for development of modified $\mathrm{U}$ factor equations. The specimens that failed in full net section rupture and block shear were not included in the development of the proposed efficiency factors because they were conservatively predicted by their respective equations.

The analysis was completed twice for each hole fabrication method (i.e. punched data and drilled data).

The following equations result:

For punched specimens

$U_{p}=0.50-0.20 \bar{x}+0.05 L \leq 0.90$,

and for drilled specimens

$U_{d}=0.50-0.20 \bar{x}+0.053 L \leq 0.95$

Note that Eqns. 5.2 and 5.3 are shown in U.S. units (i.e. inches).

\subsection{Comparison of Model Predictions with Current Specifications}

Figure 5.1 shows the experimental failure loads versus the net section rupture load capacities obtained with the current $\mathrm{U}$ factor (Eqn. 1.4). All specimens that failed in either full or partial net section rupture are included in this plot. Those specimens that failed in block shear were conservatively predicted by present LRFD considerations and their mode of failure is different then a net section rupture mode of failure. Therefore, these specimens $(8,5 b, 6 b)$ are not included in any of the comparisons found in this section. Conservative predictions are obtained with small connection eccentricities, while unconservative predictions are generally obtained in specimens having connection 
eccentricities greater than $19 \mathrm{~mm}$ (0.75 inches), particularly with punched bolt holes. Figure 5.2 shows the experimental failure loads versus the net section rupture load capacities obtained with the proposed $U$ factors (Eqns. 5.2 and 5.3 ). The proposed $U$ factors predict most of the specimens examined to with in $\pm 10 \%$ of unity; a good correlation between predicted and experimental results. Figures (5.3) through (5.5) show the net section efficiency for full and partial net section rupture versus connection eccentricity for specimens with five, four and three bolt connections, respectively. Net section efficiencies are predicted by Eqns. 1.4, 5.2 and 5.3. Table 5.1 shows the professional factors obtained using Eqns. 1.4, 5.2 and 5.3. The professional factors $\left(P_{\text {exper }} / P_{\text {pred }}\right)$ given by the Eqn. 1.4 have a maximum of 1.04 , a minimum of 0.50 , and a mean of 0.81 , with a standard deviation of 0.21 . The professional factors produced by Eqns. 5.2 and 5.3 have a maximum of 1.21 , a minimum of 0.85 , mean of 1.00 , with a standard deviation of 0.095 .

The proposed net section efficiency factors should be valid for WT sections with eccentricities ranging from zero up through to $82.6 \mathrm{~mm}$ (3.25 inches). For larger eccentricities it seems possible that the net section efficiency will produce conservative predictions and member load capacity should be evaluated using the axial and flexural interaction equations listed in Chapter H of LRFD. It is also noted that the proposed net section efficiency factors were developed using a relatively small database of test results. In particular, the database does not contain test results from tension specimens other than WT sections or specimens having connection lengths shorter than $152.4 \mathrm{~mm}$ (6 inches) or longer than $304.8 \mathrm{~mm}$ (12 inches). 


\subsection{Fabrication Factor for Punched Holes}

As shown in Chapter 4 in Table 4.1 and Figs. 4.7 through 4.9, the present practice of accommodating for hole fabrication by increasing the effective diameter by $2 \mathrm{~mm}$ is not sufficient to account for punching fabrication method effects. Previous investigators have suggested that the influence of punched hole fabrication on net section capacity may be accounted for by reducing the effective net section rupture strength by $10-15 \%$ (Munse and Chesson, 1963; Gaylord et al., 1992). In the present study, the punching effects for minimum edge distances reduced some of the specimen capacities up to $11 \%$. There was an average of an $8 \%$ reduction in strength. Therefore, suggesting that a punched hole factor to be applied to equivalent drilled hole specimen capacities of 0.85 , a $15 \%$ reduction in capacity, is not unreasonable (Orbison, 2000). 


\begin{tabular}{|c|c|c|}
\hline $\begin{array}{l}\text { Spec. } \\
\text { No. }\end{array}$ & $\begin{array}{c}\text { AISC-LRFD } \\
\text { U factor, Eq. } \\
1.4\end{array}$ & $\begin{array}{c}\text { Proposed } \\
\text { U factor, Eq. 5.2, } \\
5.3^{\mathrm{a}}\end{array}$ \\
\hline $1(\mathrm{p})$ & 0.57 & 1.21 \\
\hline 2 (d) & 0.64 & 1.14 \\
\hline $3(p)$ & 0.81 & 1.08 \\
\hline 4 (d) & 0.89 & 1.10 \\
\hline $5(d)$ & 0.97 & 1.04 \\
\hline $6(p)$ & 0.91 & 1.02 \\
\hline $7(p)$ & 1.01 & 1.00 \\
\hline & & \\
\hline $1 \mathrm{a}(\mathrm{d})$ & 0.62 & 0.87 \\
\hline $2 a(p)$ & 0.56 & 0.89 \\
\hline $3 a(d)$ & 0.97 & 1.04 \\
\hline $4 a(d)$ & 0.97 & 1.02 \\
\hline $5 a(d)$ & 1.04 & 0.99 \\
\hline $6 a(p)$ & 1.00 & 1.00 \\
\hline $7 a(d)$ & 1.09 & 1.03 \\
\hline $8 a(p)$ & 1.02 & 1.02 \\
\hline $1 b(d)$ & 0.53 & 0.86 \\
\hline $2 b(p)$ & 0.50 & 0.90 \\
\hline $3 b(d)$ & 0.63 & 0.93 \\
\hline $4 b(p)$ & 0.59 & 0.93 \\
\hline Mean & 0.81 & 1.00 \\
\hline Std. Dev. & 0.210 & 0.093 \\
\hline
\end{tabular}

a. Eqn. 5.2 was used for the punched specimens while Eqn. 5.3 was used for the drilled specimens. 


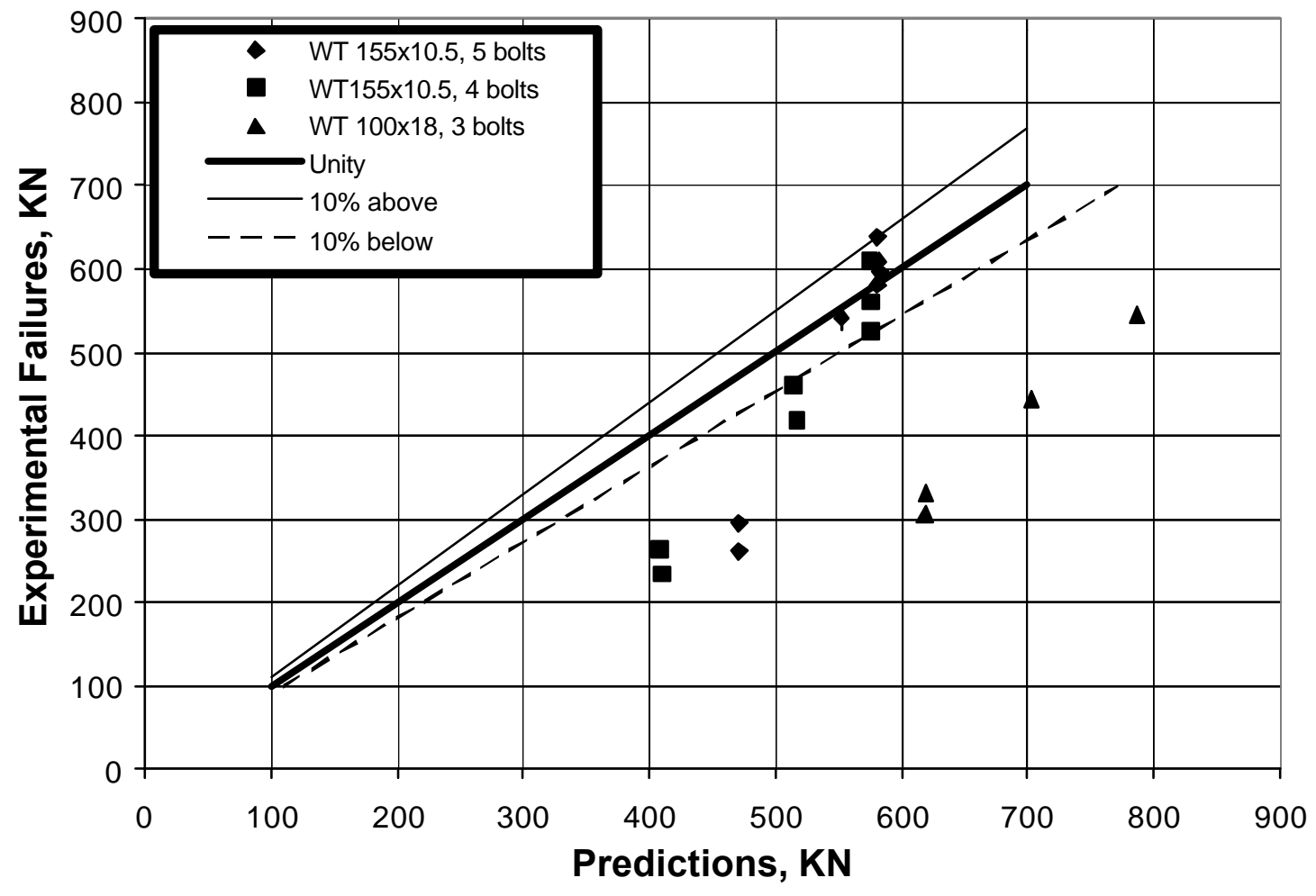

Figure 5.1: Actual versus predicted capacities using Eqn. 1.2 


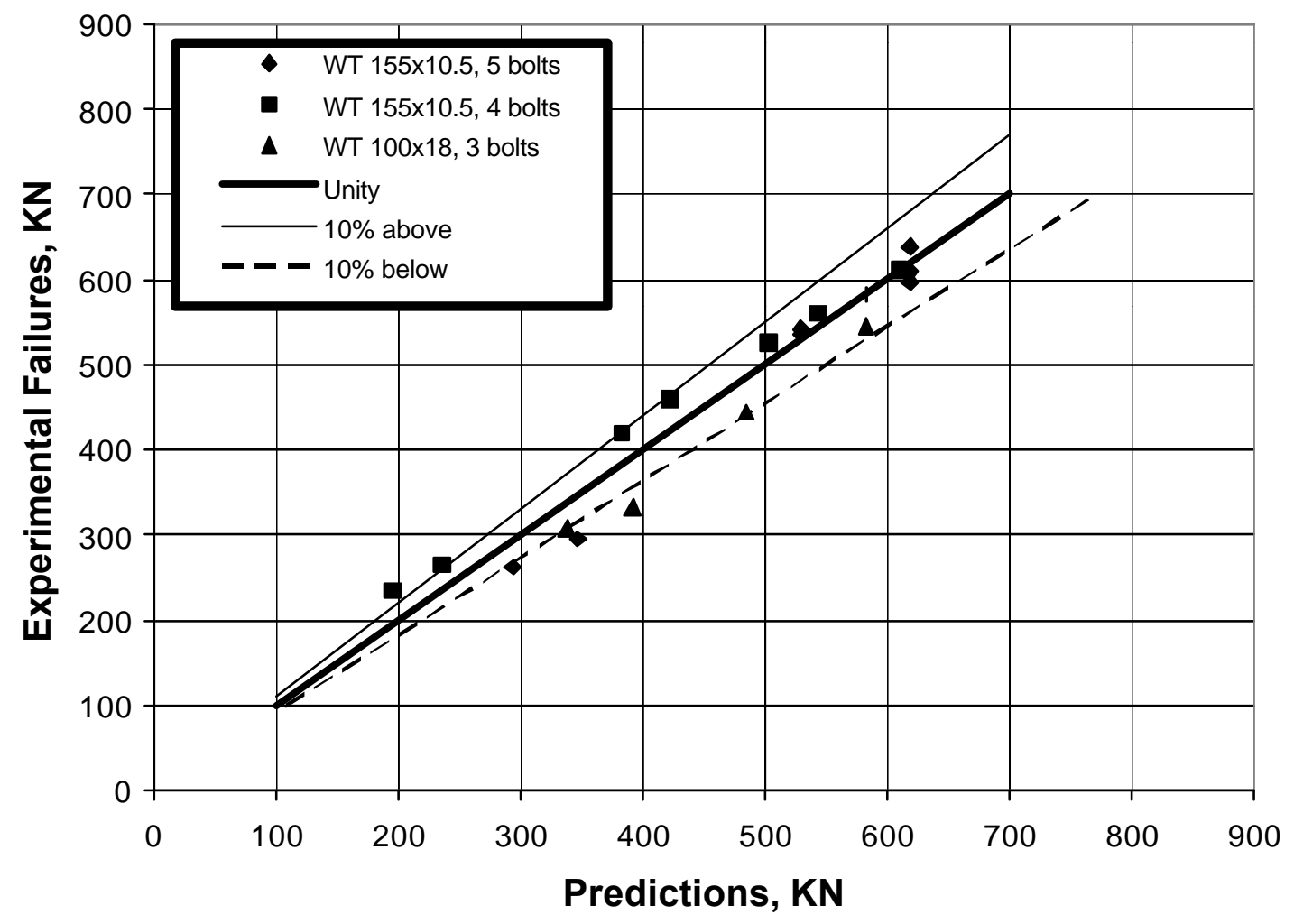

Figure 5.2: Actual versus predicted capacities using Eqns. 5.2 and 5.3 


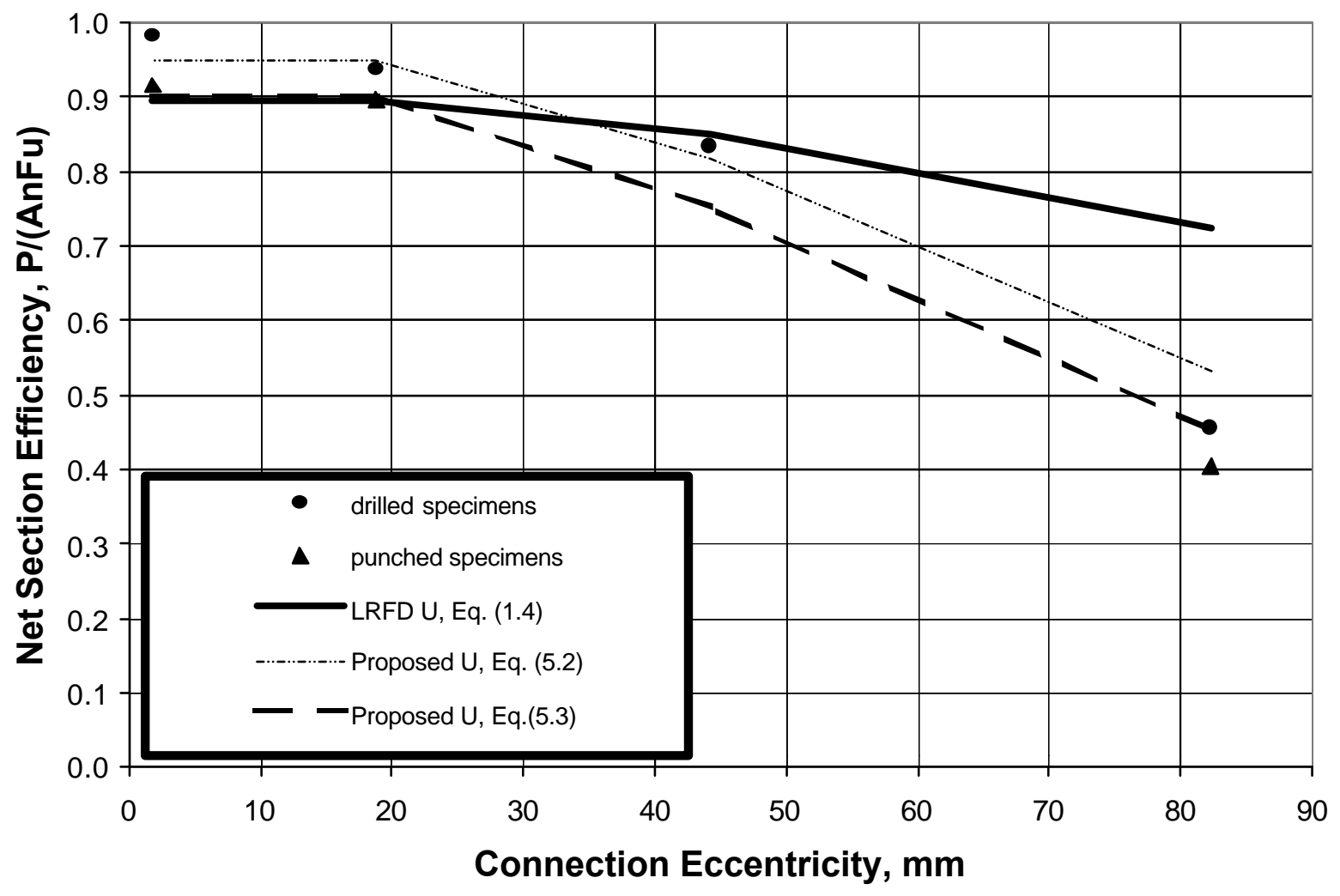

Figure 5.3: WT $155 \times 10.55$ bolt connections

Net section efficiency versus connection eccentricity using Eqns. 1.4, 5.2 and 5.3 


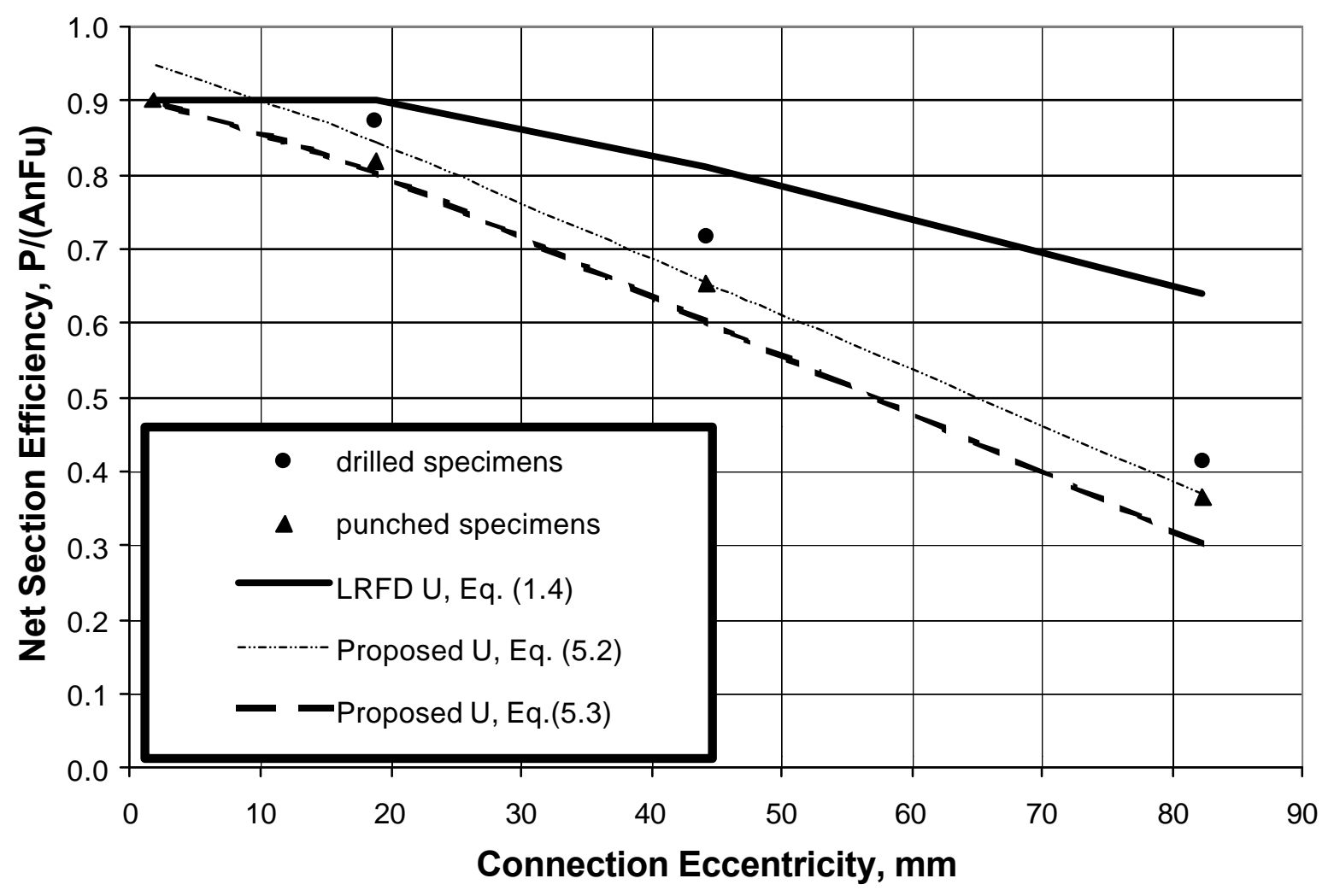

Figure 5.4: WT $155 \times 10.54$ bolt connections

Net section efficiency versus connection eccentricity using Eqns. 1.4, 5.2 and 5.3 


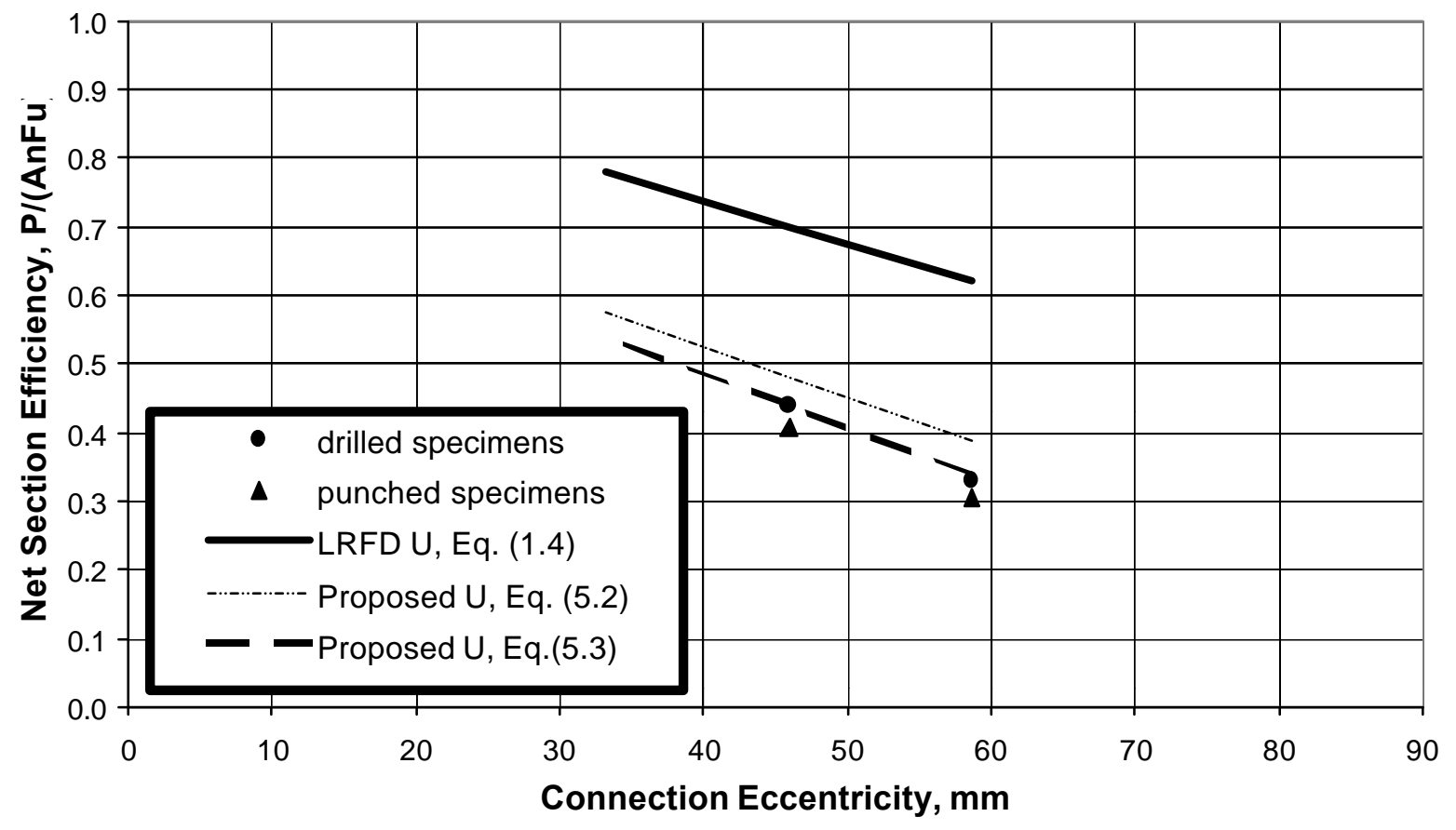

Figure 5.5: WT 100x18 3 bolt connections

Net section efficiency versus connection eccentricity using Eqns. 1.4, 5.2 and 5.3 


\section{Chapter 6}

\section{SUMMARY AND RECOMMENDATIONS}

\subsection{Summary}

It has been shown that for a wide range of WT bolted connection geometries present LRFD tension capacity predictions range from adequate to unconservative. The unconservative predictions result from the inability of current shear lag provisions to account for the effects of primary bending induced by the eccentricity between the centroid of a bolt line and the centroid of the section.

This over estimation of failure load capacity by LRFD's net section shear lag equation, Eqn. 1.4, has been shown to be due to the fact that it only accommodates eccentricity effects as they relate to shear lag and bending effects of small eccentricities. This is because the present shear lag factor was developed empirically test data having small eccentricities are tested in such configurations as to have differing amounts of bending. Though this factor is explicitly stated to account for the influence of shear-lag alone, inherently it accounts for the in-plane flexure existing in the tests from which it was developed. Thus the reason for the extremely unconservative predictions for those specimen tests with large eccentricities, producing professional factors as low as 0.50 for punched specimens and 0.62 for drilled specimens. 
Clearly, an interaction equation approach would be desirable. Reasonable estimates may be produced for large eccentricities (e.g. $\bar{x}>90 \mathrm{~mm}$ ) when using the combined tension and bending equation in LRFD, Eqn. H1-1a. However, for the majority of connections net section capacity will be increased due to a restoring moment. The restoring moment develops in the opposite direction as the eccentricity induced bending moment, reducing its severity and thus, allowing the member to develop higher axial loads before partial fracture of the net section occurs. The calculation of the restoring moment is based on the second order effects, connection length, and the in-plane stiffness of the gusset plate.

Connection length increases the specimen capacity in two manners. Firstly, it decreases the effects of shear lag (Munse and Chesson, 1963; Kulak and Wu, 1997). Second, it increases the magnitude of the restoring moment.

Shear lag effects were seen to have negligible influence when a WT member is connected through its centroidal axis. As seen in this present study and Kulak and Wu's (1997) study, regardless that not all of a member's elements are connected, WT and angle tension specimens are able to exceed the present net section efficiency cut off of $90 \%$. Also, based on the specimens used in the development of the present shear lag reduction factor and the lack of conservative predictions of the shear lag factor for members with large eccentricities, it is possible to suggest that the effects of shear lag in tension members is over-estimated.

The influence of punched hole fabrication versus drilled fabrication is found to be considerably more significant than accounted for by present LRFD specification provisions. An average of $8 \%$ reduction in capacity was seen for all specimens, 
regardless of the location of the bolt line with respect to the centroidal axis, whereas, LRFD's recommendations reduce section capacities by less than $2 \%$. Also, it was seen that the detrimental effects of punching increase with a decrease in edge distance, reaching $11 \%$ loss in capacity due to punching effects. Designing a tension member on the assumption of higher losses due to punching effects are recommended by others (Munse and Chesson, 1963; Gaylord et al., 1992), as much as a $15 \%$ reduction in capacity. All this is strongly supportive of the fact that present specification provisions need to be re-examined.

\subsection{Recommendations}

The present study examined the effects of connection eccentricity, connection length, and fabrication effects on net section efficiencies. From the results of the experiments in this study it has been shown that connection eccentricity and fabrication effects are not accurately accounted for in present design specification equations or provisions. Therefore, based on the trends seen in this study and the subsequent conclusions drawn, the following recommendations are made:

1) Provisions need to be considered that account for connection eccentricity effects. Presently, eccentricity induced bending effects are disregarded in design, but as shown in this study the effects of eccentricity reducing the net section efficiency of bolted connections needs to be considered.

2) A more extensive review of specimens needs to be made to see if the present findings are applicable to other specimen configurations and connection geometries. 
3) The proposed equations should be applicable to WT specimens that lie with in the same range of eccentricity and connection length as examined in this study. For larger eccentricities it seems possible that the proposed efficiency equation will produce overly conservative predictions and, therefore, it has been suggested that the LRFD interaction equation, Eqn. H1-1a, be used in determining net section capacity for members with large connection eccentricity.

4) A punched hole factor should be used instead of the present $2 \mathrm{~mm}$ increase. The present study saw percent losses as high as $11 \%$. Therefore, recommending that a fabrication factor of 0.85 be multiplied to predicted capacities whose bolt holes are punched is not unreasonable and is in agreement with the fabrication factors suggested by others (Munse and Chesson, 1963, Kulak and Wu, 1997). 
REFERENCES CITED 


\section{References Cited}

AISC. Allowable Stress Design and Plastic Design Specification for Structural Steel

Buildings. $9^{\text {th }}$ edition, Chicago, IL: American Institute of Steel Construction, 1989.

AISC. Load and Resistance Factor Design Specification for Structural Steel

Buildings. $2^{\text {nd }}$ edition, Chicago, IL: American Institute of Steel Construction, 1995.

Birkemoe, Peter C., and Gilmor, Michael I., "Behavior of Bearing Critical DoubleAngle Beam Connections," AISC Engineering Journal, Vol. 15, No. 4, 1978, pp. $109-115$.

Chesson, E. Jr., and Munse, W. H., Transactions, ASCE, Vol. 123, 1958, pp. 1087 1128.

Chesson, E. Jr., "Behavior of Large Riveted and Bolted Structural Connections," Thesis presented to the University of Illinois, at Urban, IL, in 1959, in partial fulfillment of the requirements for the degree of Doctor of Philosophy.

Easterling, W. S., and Gonzales, L., "Shear Lag Effects in Steel Tension Members," AISC Journal of Engineering, Vol. 30, No.2, $2^{\text {nd }}$ Qtr., 1993, pp. 77 - 89. 
Epstein, Howard I., “ Block Shear of Structural Tees in Tension-Alternate Paths,” AISC Journal of Engineering, Vol. 33, $4^{\text {th }}$ quarter, 1996, pp. 147-152.

Epstein, Howard I., "An Experimental Study of Block Shear Failure of Angles in Tension," AISC Engineering Journal, Vol. 29, 1992, pp. 75-84.

Fresse, Frank, "Elementary Statistical Methods for Foresters," Agriculture Handbook 317, U.S. Dept. of Agriculture Forest Service, U.S. Government Printing Office Washington, D.C., January 1967.

Gaylord, E. H. Jr., Gaylord, C. N., and Stallmeyer, J. E. Design of Steel Structures, $3^{\text {rd }}$ edition, New York, NY: McGraw-Hill Inc., 1992.

Gibson, G.J., and Wake, B. T., "An Investigation of Welded Connections for Angles in Tension Members," Welding Journal, Vol. 21, No. 1, January 1942, pp. 44-s 49-s.

Gross, J. M., Orbison, J. G., and Ziemian, R. D., "Block Shear Tests in High Strength Steel Angles," AISC Engineering Journal, Vol. 32. No. 3, 1995, pp. 117-122.

Hardash, Steve G., and Bjorhovde, Reidar, "New Design for Gusset Plates in Tension,” AISC Engineering Journal, Vol. 22, 2 ${ }^{\text {nd }}$ Qtr., 1985, pp. 77-94. 
Kulak, Geoffrey L., and Wu, Eric Yue, "Shear Lag in Bolted Tension Members," ASCE Journal of Structural Engineering, Vol. 123, No. 9, September, 1997, pp. $1144-1152$.

McKibbon, F. P., "Tension tests of steel angles," Proc., ASTM, ASTM West Conshohocken, Pa., Vol. 6, 1906, pp. 267-274.

McKibbon, F. P., “Tension tests of steel angles with various types of endConnections," Proc., ASTM, ASTM West Conshohocken, Pa., Vol. 7, 1907, pp. 287-295.

Mueller, W. H., and Wagner, A. L., "Plastic behavior of steel angle columns," Res. Rep., Bonneville Power Administration, Portland, Oreg., 1985.

Munse, W. H., and Chesson, E., J.R., "Riveted and Bolted Joints: Net Section Design," ASCE Journal of Structural Engineering, Vol. 89, No. ST1, February 1963, pp. 107-126.

Munse, W. H., "The Effect of Bearing Pressure on the Static Strength of Riveted Connections," Bulletin 454, Univ. of Illinois Engrg. Experiment Sta., 1959.

Nelson, H. M., "Angles in tension," Report Publication No. 7, British Constructional Steelwork Association, United Kingdom, 1953, pp. 8-18. 
Orbison, J. G., Barth, K. E., and Bartels, P. A. (submitted for publication), "Net Section In Tension Members With Connection Eccentricity," ASCE Journal of Structural Engineering.

Orbison, J. G., Wagner, M. E., and Fritz, W. P., “Tension Plane Behavior in SingleRow Bolted Connections Subject to Block Shear," Journal of Constructional Steel Research, March, 1999, pp. 2-15.

Shulz, F. W., "The Efficiency of Riveted Structural Joints,” Thesis presented to the University of Illinois, at Urban, IL, in 1952, in partial fulfillment of the requirements for the degree of Doctor of Philosophy.

Wilson, W. M., Munse, W. H., and Cayci, M. A., “A Study of the Practical Efficiency Under Static Loading of Riveted Connections," Bulletin 402, Univ. of Illinois Engrg. Experiment Sta., July, 1952.

Wu, Y., and Kulak, G. L., "Shear Lag in Bolted Single and Double Angle Tension Members," Struct. Engrg. Rep. No. 187, Dept of Civl Engrg., Univ. of Alberta, Edmonton, Canada, 1993. 
APPENDIX A

NOMENCLATURE 


\section{Nomenclature}

$A_{b} \equiv$ nominal bolt cross $-\sec$ tional area

$A_{e} \equiv$ effective net area

$A_{g} \equiv$ gross cross - sectional area

$A_{g t} \equiv$ gross tension area

$A_{g v} \equiv$ gross shear area

$A_{n} \equiv$ net cross - sectional area

$A_{n t} \equiv$ net tension area

$A_{n v} \equiv$ net shear area

$F_{n} \equiv$ allowable bolt shear strength

$F_{u} \equiv$ material's ultimate tensile strength

$F_{y} \equiv$ material's yield strength

$h_{b} \equiv$ effective hole diameter

$L \equiv$ connection length

$m \equiv$ number of shear planes

$n \equiv$ number of bolts in a connection

$P_{n} \equiv$ nominal axial capacity, gross section yielding or net section rupture

$R_{n} \equiv$ nominal connection capacity, bolt bearing, bolt shear or block shear capacities

$U \equiv$ shear lag reduction factor or net section efficiency

$\bar{x} \equiv$ connection eccentricity

$Z_{x} \equiv$ plastic section modulus 
APPENDIX B

WT SPECIMEN GEOMETRY 


\section{WT $155 \times 10.55$ bolt connection specimen geometry}
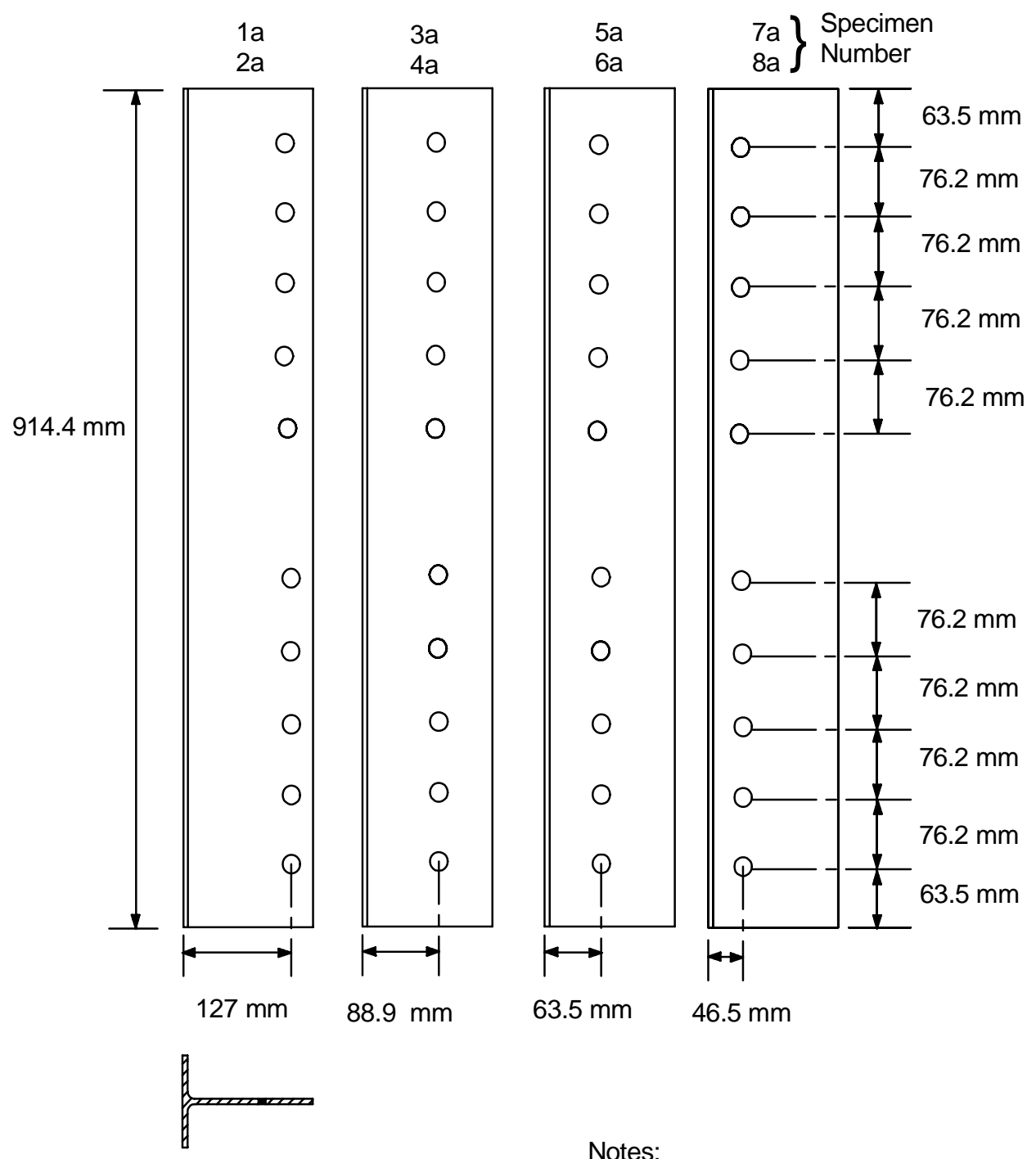

WT $155 \times 10.5$

Notes:

1. All specimens have $21 \mathrm{~mm}$ holes, punched or drilled.

2. There are a total of eight specimens; a matched punched and drilled specimen for each gage dimension shown (with the noted exception of specimen $4 a$ ). 


\section{WT 155x10.5 4 bolt connection specimen geometry}

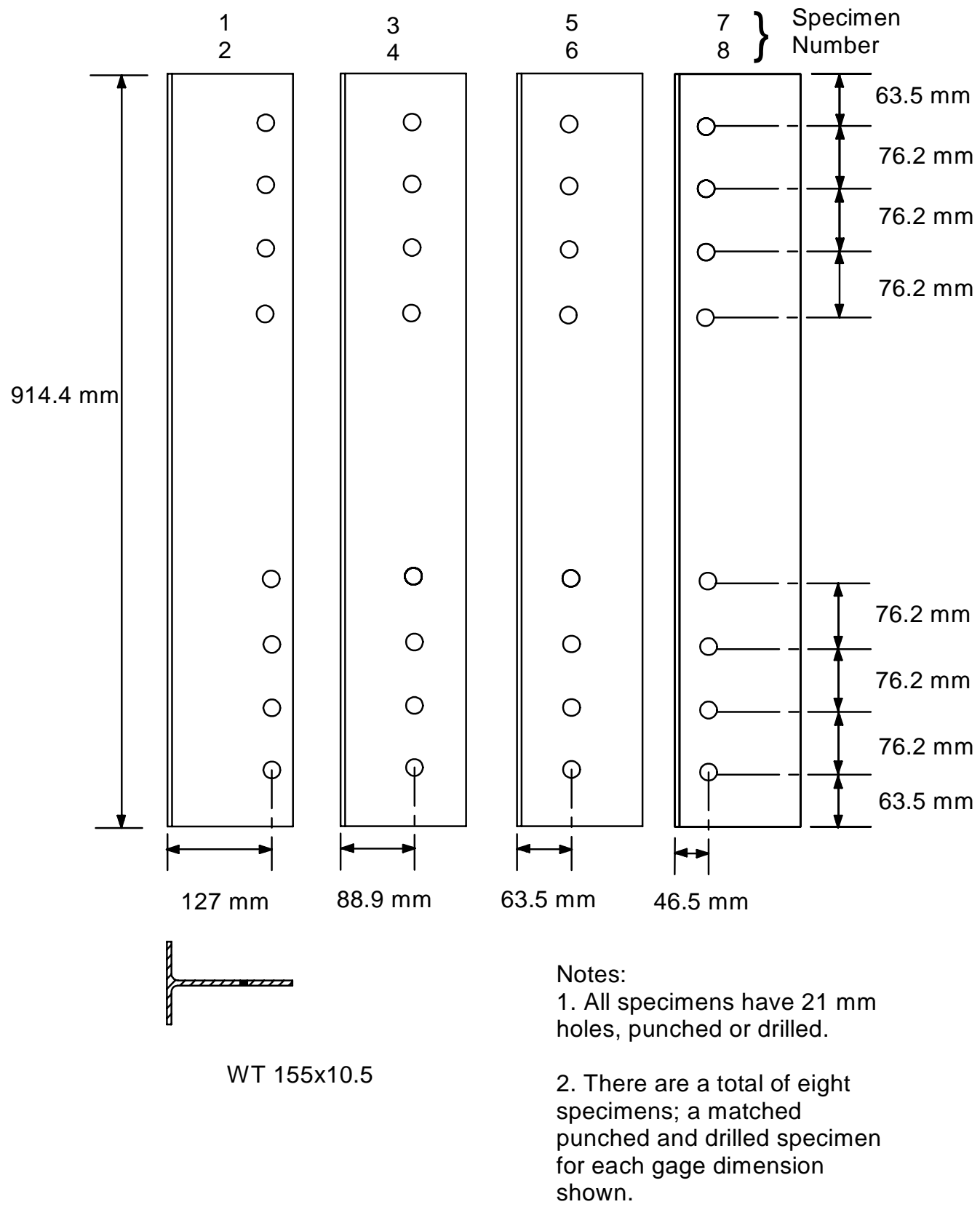




\section{WT 100x18 3 bolt connection specimen geometry}

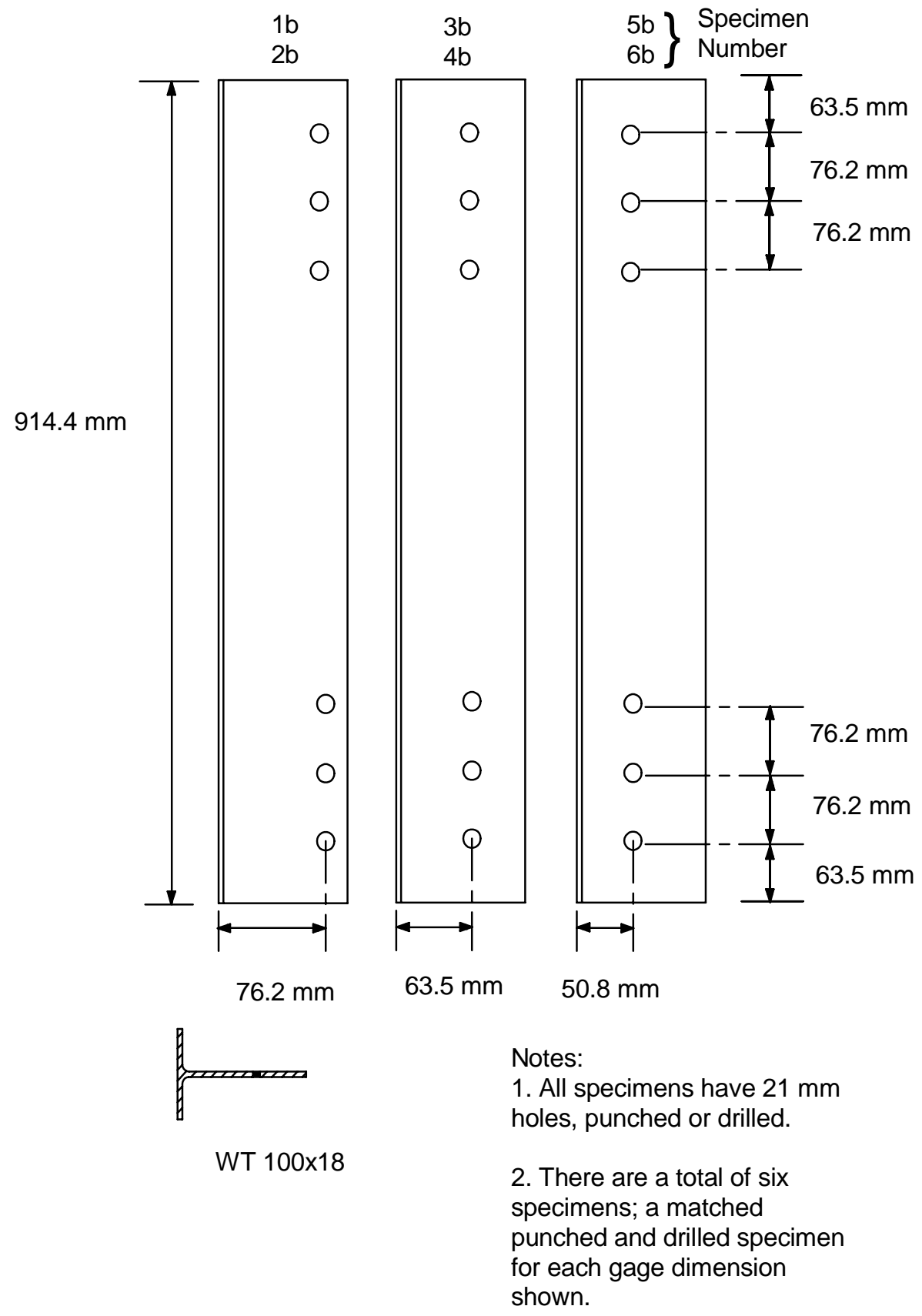


APPENDIX C

BAR STOCK GRIP GEOMETRY 


\section{Bolt bar stock grip geometry}

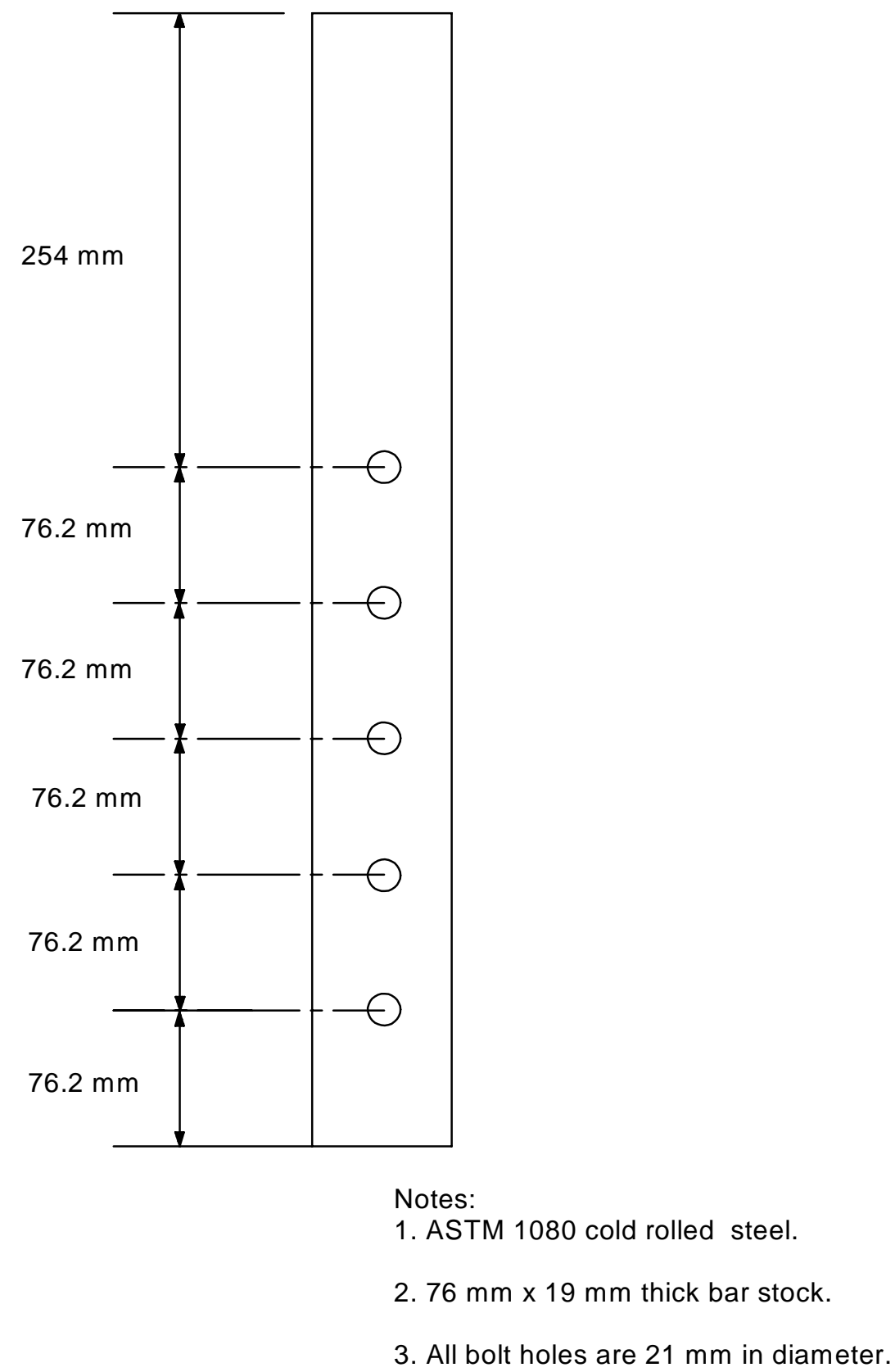




\section{Bolt bar stock grip geometry}

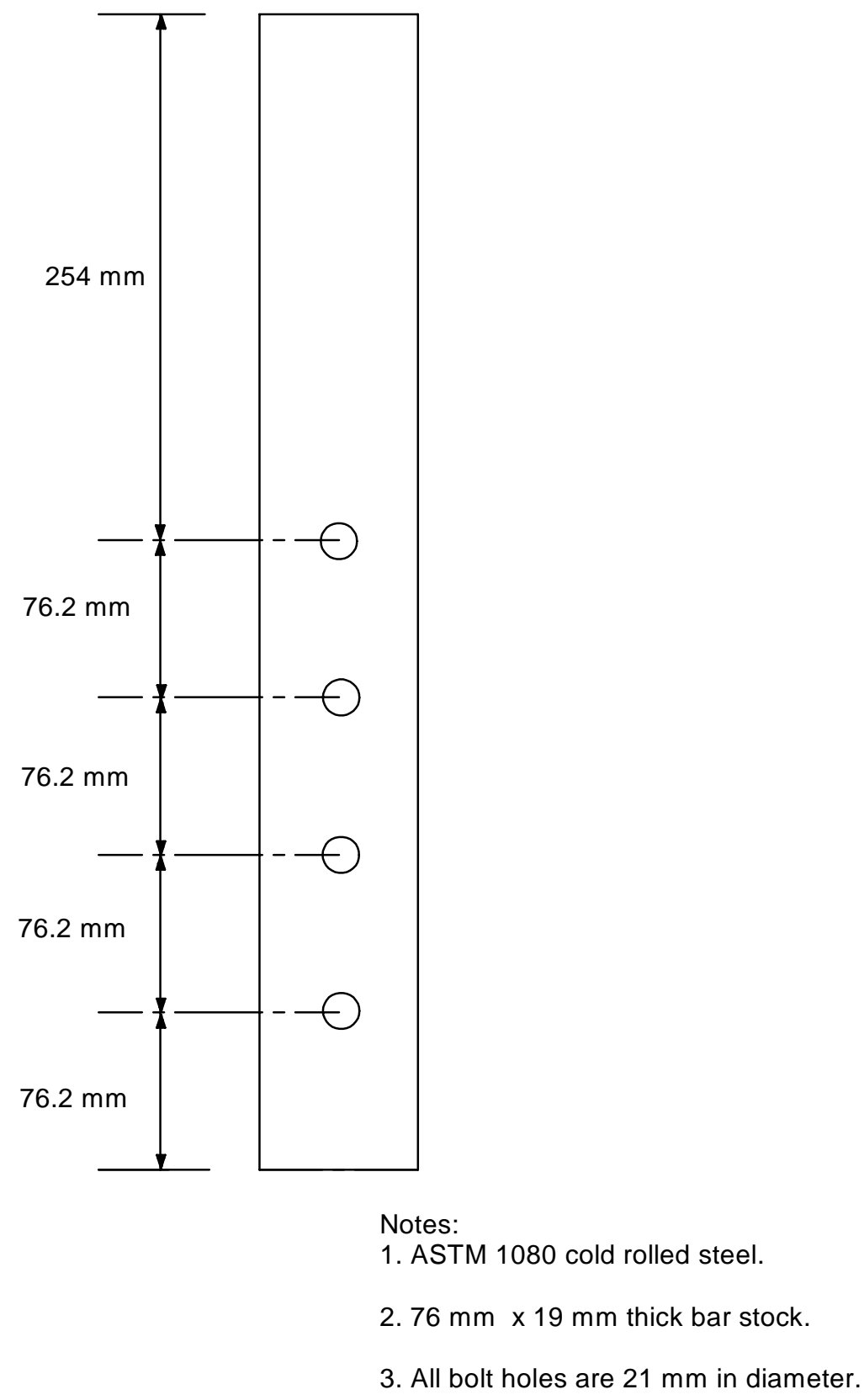




\section{APPENDIX D}

EXCEL SPREADSHEETS USED FOR MULTIPLE LINEAR REGRESSION 
Multiple Linear Regression Analysis for Drilled data (Fresse, 1967)

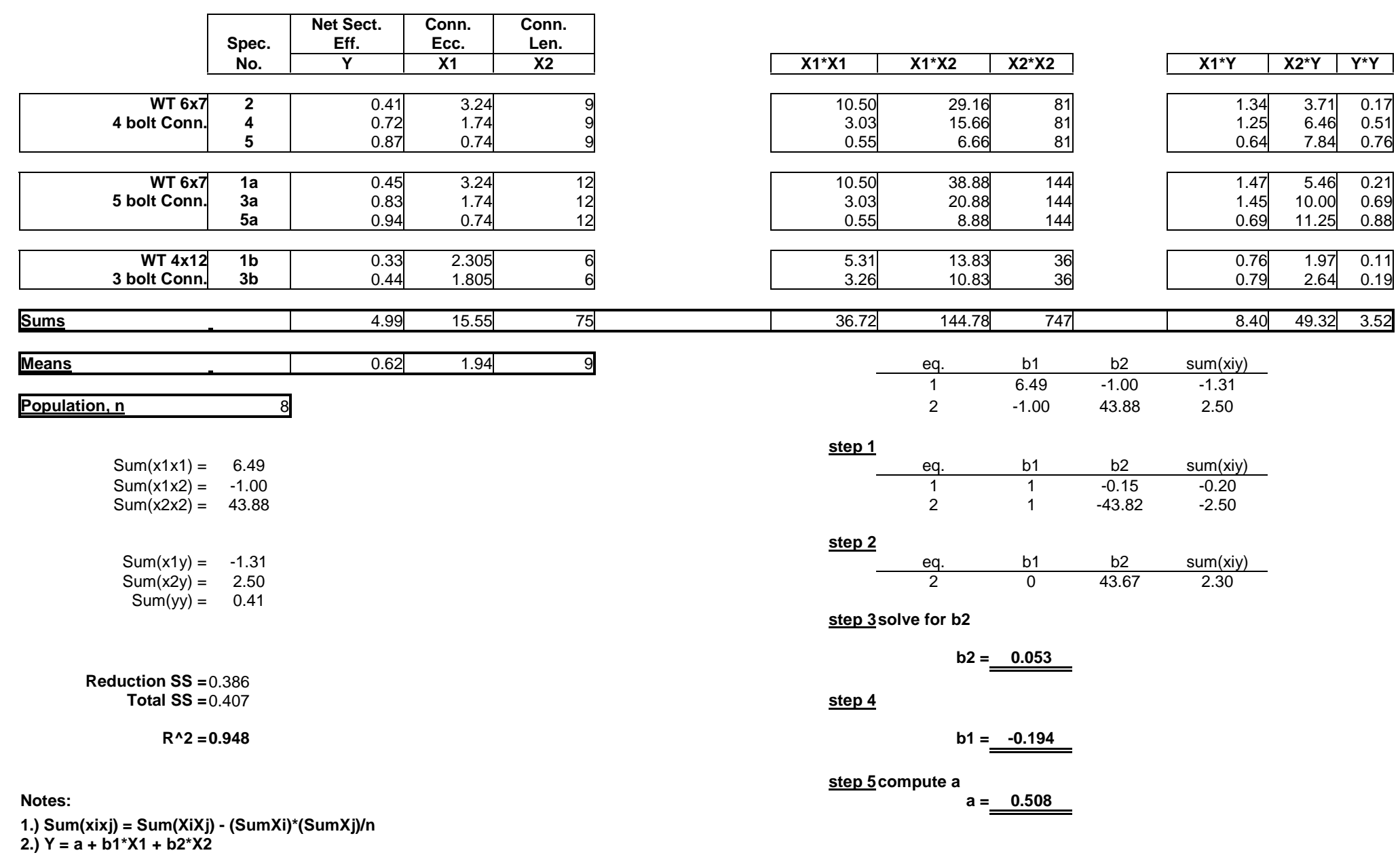


Multiple Linear Regression Analysis for Punched data (Fresse, 1967)

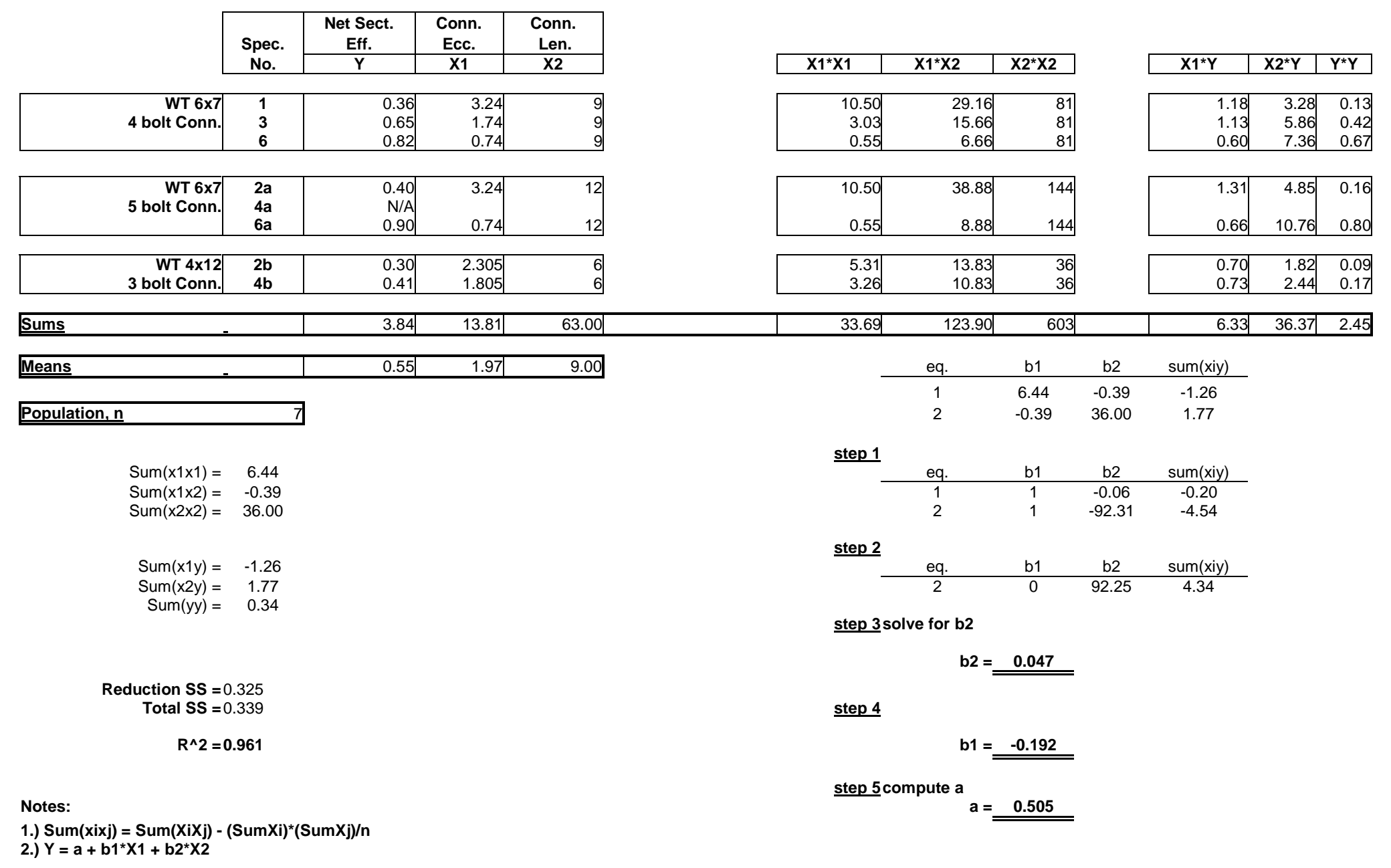


APPENDIX E

KULAK AND WU SPECIMEN TEST SETUPS 
Kulak and Wu (1997) specimen test setups

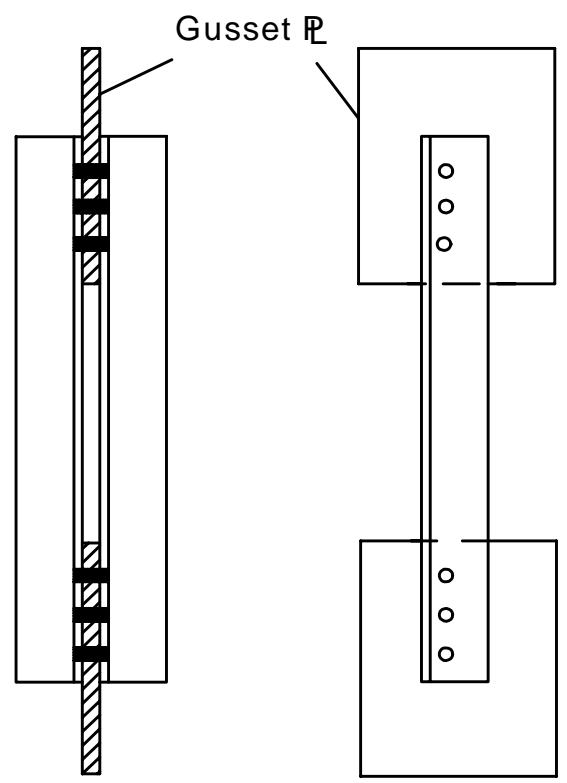

Double Angle

Setup

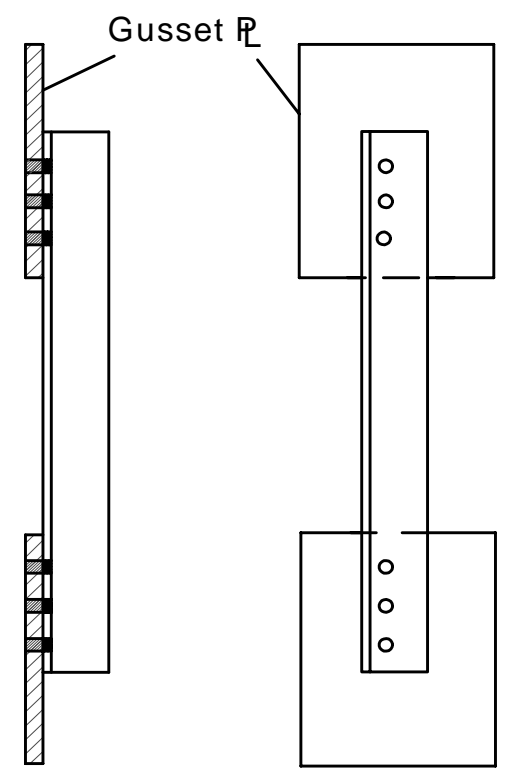

Single Angle Setup

Note: Specimen size, connection length, connection eccentricity and specimen length were varied. Pitch and end distance were kept constant. 
APPENDIX F

AISC LRFD ACCOMMODATION FOR PUNCHING EFFECTS 
AISC LRFD Accommodation for Punching Effects on Net Section Rupture Capacities of WT 6x7s and WT 4x12s

\section{For a WT 6x7 section}

Using Structural Tee Dimensions from LRFD p 1-81

For drilled hole of $21 \mathrm{~mm}$ the net area is:

$$
A_{n}=A_{g}-t_{w} h_{b}=1342 \mathrm{~mm}^{2}-(5.7 \mathrm{~mm})(21 \mathrm{~mm})=1222 \mathrm{~mm}^{2}
$$

For a punched hole of $21 \mathrm{~mm}$ the net area is:

$$
A_{n}=A_{g}-t_{w} h_{b}=1342 \mathrm{~mm}^{2}-(5.7 \mathrm{~mm})(21 \mathrm{~mm}+2 \mathrm{~mm})=1211 \mathrm{~mm}^{2}
$$

Subtracting the ratio of the punch to drilled specimen net areas and multiplying by 100 will give the percent reduction in capacity for punching effects as suggested by the code.

The $\%$ reduction in net section capacity is:

$$
\left(1-\frac{1211 \mathrm{~mm}^{2}}{1222 \mathrm{~mm}^{2}}\right)(100)=0.9 \%
$$

\section{For a WT 4x12 section}

Using Structural Tee Dimensions from LRFD p 1-84

For drilled hole of $21 \mathrm{~mm}$ the net area is:

$$
A_{n}=A_{g}-t_{w} h_{b}=2097 \mathrm{~mm}^{2}-(6.2 \mathrm{~mm})(21 \mathrm{~mm})=1967 \mathrm{~mm}^{2}
$$

For a punched hole of $21 \mathrm{~mm}$ the net area is:

$$
A_{n}=A_{g}-t_{w} h_{b}=2097 \mathrm{~mm}^{2}-(6.2 \mathrm{~mm})(21 \mathrm{~mm}+2 \mathrm{~mm})=1954 \mathrm{~mm}^{2}
$$

Subtracting the ratio of the punch to drilled specimen effective net areas and multiplying by 100 will give the percent reduction in capacity for punching effects as suggested by the code.

For a $\mathrm{U}$ factor of 0.85 the $\%$ reduction in net section capacity is:

$$
\left(1-\frac{1954 \mathrm{~mm}^{2}}{1967 \mathrm{~mm}^{2}}\right)(100)=0.7 \%
$$


APPENDIX G

AISC LRFD LIMIT STATE CALCULATION EXAMPLES 
AISC LRFD Limit State Calculations for specimens 1 and 2 as shown in Table 4.1

\section{Specimen 1}

(a punched specimen whose effective hole diameter $=2 \mathrm{~mm}+19.8 \mathrm{~mm}=21.8 \mathrm{~mm}$ )

\section{Gross Section Yielding}

$$
\begin{aligned}
& P_{n}=A_{g} A_{y} \\
& P_{n}=\left(\frac{1342 \mathrm{~mm}^{2}}{1 \times 10^{3}}\right)(405 \mathrm{MPa})=543 \mathrm{KN}
\end{aligned}
$$

\section{$\underline{\text { Net Section Rupture }}$}

$$
\begin{aligned}
& P_{n}=A_{e} A_{u} \\
& P_{n}=\left(\frac{789 \mathrm{~mm}^{2}}{1 \times 10^{3}}\right)(518 \mathrm{MPa})=409 \mathrm{KN}
\end{aligned}
$$

[LRFD (D1-2)]

or

$P_{n}=\left(\frac{1048 \mathrm{~mm}^{2}}{1 \times 10^{3}}\right)(518 \mathrm{MPa})=543 \mathrm{KN}$

Where:

Shear Lag Reduction Factor

$$
U=1-\frac{\bar{x}}{L}=1-\frac{82.3 \mathrm{~mm}}{228.6 \mathrm{~mm}}=0.64 ; \text { or } \quad U=0.85
$$

[LRFD, (B3-2)]

Effective Net Area

$$
\begin{aligned}
& A_{e}=U A_{n}=0.64[1342 \mathrm{~mm}-21.8 \mathrm{~mm}(5.0 \mathrm{~mm})]=789 \mathrm{~mm}^{2} \\
& \text { or } \\
& A_{e}=U A_{n}=0.85[1342 \mathrm{~mm}-21.8 \mathrm{~mm}(5.0 \mathrm{~mm})]=1048 \mathrm{~mm}^{2}
\end{aligned}
$$

\section{Bolt Bearing}

[LRFD, (J3-1b)] $R_{n}=3.0 d_{b} t F_{u} n=3.0\left(\frac{19 \mathrm{~mm}(5.0 \mathrm{~mm})}{1 \times 10^{3}}\right)(518 \mathrm{MPa})(4 \mathrm{bolts})=591 \mathrm{KN}$ 
AISC LRFD Limit State Calculations for specimens 1 and 2 as shown in Table 4.1

Bolt Shear

[LRFD, J3.6]

$R_{n}=F_{n} A_{b} m n=(517 \mathrm{MPa})\left(\frac{284 \mathrm{~mm}^{2}}{1 \times 10^{3}}\right)(2)(4$ bolts $)=1175 \mathrm{KN}$

Block Shear

[LRFD, J4.3]

Where:

$$
\begin{gathered}
A_{g t}=t(d-g)=(5 \mathrm{~mm})(150 \mathrm{~mm}-127 \mathrm{~mm})=115 \mathrm{~mm}^{2} \\
A_{n t}=A_{g t}-0.5 h_{b} t=115 \mathrm{~mm}^{2}-0.5(21.8 \mathrm{~mm})(5.0 \mathrm{~mm})=61 \mathrm{~mm}^{2} \\
A_{g v}=t(L+63.5 \mathrm{~mm})=(5 \mathrm{~mm})(228.6 \mathrm{~mm}+63.5 \mathrm{~mm})=1461 \mathrm{~mm}^{2} \\
A_{n v}=A_{g v}-3.5 h_{b} t=1461 \mathrm{~mm}^{2}-3.5(21.8 \mathrm{~mm})(5.0 \mathrm{~mm})=1080 \mathrm{~mm}^{2} \\
h_{b} \equiv \text { effective bolt hole diameter } \\
F_{u} A_{n t}=(518 \mathrm{MPa})\left(\frac{61 \mathrm{~mm}^{2}}{1 \times 10^{3}}\right)=32 \mathrm{KN} \leq 0.6 F_{u} A_{n v}=0.6(518 \mathrm{MPa})\left(\frac{1080 \mathrm{~mm}^{2}}{1 \times 10^{3}}\right)=336 \mathrm{KN}
\end{gathered}
$$

Therefore, LRFD Eqn. (J4-3b) controls

$$
R_{n}=F_{y} A_{g t}+0.6 F_{u} A_{n v}=(405 \mathrm{MPa})\left(\frac{115 \mathrm{~mm}^{2}}{1 \times 10^{3}}\right)+0.6(518 \mathrm{MPa})\left(\frac{1080 \mathrm{~mm}^{2}}{1 \times 10^{3}}\right)=383 \mathrm{KN}
$$

Interaction Equation, using a modified form

[LRFD, (H1-1a)]

$$
\begin{aligned}
& \frac{P_{u}}{P_{n}}+\frac{P_{u} \bar{x}}{F_{y} Z_{x}} \leq 1.0 \\
& \frac{P_{u}}{543 \mathrm{KN}}+\frac{P_{u}(82.3 \mathrm{~mm})\left(1 \times 10^{3}\right)}{(405 \mathrm{MPa})\left(54410 \mathrm{~mm}^{3}\right)} \leq 1.0 \Rightarrow P_{u}=179 \mathrm{KN}
\end{aligned}
$$


AISC LRFD Limit State Calculations for specimens 1 and 2 as shown in Table 4.1

\section{$\underline{\text { Specimen } 2}$}

(a drilled specimen whose effective hole diameter $=20.9 \mathrm{~mm}$ )

\section{Gross Section Yielding}

$$
\begin{aligned}
& P_{n}=A_{g} A_{y} \\
& P_{n}=\left(\frac{1342 \mathrm{~mm}^{2}}{1 \times 10^{3}}\right)(405 \mathrm{MPa})=543 \mathrm{KN}
\end{aligned}
$$

\section{Net Section Rupture}

$$
\begin{aligned}
P_{n} & =A_{e} A_{u} \\
P_{n} & =\left(\frac{792 \mathrm{~mm}^{2}}{1 \times 10^{3}}\right)(518 \mathrm{MPa})=410 \mathrm{KN} \\
\text { or } & \left(\frac{1057 \mathrm{~mm}^{2}}{1 \times 10^{3}}\right)(518 \mathrm{MPa})=545 \mathrm{KN}
\end{aligned}
$$

Where:

Shear Lag Reduction Factor

$$
U=1-\frac{\bar{x}}{L}=1-\frac{82.3 \mathrm{~mm}}{228.6 \mathrm{~mm}}=0.64 ; \text { or } \quad U=0.85
$$

Effective Net Area

$$
\begin{aligned}
& A_{e}=U A_{n}=0.64[1342 \mathrm{~mm}-20.9 \mathrm{~mm}(5.0 \mathrm{~mm})]=792 \mathrm{~mm}^{2} \\
& \text { or } \\
& A_{e}=U A_{n}=0.85[1342 \mathrm{~mm}-20.9 \mathrm{~mm}(5.0 \mathrm{~mm})]=1052 \mathrm{~mm}^{2}
\end{aligned}
$$

\section{Bolt Bearing}

[LRFD, (J3-1b)]

$$
R_{n}=3.0 d_{b} t F_{u} n=3.0\left(\frac{19 \mathrm{~mm}(5.0 \mathrm{~mm})}{1 \times 10^{3}}\right)(518 \mathrm{MPa})(4 \mathrm{bolts})=591 \mathrm{KN}
$$


AISC LRFD Limit State Calculations for specimens 1 and 2 as shown in Table 4.1

Bolt Shear

[LRFD, J3.6]

$R_{n}=F_{n} A_{b} m n=(517 \mathrm{MPa})\left(\frac{284 \mathrm{~mm}^{2}}{1 \times 10^{3}}\right)(2)(4$ bolts $)=1175 \mathrm{KN}$

Block Shear

[LRFD, J4.3]

Where:

$$
\begin{gathered}
A_{g t}=t(d-g)=(5 \mathrm{~mm})(151 \mathrm{~mm}-127 \mathrm{~mm})=120 \mathrm{~mm}^{2} \\
A_{n t}=A_{g t}-0.5 h_{b} t=120 \mathrm{~mm}^{2}-0.5(20.9 \mathrm{~mm})(5.0 \mathrm{~mm})=68 \mathrm{~mm}^{2} \\
A_{g v}=t(L+63.5 \mathrm{~mm})=(5 \mathrm{~mm})(228.6 \mathrm{~mm}+63.5 \mathrm{~mm})=1461 \mathrm{~mm}^{2} \\
A_{n v}=A_{g v}-3.5 h_{b} t=1461 \mathrm{~mm}^{2}-3.5(20.9 \mathrm{~mm})(5.0 \mathrm{~mm})=1095 \mathrm{~mm}^{2} \\
F_{u} A_{n t}=(518 \mathrm{MPa})\left(\frac{68 \mathrm{~mm}^{2}}{1 \times 10^{3}}\right)=35 \mathrm{KN} \leq 0.6 F_{u} A_{n v}=0.6(518 \mathrm{MPa})\left(\frac{1095 \mathrm{~mm}^{2}}{1 \times 10^{3}}\right)=340 \mathrm{KN}
\end{gathered}
$$

Therefore, LRFD Eqn. (J4-3b) controls

$$
R_{n}=F_{y} A_{g t}+0.6 F_{u} A_{n v}=(405 \mathrm{MPa})\left(\frac{120 \mathrm{~mm}^{2}}{1 \times 10^{3}}\right)+0.6(518 \mathrm{MPa})\left(\frac{1095 \mathrm{~mm}^{2}}{1 \times 10^{3}}\right)=389 \mathrm{KN}
$$

Interaction Equation, using a modified form

[LRFD, (H1-1a)]

$\frac{P_{u}}{P_{n}}+\frac{P_{u} \bar{x}}{F_{y} Z_{x}} \leq 1.0$

$\frac{P_{u}}{543 K N}+\frac{P_{u}(82.3 \mathrm{~mm})\left(1 \times 10^{3}\right)}{(405 \mathrm{MPa})\left(54410 \mathrm{~mm}^{3}\right)} \leq 1.0 \Rightarrow P_{u}=179 \mathrm{KN}$ 